CARLOS ALEXANDRE DE SOUSA PENIN

\title{
Análise de Índices de Qualidade no Planejamento Agregado de Investimentos em Ambiente de Incertezas
}

Dissertação apresentada à Escola Politécnica da Universidade de São Paulo para obtenção do título de Mestre em Engenharia.

São Paulo

2000 


\section{CARLOS ALEXANDRE DE SOUSA PENIN}

\section{Análise de Índices de Qualidade no Planejamento Agregado de Investimentos em Ambiente de Incertezas}

Dissertação apresentada à Escola Politécnica da Universidade de São Paulo para obtenção do título de Mestre em Engenharia.

Área de Concentração:

Sistemas de Potência.

Orientador:

Prof. Dr. Nelson Kagan.

São Paulo 2000 
À Silvério e Sonia, meus queridos pais, pelo incentivo e apoio em todas as etapas da minha vida. 


\section{AGRADECIMENTOS}

Ao Prof. Dr. Nelson Kagan, meu mestre e orientador, pela dedicação, apoio e valiosas contribuições, fundamentais para o desenvolvimento deste trabalho.

Aos professores Carlos Márcio Vieira Tahan e Carlos César Barioni de Oliveira, pelas valiosas contribuições na etapa de Qualificação desta dissertação.

Aos meus amigos Alden, André, Hernán e à minha namorada Fernanda, pelo apoio e amizade durante essa etapa importante.

Um agradecimento especial à minha irmã Lara, à minha avó Pastora, à minha tia Nena e ao meu tio Júlio, pelo carinho e incentivo em todas as etapas da minha vida.

A Deus, que fez das minhas preces, instrumento para conquistar esse objetivo. 
Penin, Carlos Alexandre de Sousa

Análise de Índices de Qualidade no Planejamento Agregado de Investimentos em Ambiente de Incertezas. São Paulo, 2000.

143p.

Dissertação (Mestrado) - Escola Politécnica da Universidade de São Paulo. Departamento de Engenharia de Energia e Automação Elétricas.

1. Redes Elétricas de Distribuição Primárias 2. Planejamento de Investimentos I. Universidade de São Paulo. Escola Politécnica. Departamento de Engenharia de Energia e Automação Elétricas II. t 


\section{ABSTRACT}

This work aims at developing new tools for the analysis of quality of supply indices regarding long term investment planning of primary electric power distribution systems.

Investment planning in aggregated basis represents a established methodology for estimating future investments in all distribution systems of a utility, by using statistic and clustering analysis to represent the overall network through groups of elementary distribution systems. The methodology also considers uncertainty and makes use of a number of criteria to prioritize new facilities to be incorporated into the system, taking into account financial constraints. For each new facility the system determines costs and corresponding benefits.

This dissertation complements such model through the introduction and analysis of various quality of supply indices, helping the planner engineer to assess all benefits related to a given investment plan. The developed computational system is based on the results obtained for each elementary distribution system. It then evaluates global and regional technical indices, that allows for important managerial analysis concerning the system expansion.

The computational system also evaluates the average long range incremental and the marginal costs associated with a specific investment plan, thus taking into account new facilities concerning substations and network feeders.

A case study considering a fictitious distribution company and its overall system illustrates the tools developed, showing all potential studies and decision making capabilities which were made available during this research work. 


\section{SUMÁRIO}

Resumo

Abstract

1. Introdução 1

1.1. Histórico do Planejamento Agregado e sua importância no cenário atual do Setor Elétrico

1.2. Objetivos do trabalho 4

1.3. Organização do documento 6

2. Bases Conceituais e Metodologia Geral do Planejamento Agregado de Investimentos 8

2.1. Considerações Gerais 8

2.2. Classificação da rede em famílias 10

2.3. Determinação de Leis Estatísticas 13

2.4. Modelo de Evolução de Redes 15

2.5. Incertezas, Cenários e Decisão 17

2.6. Custo Marginal 18

3. Descrição do Sistema SISPAI para Planejamento Agregado de Investimentos $\quad 19$

3.1. Considerações Gerais 19

3.2. Dados necessários e Módulos Principais 20

3.3. Principais Resultados e Relatórios na Versão Básica 22

3.4. Análise crítica do sistema 25

4. Acompanhamento dos Índices Técnicos de Qualidade 27

4.1. Introdução 27

4.2. Índices de Qualidade $\quad 29$ 
4.2.1. Perdas por Demanda 29

4.2.2. Perdas por Energia 32

4.2.3. END - Energia Não Distribuída na Rede Primária 34

4.2.4. DEC - Duração Equivalente da Interrupção por Consumidor

4.2.5. FEC - Freqüência Equivalente de Interrupção por Consumidor

4.2.6. Queda de Tensão 39

4.2.7. Carregamento de Alimentadores 40

4.2.8. Carregamento de Subestações 42

4.2.9. Relatórios de Investimento - Distribuição dos Dispêndios por Família 44

4.3. Os Índices de Qualidade Implementados 46

4.4. SisFamílias 50

4.4.1. Relatórios de Evolução dos Índices no Período de Planejamento - Desempenho das Famílias 51

4.4.2. Relatórios de Distribuição de Probabilidades e Análise de Risco dos Índices de Qualidade 53

4.4.3. Custo Incremental e Custo Marginal 57

4.5. SisRegionais 59

4.5.1. Relatórios de Evolução dos Índices no Período de Planejamento - Desempenho das Regionais 59

4.5.2. Cálculo dos Índices para Regionais 62

4.5.2.1. Perdas por Demanda 63

4.5.2.2. Perdas por Energia 64

4.5.2.3. END - Energia Não Distribuída na Rede Primária 64

4.5.2.4. DEC - Duração Equivalente da Interrupção por Consumidor 65

4.5.2.5. FEC - Freqüência Equivalente de Interrupção por Consumidor 66

4.5.2.6. Queda de Tensão 66

4.5.2.7. Carregamento de Alimentadores 67

4.5.2.8. Carregamento de Subestações 67 
4.5.2.9. Relatórios de Investimento - Distribuição dos Dispêndios por Família

5. Caso Teste de Aplicação

5.1. Descrição do Caso Teste

69

5.2. Processamento do Sispai Básico

70

5.2.1. Cadastramento de Dados

71

5.2.2. Módulo 1 - Formação de Famílias 75

5.2.3. Módulo 2 - Leis Estatísticas 78

5.2.4. Módulo 3 - Evolução de Redes 82

5.2.4.1. Dados Complementares de Redes Representantes 84

5.2.4.2. Dados Complementares de Famílias de Subestações $\quad 85$

5.2.4.3. Dados Complementares de Alimentadores $\quad 87$

5.2.5. Resultados para o Caso Base 90

5.2.6. Análise de Cenários 90

5.3. Relatórios de Evolução de Índices para o Caso de Referência 93

5.4. Relatórios para Análise de Incertezas e Cenários 101

5.5. Custo Marginal 109

5.6. Resultados por Regional 111

5.7. Discussão dos Resultados 116

$\begin{array}{ll}\text { 6. Conclusões } & 118\end{array}$ 
Anexo A - Relatório do Cluster de Subestações para o Caso Teste de Aplicação

Anexo B - Relatório do Cluster de Alimentadores para o Caso Teste de Aplicação

Anexo C - Relatório de Leis Estatísticas para o

Caso Teste de Aplicação

Anexo D - Relatório Geral para o Caso Teste de Aplicação

Anexo $\mathrm{E}$ - Tabela de Regionais definidas para o Caso Teste de Aplicação 


\section{CAPÍTULO 1}

\section{INTRODUÇÃO}

O presente trabalho visa fornecer novas ferramentas para a análise de índices de qualidade no âmbito do planejamento agregado de investimentos em sistemas de distribuição primária.

O planejamento agregado de investimentos representa uma metodologia de previsão de investimentos em Sistemas de Distribuição, que considera aspectos de incertezas e critérios de priorização de obras, em função dos recursos disponíveis.

Distintamente ao planejamento local, ou convencional, nota-se que o caráter agregado do planejamento dissocia as obras da realidade geográfica e informa apenas o tipo de obra a ser realizada e o montante de investimentos necessário por tipo de obra.

Conforme estudado por Gouvêa [1], principal referência deste trabalho, no planejamento agregado o sistema é modelado através de representantes de grupos de redes que, a medida que evoluem, vão determinando obras, algumas por exigência de atendimento de critérios técnicos, outras por qualidade de serviço. A priorização é feita com base em indicadores de custo/benefício, e é restrita aos limites orçamentários.

Ao final são analisados diversos cenários considerando-se as variáveis envolvidas (orçamento, perdas, qualidade, critérios técnicos, etc.), ficando a critério do planejador as decisões finais de investimentos.

Partindo-se do sistema desenvolvido pelo CED/USP (Centro de Excelência em Distribuição de Energia Elétrica / Universidade de São Paulo) no âmbito do projeto "Planejamento Agregado de Investimentos 
em Sistemas de Distribuição", conforme [8], [9], [10], [11], [12] e [13], foram desenvolvidas ferramentas que permitem estudar os resultados do planejamento agregado para cada um dos representantes dos grupos de redes. Desta forma, este trabalho procura complementar o modelo através da análise técnica dos índices de qualidade, quantificando-se os benefícios obtidos ao longo do horizonte de estudo.

Procurou-se ainda elaborar um sistema computacional que, baseado nos resultados dos representantes dos grupos de redes, possa determinar os índices técnicos para regionais definidas no sistema. Adicionalmente foi desenvolvida ferramenta que permite a determinação do Custo Incremental Médio de Longo Prazo (CIMLP) e do Custo Marginal do sistema de média tensão, englobando subestações de distribuição e circuitos primários, que representa uma estimativa dos custos a incorrer quando se acrescenta uma unidade adicional de demanda no sistema elétrico.

O trabalho é finalizado com o estudo de um caso de planejamento de uma área de concessão de uma empresa fictícia, onde são executados os processamentos e analisados os resultados. Ao final é feita a análise de custos, qualidade e resultados técnicos representativos.

\subsection{Histórico do Planejamento Agregado e sua importância no cenário atual do Setor Elétrico}

A metodologia do planejamento agregado teve origem em trabalhos desenvolvidos pela EDF - Eletricité de France [19]. Na década de 80, a Eletrobrás, oligarquia responsável pelo sistema elétrico brasileiro até então, contratou serviços de consultoria junto a EDF, para absorção de uma tecnologia que avaliasse os níveis de investimentos requeridos para índices de qualidade desejados. Sobre esta base de conhecimento, foram introduzidos conceitos e abordagens específicas, como estudado por Gouvêa [1], Valente [6] e Simões [3], no âmbito do projeto "Planejamento 
Agregado de Investimentos em Sistemas de Distribuição". Tal projeto foi desenvolvido no início da década de 90 sob coordenação do Grupo de Planejamento do CODI (Comitê de Distribuição de Energia Elétrica). A USP (Universidade de São Paulo) colaborou decisivamente nesse desenvolvimento através do CED e da EPUSP - PEA (Escola Politécnica da USP - Departamento de Energia e Automação Elétricas). A partir de 1995 o sistema teve continuidade na EPUSP - PEA, onde foi aprimorado e vem sendo implantado com sucesso em diversas empresas de distribuição de energia elétrica do Brasil, com o nome de SISPAI (Sistema de Planejamento Agregado de Investimentos) [14], [15], [16].

A importância do planejamento agregado é melhor entendida levando-se em consideração as dificuldades de análise e planejamento de redes com elevado número de subestações, em horizontes de longo prazo. Assim, devem ser considerados cenários que, invariavelmente, estão sujeitos a uma série de incertezas quanto a juros, custos e crescimento de carga, dentre outros. Considerando-se ainda o ambiente de expressivas mudanças pelo qual passa o setor elétrico nacional, a economia brasileira e a economia mundial globalizada, o planejamento agregado mostra-se bastante útil, sobretudo nos casos de estudos a médio e longo prazos.

Com as privatizações passando o controle do setor elétrico para a iniciativa privada, o governo deixa a administração das empresas e tem agora um novo papel: a regulamentação e o controle da qualidade de fornecimento da energia elétrica no Brasil. Surge então a necessidade de um órgão regulador para o acompanhamento e auditoria da qualidade no fornecimento da energia elétrica. Para tanto foi criada a ANEEL - Agência Nacional de Energia Elétrica, e as agências estaduais, que detêm o controle e fiscalização do setor elétrico. Os órgãos reguladores têm como uma de suas funções fornecer padrões para medição e controle dos valores disponibilizados pelas empresas recém privatizadas, de maneira a uniformizar os dados fornecidos por todas as concessionárias. A ferramenta de planejamento agregado permite a adequada análise de 
investimentos no sistema de distribuição em função dos níveis de qualidade de serviço, auxiliando as empresas para que se mantenham com níveis de interrupção e de qualidade de fornecimento adequados e dentro dos padrões estabelecidos pelos órgãos reguladores.

\subsection{Objetivos do trabalho}

Originalmente, o SISPAI fornece como resultado as obras e os investimentos necessários para executá-las. Uma vez que o modelo trabalha com representantes de subestações, os resultados são obtidos para tais representantes. Desta forma observa-se, definido um cenário, as obras determinadas anualmente para cada um dos representantes de famílias de subestações.

Nesse trabalho são desenvolvidas ferramentas para estudo dos índices de qualidade do sistema, buscando complementar o modelo SISPAI no que tange à análise técnica e econômica em ambiente de incertezas. Tais ferramentas informam a evolução dos índices (queda de tensão, por exemplo) a medida que são geradas obras, e os resultados podem ser visualizados para cada representante de subestações ou para regionais definidas pelo usuário, ou ainda para todo o sistema. Possibilitam também a análise de risco dos diversos índices de qualidade.

Os índices de qualidade considerados neste estudo são: perdas, DEC (duração equivalente de interrupção por consumidor), FEC (freqüência equivalente de interrupção por consumidor), END (energia não distribuída), $\Delta \mathrm{V}$ (queda de tensão), carregamento de alimentadores e carregamento de subestações.

As seguintes ferramentas são objetivo deste trabalho: 


\section{Análise de Índices de Qualidade por Famílias}

Foi desenvolvida uma ferramenta para, a partir de resultados gerados pelo SISPAI, permitir a visualização do desempenho dos índices de qualidade no sistema. Isso pode ser feito de duas maneiras:

\section{a) Evolução no tempo para um dado cenário}

É realizada uma análise dos índices de qualidade ao longo dos anos de estudo. Através de tabelas e gráficos pode-se analisar o comportamento das famílias para cada um dos índices de qualidade observados. Por exemplo, pode-se observar a evolução das perdas ao longo do horizonte de estudo, para as famílias escolhidas e para um orçamento determinado. Desta forma, o planejador tem uma visão global do desempenho da rede em relação a cada um dos índices de qualidade.

b) Análise de Risco/incerteza a partir dos cenários

É possível analisar a probabilidade de um determinado índice de qualidade encontrar-se dentro de determinadas faixas de valores. Os gráficos mostram as probabilidades, para o orçamento escolhido, das perdas percentuais das famílias divididas em faixas.

Portanto, para cada orçamento proposto, obtém-se uma curva de distribuição de probabilidades de ocorrência de níveis de qualidade. Dessa forma será possível, por exemplo, verificar o orçamento necessário para garantir um determinado nível de qualidade (por exemplo, perdas entre 1 e 4\%, DEC inferior a 10 horas/ano e END menor que 0,1\%), conhecendo-se as probabilidades ou riscos associados.

\section{Impacto dos Investimentos na Qualidade - Relatórios Econômicos}

Tem-se a possibilidade de analisar, para cada família, o volume de investimentos exigido em cada cenário, verificando-se assim qual o impacto gerado por aumento ou diminuição de investimentos na 
qualidade. Outra contribuição importante deste módulo é permitir a verificação dos dispêndios totais e por família, permitindo-se precisar a contribuição de cada família no investimento global, ao longo do horizonte de estudo.

\section{Análise de Índices de Qualidade por Regionais}

Foi desenvolvida uma ferramenta para permitir ao planejador a regionalização do sistema, possibilitando-se o agrupamento de subestações existentes de acordo com algum tipo de afinidade entre elas (proximidade, por exemplo, onde pode-se agrupar as SE's de um mesmo bairro ou de bairros vizinhos). Observa-se, portanto, a evolução dos índices de qualidade e dos investimentos por regional.

\section{Custo Incremental e Custo Marginal}

O sistema também permite que se obtenha graficamente os custos incrementais médios de longo prazo (CIMLP) de distribuição do sistema elétrico estudado, ou por regional, e fornece, como resultado dessas variações, o valor de Custo Marginal para os diversos cenários abordados.

\subsection{Organização do documento}

Este documento está organizado da seguinte forma, após esse capítulo introdutório:

No segundo capítulo são apresentadas as Bases Conceituais do trabalho, sendo descritos os conceitos e a Metodologia Geral do Planejamento Agregado de Investimentos.

No terceiro capítulo é feita uma descrição do sistema SISPAI, abrangendo os dados necessários, processamentos, resultados e relatórios. O capítulo é concluído com uma análise crítica do sistema. 
O quarto capítulo é onde encontra-se a descrição dos índices técnicos de qualidade por família e por regional, os índices econômicos e o custo marginal propostos neste trabalho. São definidos os índices a serem avaliados, e, ao final, os relatórios e gráficos criados para análise.

O capítulo cinco refere-se ao caso teste de aplicação, onde é processado o caso escolhido, desde a criação de famílias até a análise final através dos gráficos de evolução e incertezas.

O sexto capítulo foi reservado aos comentários finais, prosseguimentos e conclusões. 


\section{CAPÍTULO 2}

\section{BASES CONCEITUAIS E METODOLOGIA GERAL DO PLANEJAMENTO AGREGADO DE INVESTIMENTOS}

\subsection{Considerações Gerais}

Como mencionado no capítulo anterior, o planejamento agregado de investimentos, em estudo neste trabalho, representa uma metodologia de previsão de investimentos em Sistemas de Distribuição de Energia Elétrica. Estudos de planejamento convencional de redes de distribuição, isto é, de planejamento de curto/médio prazo, são utilizados para regiões específicas, sendo um importante resultado desses a localização das obras a serem comissionadas no sistema. Desta forma, a representação da rede deve ser tal que espelhe as características geográficas do sistema, necessitando grande quantidade de informações relativas aos trechos, barras e demais componentes de rede. Estes modelos não são adequados para o planejamento de longo prazo, pois as incertezas quanto ao crescimento espacial de carga impossibilitariam sua aplicação. Além disso, quando o interesse maior está no planejamento de investimentos, é importante a representação de toda a área de concessão da empresa, pois as restrições orçamentárias devem ser aplicadas à expansão de todo o sistema. É importante, para este tipo de estudo, ferramenta ágil que permita a análise de diferentes cenários, em função das incertezas presentes nos dados. Esta ferramenta constitui-se no modelo de planejamento agregado de investimentos a ser descrito neste capítulo.

No planejamento agregado de investimentos, o sistema é modelado de forma que os resultados obtidos com as redes representantes podem ser 
estendidos a todo universo que essas redes representam. Pode-se dizer então que, no planejamento agregado, privilegia-se o global em detrimento do particular. Assim, as individualidades das redes, com suas peculiaridades como localização geográfica, topologia física e carregamento, cedem espaço à visão geral que classifica as redes em famílias (representantes), e as trata como se fossem iguais às entidades representadas. A compensação dos desvios positivos e negativos inerentes deste procedimento garantem resultados satisfatórios.

Nessa modelagem, inicialmente divide-se o sistema em estudo conforme o tipo de região atendida. As subestações para as quais se verifica uma independência ou fraca interação entre as redes associadas a elas, são classificadas como do tipo não urbano.

Quando há forte interação entre as redes das subestações adjacentes, o sistema será considerado densamente urbanizado, ou, simplesmente, urbano.

Ficam assim definidas duas diferentes estruturas que constituem cada um dos dois tipos de sistema, no início do período de estudo:

- $\quad$ nas regiões não completamente urbanizadas, a estrutura primordial é um SED (Sistema Elementar de Distribuição), constituído por uma única subestação e seus alimentadores radiais associados.

- Nas regiões densas (urbanas), a estrutura principal é um grupo de SEDs, que envolve redes primárias que permitem a interação significativa (troca de carga) entre as subestações.

Embora inicialmente fossem dados tratamentos diferentes na modelagem de cada um dos tipos descritos acima, atualmente o sistema considera o modelo não urbano como sendo um caso particular do urbano (quando não há troca de cargas). Desta forma simplificou-se toda a estrutura do sistema SISPAI, de forma que agora os resultados são obtidos para o sistema como um todo, sem distinção entre redes urbanas e não urbanas. 


\subsection{Classificação da rede em famílias}

Os sistemas de distribuição existentes fisicamente, correspondentes aos SEDs reais, são agrupados em conjuntos, cujos elementos (subestações, alimentadores e ramais de subtransmissão) apresentam características técnicas, topológicas e operacionais semelhantes e têm a mesma tendência de evolução futura. Assim, é possível a determinação de um SED típico, com características adequadas, que representa adequadamente um conjunto (uma família) de SEDs reais.

Portanto, neste primeiro módulo o conjunto de subestações e alimentadores reais passam por um processo estatístico onde são agrupados em subconjuntos(famílias) com atributos semelhantes, determinando um SED típico que representará cada subconjunto.

No caso de subestações que trocam carga entre si, posteriormente procede-se à formação de grupos de SEDs, e esses grupos serão usados para evolução da rede. Nesse caso, porém, os integrantes dos grupos não serão as subestações reais, e sim os representantes das famílias as quais essas subestações pertencem.

Fundamentalmente a metodologia consiste no desenvolvimento de três etapas, quais sejam:

a) classificação das subestações em famílias conforme suas características;

b) classificação dos diversos conjuntos de alimentadores pertencentes a cada família de subestações, em famílias de alimentadores conforme características técnicas;

c) definição das famílias através dos descritores das famílias de subestações e de alimentadores correspondentes.

Os atributos para classificação das subestações são: 
- $\quad$ tensões nominais AT/MT da subestação

- $\quad$ potência instalada da SE

- $\quad$ número de transformadores

- $\quad$ número de alimentadores

- $\quad$ fator de utilização

- $\quad$ taxa de crescimento de carga

- $\quad$ fator de carga

Durante o processo de classificação de SE's em famílias, aquelas que apresentam potência instalada inferior a um percentual pré-definido são consideradas pouco significativas. Assim, suas subestações são incorporadas em outros grupos, conforme critérios de reagrupamento fornecidos pelo planejador, onde considera-se o peso dos atributos.

Os atributos para classificação dos alimentadores são:

- $\quad$ extensão total do alimentador

- $\quad$ número de pontos de carga

- demanda de ponta

- $\quad$ ângulo de ação

- $\quad$ taxa de crescimento horizontal das cargas

- $\quad$ taxa de crescimento vertical das cargas

- fator de carga

- $\quad$ expoente da função densidade de carga

Esse último item merece uma atenção especial, pois não é tão usual quanto os demais e foi introduzido posteriormente às aplicações iniciais do SISPAI. Conforme Valente [6], o expoente da função densidade de carga, conhecido como $\alpha$, é um valor que diz respeito a topologia da rede, ou seja, à configuração do alimentador. Usualmente este valor encontrase na faixa entre -1 e 8, e sua definição é empírica. Alimentadores curtos, com área de atendimento próxima à subestação, tem valores de $\alpha$ 
próximos de zero; para alimentadores com carga urbana próxima a subestação, o a normalmente é negativo; alimentadores longos, geralmente utilizados para atender cargas distantes, como por exemplo pequenas cidades ou cooperativas, podem apresentar $\alpha$ próximo a 8 , conforme a expressão $D_{r}=D_{0}{ }^{*}{ }^{\alpha}$. As figuras 2.2(a), 2.2(b) e 2.2(c) ilustram, respectivamente, o exposto.

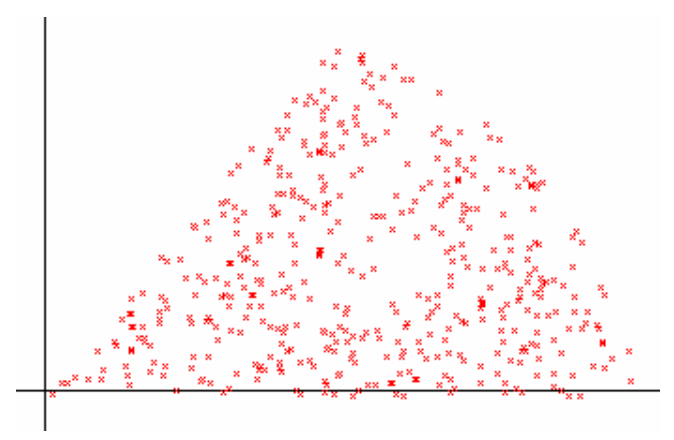

Figura 2.2(a): exemplo de rede com $\alpha=0$

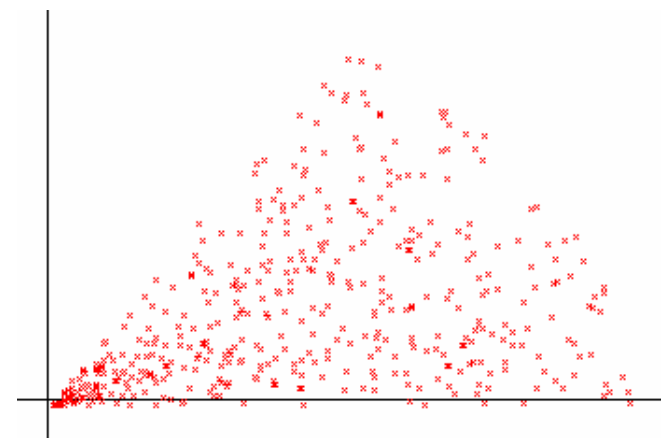

Figura 2.2(b): exemplo de rede com $\alpha=-1$

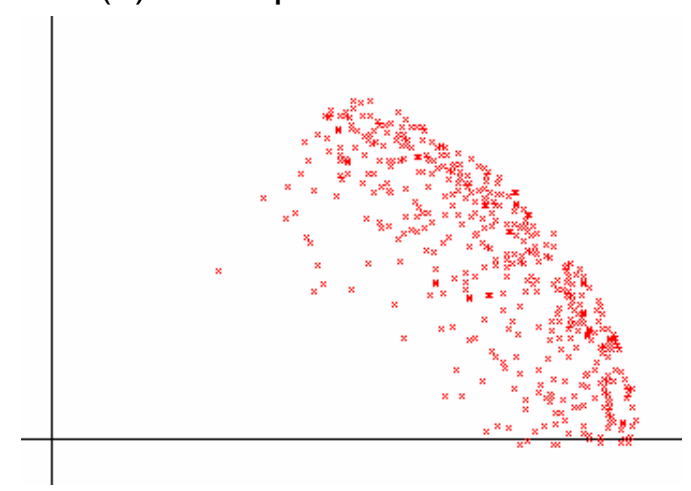

Figura 2.2(c): exemplo de rede $\operatorname{com} \alpha=8$ 


\subsection{Determinação de Leis Estatísticas}

Neste módulo são determinadas as leis de desenvolvimento de redes primárias, a serem utilizadas nos módulos seguintes.

A cada ano do período de análise se faz necessário o cálculo dos parâmetros operacionais das redes, que são:

- $\quad$ DV - queda máxima de tensão no alimentador;

- $\quad$ IAD - carregamento máximo dos alimentadores e da SE;

- $\quad$ PERD - perdas máximas;

- $\quad$ END - energia não distribuída;

- $\quad$ DEC - duração equivalente por consumidor;

- $\quad$ FEC - freqüência equivalente de interrupção por consumidor.

Esses valores são determinados através de leis estatísticas, a partir de características topológicas, técnicas e de carga, a seguir:

- $\quad \mathrm{N}_{\mathrm{p}}$ - número de pontos de carga;

- $\quad \mathrm{P}_{0}-$ valor da carga inicial de cada ponto $(\mathrm{kW})$;

- $\quad T_{h}, T_{v}-$ taxas horizontal e vertical de crescimento de carga;

- $\quad \mathrm{S}_{\mathrm{t}}, \mathrm{S}_{\mathrm{r}}$ - seção do condutor do tronco e dos ramais;

- $\quad \operatorname{Cos}_{\mathrm{Fi}}$ - fator de potência;

- Topologia da rede, representada pelo expoente da função densidade de pontos $(\alpha)$;

- $\quad$ Confiabilidade - critérios de alocação de chaves, de política de socorro, tempos de interrupção, etc.

Em função do caráter não determinístico das análises no processo da previsão do investimento agregado, foi adotado um instrumento estatístico para o cálculo dos parâmetros operacionais. Esse instrumento consiste em estabelecer "funções potência" que correlacionam os parâmetros operacionais às características técnicas, topológicas e de carga da rede. Para tanto, hipóteses de trabalho são assumidas, sobretudo no que tange à topologia, adotada como sendo arborescente e crescente no tempo. 
O estabelecimento das "funções potência" é realizado através de ajustes, pelo método dos mínimos quadrados, em um espaço n dimensional, onde são geradas, de um lado, redes arborescentes aleatórias, com características técnicas, topológicas e de carga definidas (variáveis independentes) e de outro lado, são calculados, pelas adequadas leis físicas, os parâmetros operacionais (DV, PERD, DEC, FEC, END) correspondentes (variáveis dependentes). Da correlação entre as variáveis dependentes e independentes resultam as funções desejadas.

Os cálculos da queda de tensão e de perdas utilizam apenas as leis de Ohm e de Joule. Entretanto, o cálculo da END implica em estabelecimento de regras de alocações de chaves e hipóteses da existência de socorro por redes vizinhas.

A título de exemplo, apresenta-se a expressão para o cálculo da queda de tensão (DV).

$$
\Delta V=\frac{P \cdot L_{T}}{\alpha \cdot\left(360^{\circ} / \theta\right)^{\beta} \cdot \sqrt{N_{p}}}
$$

onde

P: potência de carga

$\mathrm{L}_{\mathrm{T}}$ : comprimento total do alimentador

$\alpha=10,208\left(Z_{T}+Z_{R}\right)^{-0,989}$

$\beta=0,69\left(Z_{T /} Z_{R}\right)^{0,806}$

$\theta$ : ângulo de área de ação

$Z_{\mathrm{T}}$ : módulo de impedância do tronco

$Z_{R}$ : módulo de impedância do ramal

$\mathrm{N}_{\mathrm{P}}$ : número de pontos de carga 


\subsection{Modelo de Evolução de Redes}

A evolução de redes é norteada pela necessidade de realizar obras para que os critérios de nível mínimo de qualidade (NMQ) sejam atendidos e pela conveniência de realizar obras que sejam atrativas do ponto de vista custo/benefício, sempre respeitando um nível preestabelecido de orçamento anual.

Cada rede representativa de um grupo é analisada ano a ano, de modo a identificar eventuais transgressões em critérios de NMQ e avaliar os custos e os benefícios de todas as possíveis obras realizáveis, sejam para o atendimento de critérios ou para melhoria de qualidade ou economicidade.

São propostas obras de várias naturezas, tais como ampliação de subestação, implantação de subestação nova, novos alimentadores, desdobramento de alimentadores existentes, instalação de reguladores de tensão, etc.

Com isso é elaborada uma tabulação de todas as obras possíveis e correspondentes parâmetros técnicos e econômicos associados, proporcionando a avaliação do atendimento do NMQ e custo/benefício, este último expresso através da Taxa de Rentabilidade Inicial do Investimento (TRII).

A tabulação de todas as obras possíveis para cada ano e cada família, oferece um quadro que considera todos os elementos para a priorização, uma vez que os indicadores técnicos de atendimento ao NMQ e os econômicos (TRII) para otimização estão presentes.

Basicamente, a priorização de obras é feita escolhendo-se, dentre as obras geradas com recursos dentro do orçamento anual estabelecido, aquelas que atendem aos critérios técnicos e apresentem as melhores TRII's. 
O critério de priorização adotado, embora não represente uma otimização absoluta, busca uma relação ordenada de obras próximas do ótimo. Segundo esse critério, as obras em instalações existentes (ampliação de SE, desdobramento ou recondutoramento de alimentadores e instalação de regulador de tensão) são mutuamente excludentes em relação às obras relacionadas com SE's novas.

Assim, inicialmente é elaborada uma lista ordenada de obras relativas a todas as redes representantes de grupo, escolhidas dentre aquelas aplicáveis somente nas instalações existentes e que garantam NMQ e apresentem TRII maior que um TRII mínimo preestabelecido. A lista é ordenada segundo TRII's decrescentes, sendo encabeçada pelas obras que garantem o NMQ. Caso o orçamento não seja suficiente, as obras com os menores TRIl's são descartadas. Nesse caso, se forem canceladas obras que garantam o NMQ, será verificado se existem outras que, embora de menor TRII, sejam menos onerosas a ponto de permitir o atendimento do NMQ dentro do orçamento previsto. Se não, haverá colapso por insuficiência de orçamento. Neste caso, o sistema registra em relatório a necessidade de complementação de recursos.

Paralelamente é feita uma outra lista, contendo apenas as obras referentes a subestações novas de todas as famílias.

Finalmente, obtém-se a lista definitiva substituindo-se, na primeira lista, as obras de SE nova da segunda, desde que essa última obra tenha melhor TRII, e esteja dentro do orçamento. 


\subsection{Incertezas, Cenários e Decisão}

A metodologia para indicação do orçamento ideal consiste na pesquisa de valores de orçamentos que conduzam aos menores custos anuais e níveis de qualidade satisfatórios. Porém, fatores externos ao setor elétrico influenciam na evolução dos sistemas de distribuição.

Esses fatores são, simplificadamente:

a) restrições no orçamento;

b) taxa de juros, ou de atualização do capital;

c) custos das instalações, conforme tecnologia utilizada;

d) taxa de crescimento do mercado, além do custo das perdas e da END.

Caberá ao planejador estimar as faixas de valores desses parâmetros, das mais pessimistas às mais otimistas, onde, para cada um dos cenários resultantes, estarão associados planos de investimentos e correspondentes níveis de qualidade.

Como para cada um dos cenários existem vários pares orçamento $\mathrm{x}$ qualidade, e a probabilidade de ocorrência de cada cenário é conhecida e vale $\mathrm{p} \%$, temos vários pares $\mathrm{O}_{i} \times \mathrm{Q}_{i}$ associados a uma probabilidade $\mathrm{p} \%$.

Desta forma o sistema fornece basicamente duas informações:

- $\quad$ as probabilidades dos benefícios, onde temos, para cada orçamento, a probabilidade de ocorrência de cada cenário, associado ao respectivo Valor Presente de Benefícios.

- As curvas de Orçamento Efetivo x Benefícios, em valor presente, onde tem-se, para cada orçamento efetivamente utilizado, o benefício financeiro obtido. 


\subsection{Custo Marginal}

O custo marginal pode ser definido como o incremento nos investimentos a serem realizados no sistema para atendimento de uma unidade adicional de carga. Conforme [25], o custo marginal de fornecimento constitui o fundamento para se atribuir a "cada grupo de consumidores a fração correspondente ao custo do serviço que the for prestado", conferindo, deste modo, à estrutura tarifária, a base justa e racional desejada.

A aplicação do sistema de tarifas a partir dos custos marginais de fornecimento, segundo Valente [6], é uma realidade irreversível no país. Esses custos vêm sendo citados nas publicações técnicas do setor como dado fundamental nos estudos técnico-econômicos envolvendo a Distribuição. O custo marginal, e não o custo médio contábil das instalações em serviço, como referencial tarifário, é que informa corretamente a cada usuário as conseqüências dos seus atos de consumidor.

A metodologia do planejamento agregado vem de encontro a essa necessidade, uma vez que permite o cálculo do custo marginal a partir da previsão das obras propostas para o horizonte de estudo, com grande impacto na qualidade do estudo. Um avanço significativo em relação ao cálculo convencional do custo marginal, onde utilizava-se a Lei de Quantidade de Obras, baseada em investimentos passados, para projeção de gastos futuros. O planejamento agregado permite o cálculo de investimentos futuros utilizando-se da metodologia de otimização de investimentos a longo prazo em função da qualidade de serviço, disponibilidades orçamentárias e considerando as incertezas dos fatores exógenos ao setor elétrico. Tal aspecto foi contemplado neste trabalho, e sua introdução no sistema SISPAI será melhor descrita no Capítulo 4. 


\section{CAPÍTULO 3}

\section{DESCRIÇÃO DO SISTEMA SISPAI PARA PLANEJAMENTO AGREGADO DE INVESTIMENTOS}

\subsection{Considerações Gerais}

Do modelo descrito no capítulo anterior, surgiu a ferramenta conhecida como SISPAI FOR WINDOWS, atualmente na sua $6^{a}$ versão. Neste capítulo apresenta-se sucintamente o sistema, explicitando-se as entradas e saídas e os principais processamentos. O sistema funciona em sistemas operacionais Windows de 32 bits (95/98/NT).

Na figura 3.1(a) tem-se a tela principal do SISPAI.

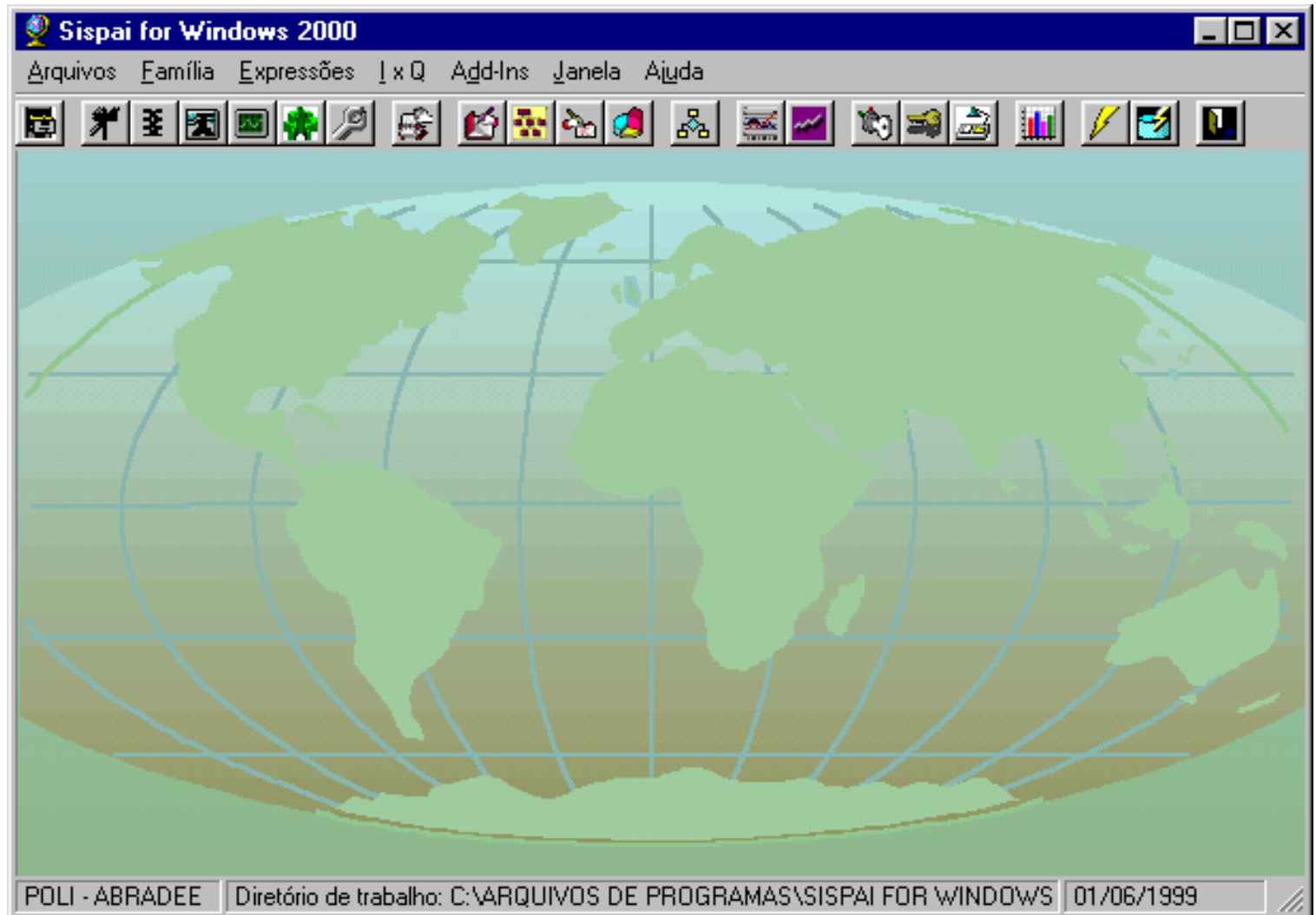

Figura 3.1(a): Tela principal do SISPAI FOR WINDOWS. 


\subsection{Dados necessários e módulos principais}

Após as configurações iniciais do sistema, é necessário fornecer os dados relacionados aos equipamentos utilizados pela empresa. São eles: cabos, transformadores, subtransmissão, reguladores, custos e bays. No capítulo 5, onde será apresentado o caso teste de aplicação, estarão explicitados cada um dos dados solicitados para o processamento do sistema SISPAI, referentes a todos os módulos do programa.

A próxima etapa é o cadastramento das subestações e seus alimentadores correspondentes. Para tanto, o SISPAI utiliza-se de um banco de dados Microsoft Access, onde os dados podem ser diretamente cadastrados, e adicionalmente possui ferramentas para importação dos dados a partir de arquivos texto formatados.

Inicia-se então o processamento do agrupamento ("cluster") de subestações, isto é, a determinação das famílias de subestações que irão representar o sistema real existente. Para tanto, escolhe-se a opção apropriada do sistema, que irá retornar uma tela como a da figura 3.2(a).

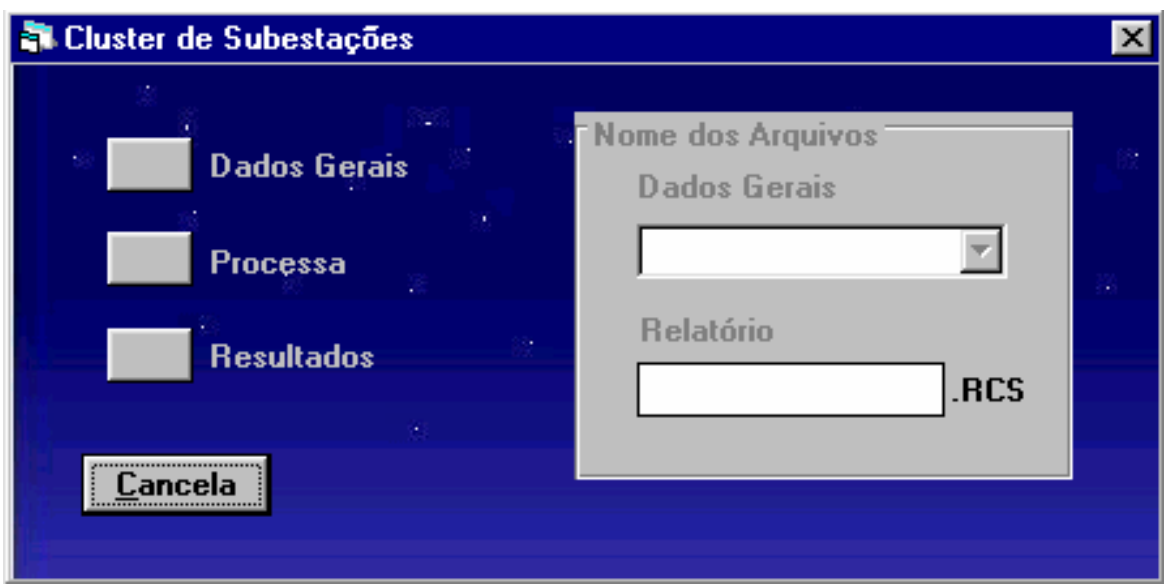

Figura 3.2(a): Tela para processamento do cluster de subestações.

Para processamento desta etapa, inicialmente devem ser fornecidos os parâmetros desejados para o agrupamento das subestações. Uma vez definidos esses parâmetros, é possível iniciar-se o processamento. Finalizado, visualiza-se o relatório, onde serão observadas as famílias resultantes do processo de agrupamento. Este processo deverá ser 
repetido até que, ajustando-se os parâmetros convenientemente, obtenha-se os agrupamentos desejados.

Processo semelhante deve ser realizado para os alimentadores, onde o sistema irá agrupar os alimentadores e automaticamente definir as famílias de SED's, através dos descritores das famílias de subestações e de alimentadores correspondentes.

Caso existam subestações que troquem carga entre si, neste momento devem ser feitas as associações devidas, em opção específica para isso. Tais associações ou grupo de subestações serão consideradas no momento de geração das obras. Assim, as subestações que trocam carga formam grupos onde as obras sugeridas consideram esses compartilhamentos de carga.

O próximo passo é fornecer os dados de entrada do módulo 2, que são na realidade os parâmetros para definição das leis estatísticas de evolução das redes. Processa-se então o módulo 2, onde dois programas devem ser executados para obtermos as leis. Na figura 3.2(b) está ilustrada a tela de processamento da regressão, que elabora o relatório com as leis e gera as interfaces necessárias aos módulos posteriores.

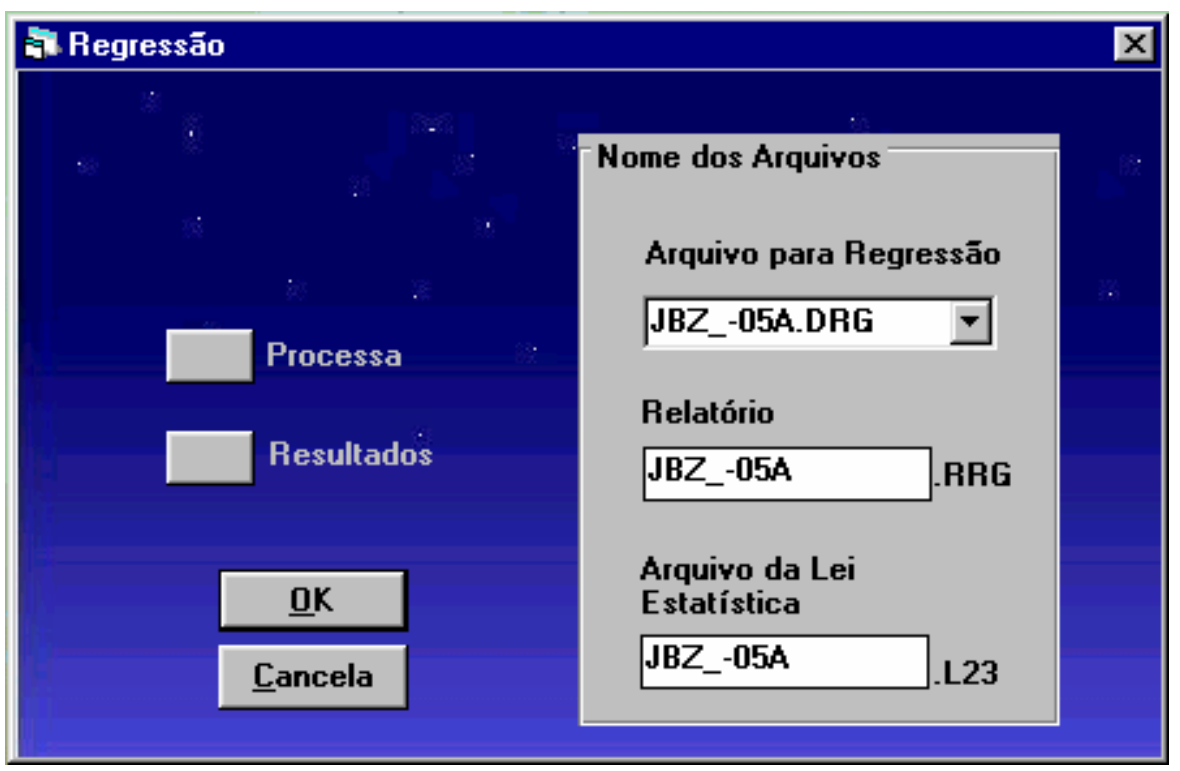

Figura 3.2(b): Tela de processamento do Módulo 2. 
No módulo 3 são necessários os parâmetros para geração das obras. Entre eles destacam-se os custos de perdas e de energia, a vida útil dos equipamentos, a taxa de atualização do capital, assim como a dotação orçamentária anual, além da parametrização das tensões de atendimento, critério e penalização. O último passo é a previsão dos cenários exógenos que imagina-se possíveis, fornecendo-se variações para a taxa de juros, de custos e de crescimento de carga. Na figura 3.2(c), está apresentada a tela onde faz-se a entrada dos dados, o processamento e a visualização dos resultados dos módulos 3 e 5 .

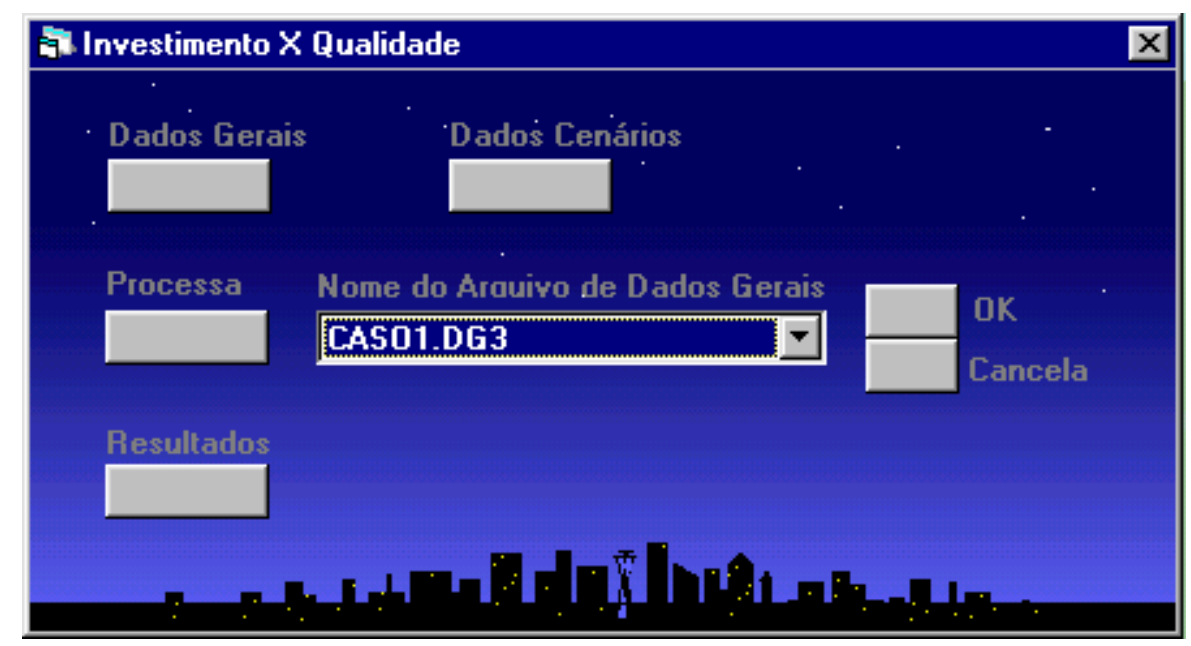

Figura 3.2(c): Tela de processamento do Módulo 3.

\subsection{Principais Resultados e Relatórios na Versão Básica}

Os resultados obtidos no módulo 3 podem ser verificados através de 4 opções disponíveis, conforme figura 3.3(a).

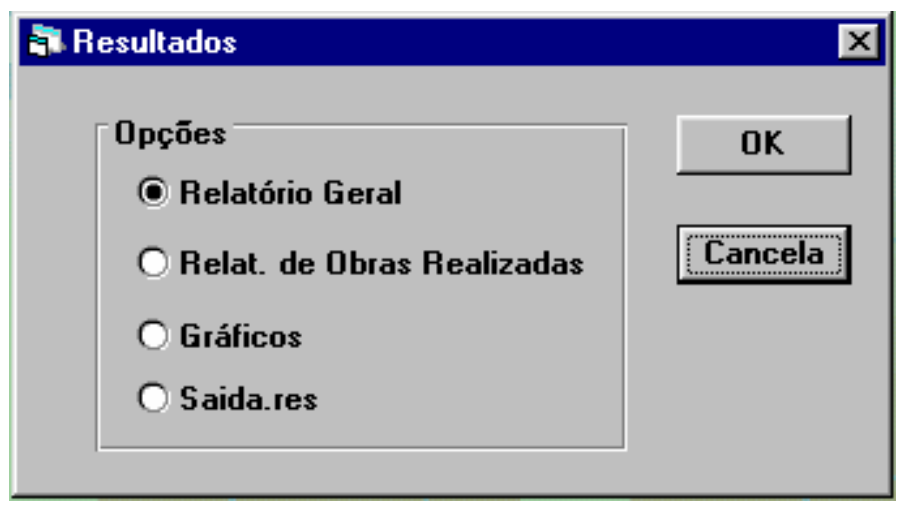

Figura 3.3(a): Resultados do SISPAI. 
O relatório geral apresenta todas as obras realizadas pelo sistema, apresentando, para cada cenário, as obras geradas ano a ano, explicitando o número da família correspondente, os custos e os benefícios caso a caso. Além disso esse relatório mostra a TRII de cada obra, se a obra é necessária ou de melhoria e o número de redes representadas pela família onde a obra foi gerada. A figura 3.3(b) ilustra o relatório descrito.

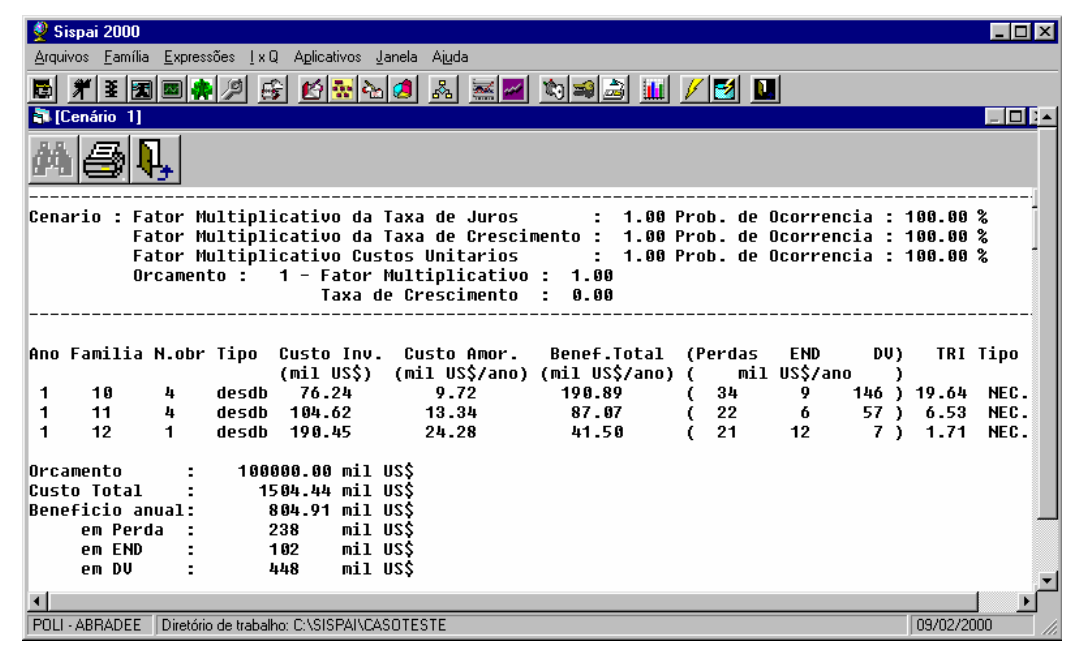

Figura 3.3(b): Visão parcial de um relatório geral de obras do SISPAI.

No relatório de obras realizadas tem-se uma síntese das obras geradas em cada ano. Nele tem-se uma visão global das obras sugeridas, assim como o investimento anual. No final tem-se o valor do investimento total, como somatória dos investimentos anuais e em valor presente. A figura 3.3(c) ilustra o relatório. 


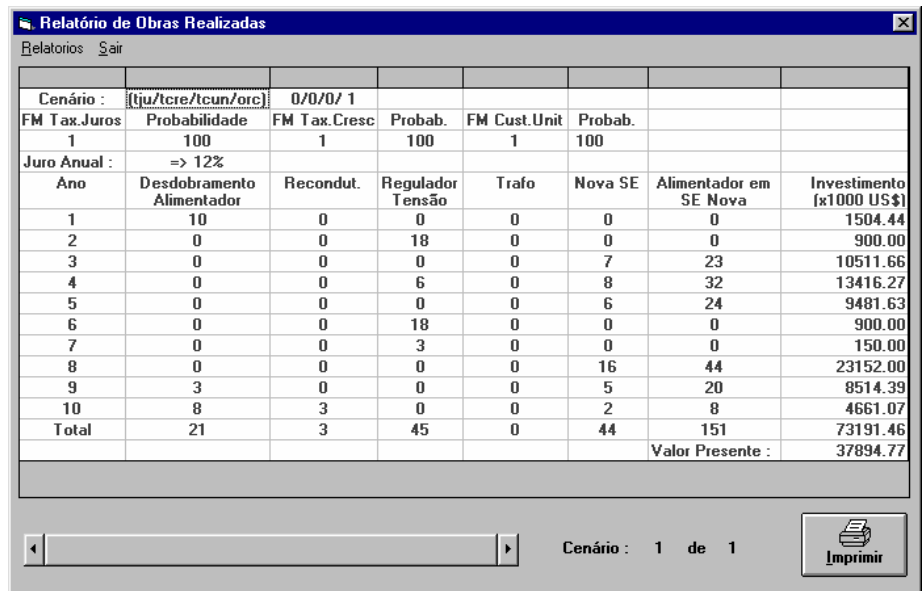

Figura 3.3(c): Relatório de obras realizadas do SISPAI.

A terceira opção refere-se a visualização gráfica da curva de Probabilidades dos Benefícios, além das curvas de Benefícios versus Orçamentos. As curvas podem ser apresentadas em termos de END, perdas, queda de tensão ou total, para cada orçamento.

Para efeito de ilustração, na figura 3.3(d) tem-se o gráfico referente a curva de probabilidade dos benefícios de um caso genérico.

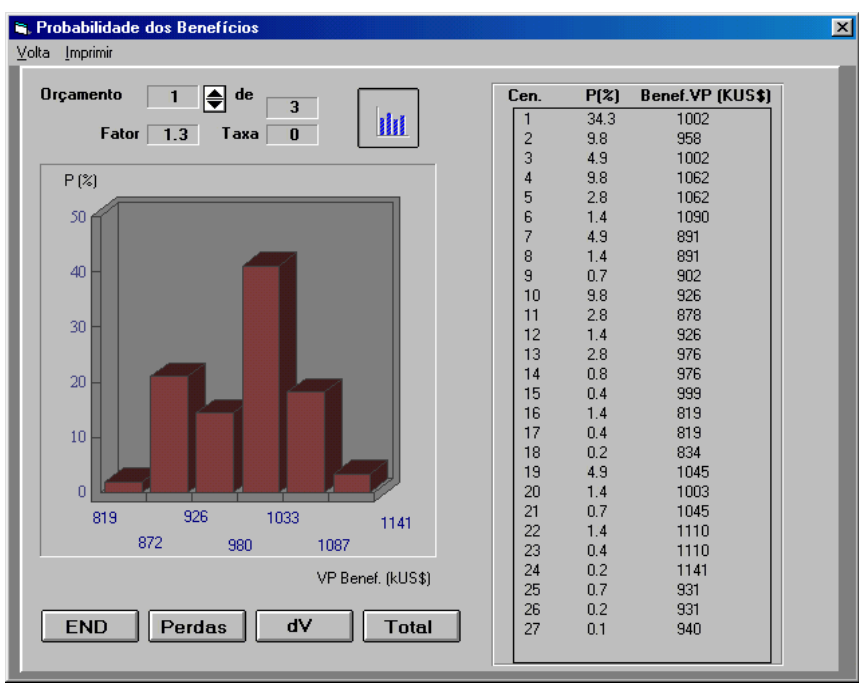

Figura 3.3(d): Curva de probabilidade dos benefícios.

A $4^{\mathrm{a}}$ opçao corresponde à geração de um arquivo (SAIDA.RES) no qual tem-se todas as obras analisadas durante o processamento do módulo 3 , 
inclusive as obras que não foram escolhidas. Através dele pode-se verificar da onde surgiu a necessidade de determinada obra, e, inclusive, consegue-se verificar que tipo de problema gerou a obra, como por exemplo queda de tensão ou índice de DEC muito elevados. Na figura 3.3(e), tem-se um exemplo de como o relatório é apresentado.

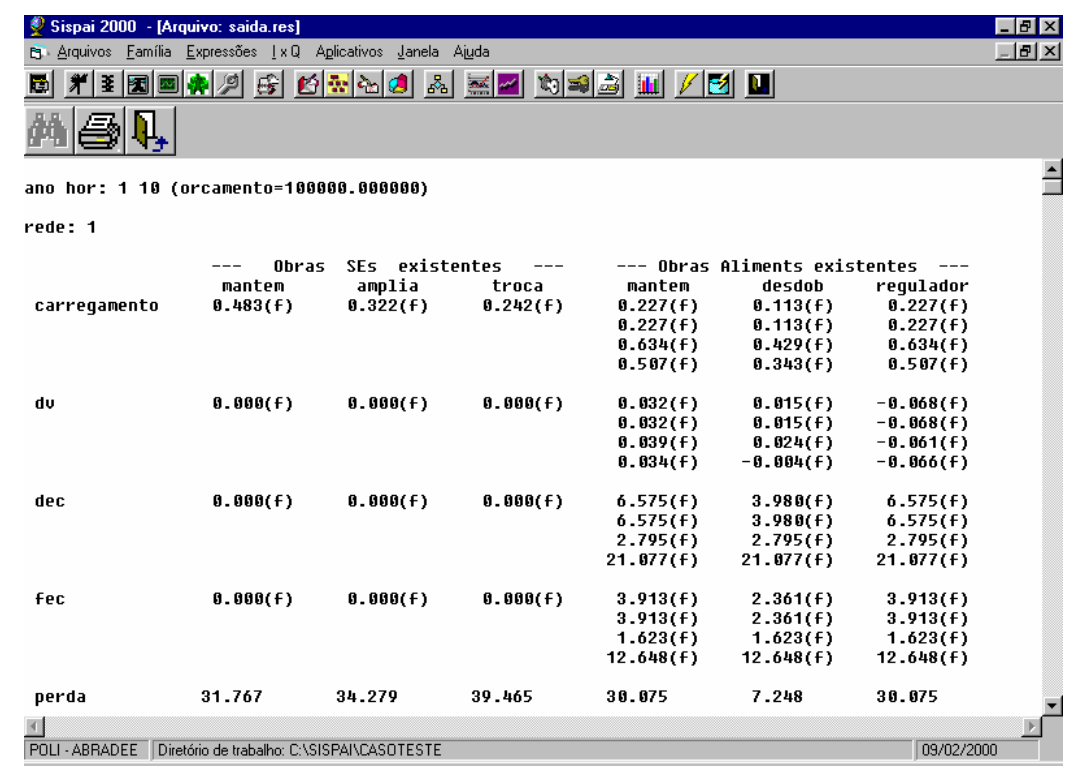

Figura 3.3(e): Relatório do arquivo SAIDA.RES.

\subsection{Análise crítica do sistema}

O sistema SISPAI tem se mostrado uma ferramenta muito útil para o planejamento de investimentos na distribuição. A sua aplicação em diversas empresas de energia tem demonstrado suas qualidades e limitações. Em um planejamento de longo prazo com o SISPAI, é possível determinar-se um valor de orçamento para garantir um nível de qualidade desejado, com determinado nível de risco. Os planos decenais também ficam facilitados, fornecendo resultados de grande valia para 0 planejamento convencional, quando são determinados os planos de obras em horizontes de curto/médio prazo.

Com este trabalho, tenta-se complementar o modelo inicial, fornecendo-se ferramentas que auxiliem o planejador no acompanhamento do 
desempenho das famílias, das regionais e do sistema como um todo, através da análise dos índices de qualidade e das curvas de distribuição de probabilidades e riscos. Desta forma, o planejador terá a sua disposição instrumentos de análise do sistema que demonstram de maneira mais aprofundada os resultados alcançados, o que antes era apresentado somente em termos globais e agregados. A obtenção de dados por regionais possibilita, conforme já exposto em Simões [3], uma análise dos correspondentes níveis de qualidade e distribuição dos recursos para diferentes áreas/regiões da empresa. 


\section{CAPÍTULO 4}

\section{ACOMPANHAMENTO DOS ÍNDICES TÉCNICOS E ECONÔMICOS DE QUALIDADE}

\subsection{Introdução}

O principal objetivo desse trabalho é a análise de índices de qualidade no âmbito do planejamento agregado de investimentos em ambiente de incertezas. Este trabalho também complementa os resultados obtidos com o sistema SISPAI, de forma a permitir ao planejador acompanhar o desempenho do sistema ao longo do horizonte de estudo, analisando os índices de qualidade calculados para cada família. A análise de incertezas também foi estendida, permitindo-se observar as distribuições das probabilidades e análise de risco dos índices de qualidade. Adicionalmente, o planejador pode proceder ao agrupamento das subestações reais do sistema de forma a agrupá-las por bairros ou regiões, permitindo as análises de desempenho, de qualidade e de investimentos por regional. Finalmente, uma ferramenta para calcular os Custos Marginais de Expansão do Sistema Elétrico de Média Tensão (subestações e alimentadores primários) também foi desenvolvida e incorporada ao sistema.

Foram desenvolvidos dois módulos, posteriormente inseridos no sistema SISPAI, denominados SISFAMÍLIAS e SISREGIONAIS. Nesses módulos, através de relatórios técnicos e econômicos, o planejador pode visualizar a evolução dos índices de qualidade por família e por regional, uma vez processado o estudo no SISPAI. Adicionalmente, esses sistemas ainda fornecem os cálculos e resultados dos custos marginais de distribuição.

No módulo denominado SISFAMÍLIAS, o planejador tem disponível a evolução anual do desempenho dos índices de qualidade das famílias e, 
consequentemente, das redes reais para cada orçamento e para cada cenário. O SISFAMÍLIAS permite ainda a visualização dos totais referentes a toda a área de concessão da empresa, ou ainda a análise de algumas famílias em particular. O sistema apresenta também as probabilidades de ocorrência de cada um dos índices de qualidade, de acordo com o orçamento escolhido, através das curvas de distribuição de probabilidades. Nos relatórios de investimentos, pode-se observar as curvas de investimentos anuais para as famílias formadas do caso em estudo. Portanto, tem-se aqui os dispêndios por família, facilitando ao planejador precisar aonde ocorrerão os maiores desembolsos.

No módulo denominado SISREGIONAIS, o planejador tem a oportunidade de subdividir o sistema em regiões independentes das famílias formadas pelo SISPAI. Isso permite que se verifique o comportamento de qualquer área em particular. O sistema então recalcula os resultados e fornece 0 desempenho dos índices de qualidade de acordo com as subdivisões arbitradas na área de concessão em estudo. Quanto aos relatórios econômicos, as curvas apresentadas referem-se aos investimentos anuais para cada regional qualificada. Tal ferramenta permite promover uma distribuição dos recursos por regionais e função de indicadores técnicos e econômicos bastante objetivos [3].

Os custos marginais são calculados para o sistema todo e para as regionais. Não são apresentados os resultados por famílias de subestações pois, ao longo do horizonte de estudo, surgem novas famílias que absorvem carga das famílias originais, distorcendo o cálculo do custo marginal. Esse efeito não é percebido no cálculo do custo marginal das regionais porque, quando da formação de uma nova família decorrente da expansão do sistema, essa família estará automaticamente incorporada à regional em questão. 


\section{2. Índices de Qualidade}

A seguir são apresentados os índices de qualidade definidos e implementados neste trabalho.

Em geral, os índices de qualidade apresentados nos sistemas SISFAMÍLIAS e SISREGIONAIS são valores médios dos alimentadores das famílias, procurando-se desta forma índices que representem o grupo de SE's reais representadas pela família correspondente. Os diversos relatórios permitem a análise de evolução dos índices de qualidade para todos os anos do período de planejamento e para cada família de subestações.

Os índices de qualidade são apresentados em unidades usuais e em porcentagem. No final, tem-se os totais do sistema, os quais também são apresentados em unidades usuais e em porcentagem. Conforme o índice de qualidade em estudo, os totais podem ser a soma ou a média dos valores das famílias. No estudo de perdas, por exemplo, claramente o valor desejado é a soma dos valores das famílias (sem esquecer de verificar o número de integrantes de cada família), para que se obtenha o valor total de perdas no sistema. Já o seu valor em porcentagem é a relação entre o valor absoluto e a demanda fornecida. Em cada caso serão apresentados os critérios adotados.

\subsubsection{Perdas por demanda}

São as perdas do sistema em kW. As perdas são calculadas, através de expressões estatísticas, a partir das correntes nos trechos e resistências do tronco e dos ramais. São de grande interesse para o planejador, pois permitem que se verifique, para cada família de subestações considerada, as perdas (máximas) dos alimentadores, além das perdas totais do sistema. Em porcentagem, demostram quanto está sendo perdido (perdas 
Joule) em relação ao que está sendo fornecido ao sistema em questão.

a) Valores por família de subestações

I) Perdasf: É definido pela somatória das perdas máximas dos alimentadores (tronco e ramal) do representante da família de SE's, em kW. Dada a curva de carga genérica de um alimentador, como a da figura 4.2(a), as perdas por demanda são os valores, em kW, correspondentes às perdas Joule $\left(r_{*} i^{2}\right)$ máximas do alimentador. No gráfico, corresponde ao valor das perdas na hora $\mathrm{k}$.

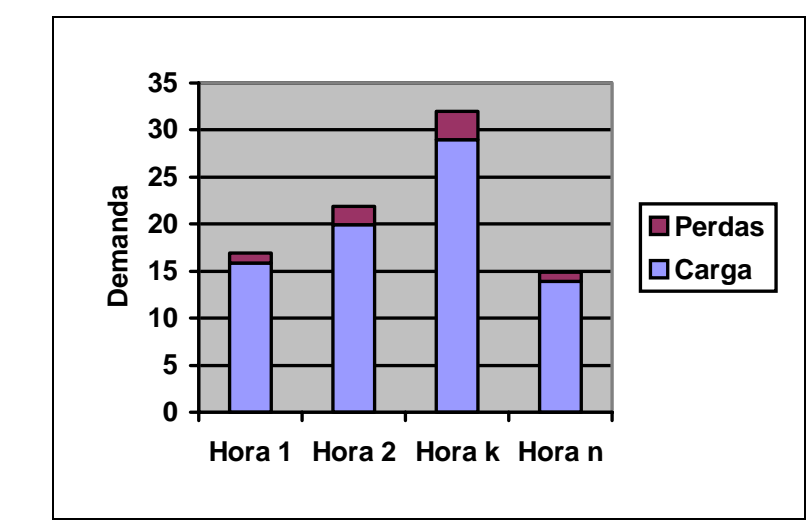

Figura 4.2(a) - Curva de carga genérica e as perdas associadas.

Ou seja:

$\operatorname{Perdas}_{f}=\sum_{i=1}^{n_{a \lim }} \operatorname{Perdas}_{M A X_{i}}$

onde

Perdas $_{\max }$ i: Perda máxima do alimentador i da família f, em $\mathrm{kW}$.

$\mathrm{n}_{\text {alim: }}$ número de alimentadores da família f. 
II) Perdas\%: Perdas, na família, como porcentagem da potência fornecida aos alimentadores.

$$
\operatorname{Perda}_{\%}=\frac{\sum_{i=1}^{n_{a \lim }} \operatorname{Perdas}_{\text {MAX }}}{\sum_{i=1}^{n_{a \lim }} P_{\text {MAX }_{i}}} * 100
$$

onde

$P_{\max }$ : Demanda máxima do alimentador i, em kW.

\section{b) Total do sistema}

I) Perdast: Somatória das perdas dos alimentadores de cada SE representante, multiplicado pelo número de subestações representadas, em kW.

$\operatorname{Perdas}_{t}=\sum_{j=1}^{n_{S E}} n_{S E j} *\left[\sum_{i=1}^{n_{a \lim }} \operatorname{Perdas}_{M A X_{i}}\right]$

onde

$\mathrm{n}_{\mathrm{SE}}$ : Número total de famílias de subestações.

$\mathrm{n}_{\mathrm{SEj}}$ : Número de subestações reais representadas pela família j.

II) Perdas ${ }_{\mathrm{t} \%}$ : A perda total do sistema em porcentagem é calculada como porcentagem da demanda máxima, considerando o número de subestações representadas em cada família de SE's.

$$
\text { Perdas }_{t \%}=\frac{\sum_{j=1}^{n_{S E}} n_{S E j} *\left[\sum_{i=1}^{n_{a \text { lim }}} \operatorname{Perdas}_{M A X_{i}}\right]}{\sum_{j=1}^{n_{S E}} n_{S E j} *\left[\sum_{i=1}^{n_{a l \text { lim }}} P_{M A X_{i}}\right]}
$$




\subsubsection{Perdas por energia}

As perdas por energia fornecem ao planejador uma importante visão do que está sendo perdido nos alimentadores do sistema em termos de energia (kWh). Aqui tem-se definidas as perdas em kWh para os alimentadores de cada representante de família de subestações e as perdas totais do sistema. As perdas por energia em porcentagem são dadas como porcentagem da energia anual fornecida ao sistema. Portanto, indica o quanto é perdido em relação ao total fornecido.

\section{a) Valores por família de subestações}

I) Eerdasf: É definida pela somatória das energias de perdas dos alimentadores (tronco e ramal) do representante da família de SE's, em kWh. Dada a curva de carga genérica de um alimentador, como a da figura 4.2(b), as perdas por energia são correspondentes às somas das áreas de perdas (em vermelho) do gráfico. Como não é representada a curva de carga no SISPAI, utiliza-se do fator de perdas de cada alimentador para a obtenção da perda média e, por conseguinte, da energia perdida anual.

$$
\varepsilon_{\text {Perdas } f}=\sum_{i=1}^{n_{a \mathrm{lim}}} f_{p_{i}} * \text { Perdas }_{\text {MAX }_{i}} * 8760
$$

onde

Perdas $_{\max }$ i: Perda máxima do alimentador i da família f, em $\mathrm{kW}$.

$\mathrm{n}_{\text {alim: }}$ número de alimentadores da família $\mathrm{f}$

Fator de perdas: $f_{p}=$ Perda $a_{\text {média }} /$ Perda $a_{\text {máxima }}=K * f_{c}+(1-K) * f_{c}{ }^{2}$

Fator de carga: $f_{c}=P_{\text {média }} / P_{\text {máxima }}$ 


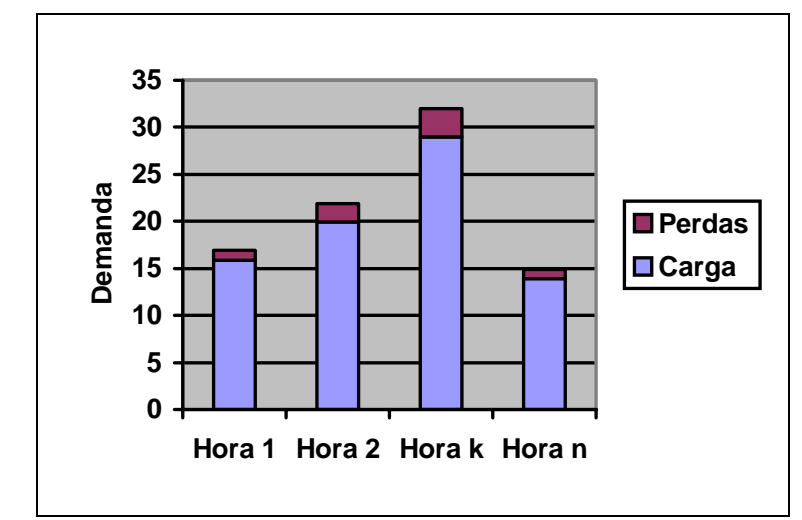

Figura 4.2(b) - Curva de carga genérica e as perdas associadas.

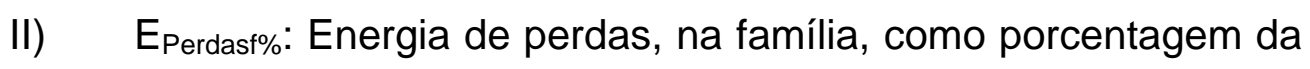
energia anual fornecida pelos alimentadores.

$$
\varepsilon_{\text {Perdas } f \%}=\frac{\sum_{i=1}^{n_{a \lim }} f_{p_{i}} * \operatorname{Perdas}_{\text {MAX }_{i}} * 8760}{\sum_{i=1}^{n_{\text {alim }}} E A F_{i}}
$$

onde

$E A F_{i}=f c_{i} * P \max _{i} * 8760:$ Energia anual fornecida pelo alimentador i.

$\mathrm{f}_{\mathrm{ci}}=\mathrm{P}_{\text {média }} / \mathrm{P}_{\text {máxima }}$

$P_{\max }$ : Demanda máxima do alimentador i, em kW.

\section{b) Total do sistema}

I) $E_{\text {Perdas t: Somatória das energias de perdas dos alimentadores }}$ de cada SE representante, multiplicado pelo número de subestações representadas, em kWh.

$$
\varepsilon_{\text {perdas }_{t}}=\sum_{j=1}^{n_{S E}} n_{S E j} *\left[\sum_{i=1}^{n_{a l i m}} f_{p_{i}} * \operatorname{Perdas}_{M A X_{i}} * 8760\right]
$$

onde

$\mathrm{n}_{\mathrm{SE}}$ : Número total de famílias. 
$\mathrm{n}_{\mathrm{SEj}}$ : Número de subestações reais representadas pela família j.

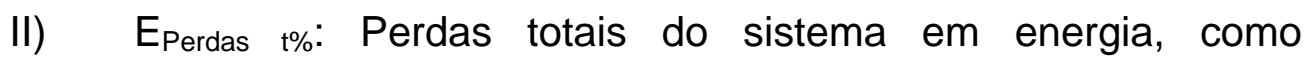
porcentagem da energia anual fornecida pelo sistema, considerando o número de subestações representadas em cada família de SE's.

$$
\varepsilon_{\text {perdas }_{t} \%}=\frac{\sum_{j=1}^{n_{S E}} n_{S E j} *\left[\sum_{i=1}^{n_{a \text { lim }}} f_{p} * \operatorname{Perdas}_{M A X_{i}} * 8760\right]}{\sum_{j=1}^{n_{S E}} n_{S E j}\left[\sum_{i=1}^{n_{\text {lim }}} E A F\right]}
$$

\subsubsection{END - Energia Não Distribuída na rede primária}

A energia não distribuída (END) indica a energia que deixou de ser entregue devido a cortes, sejam eles resultantes de manutenção corretiva ou preventiva na rede primária. A END depende das taxas de falha, dos montantes de carga não atendidos e correspondentes tempos de restabelecimento. Os montantes de carga interrompidos e restabelecidos, quer pela mesma fonte depois de isolado o trecho em defeito, quer por fontes de socorro provenientes de outros alimentadores, dependem da localização de chaves seccionadoras e chaves fusíveis. O cálculo da END, no SISPAI, é realizado a partir das leis estatísticas determinadas previamente, conforme item 2.3. Aqui tem-se definida a soma da END dos alimentadores de cada representante de família de subestações e a END total do sistema, em MWh. A END em porcentagem é dada como porcentagem da energia anual fornecida. 
a) Valores por família de subestações

I) END f A END, para cada família de SE's, é dada pela somatória da END anual dos alimentadores dos representantes das famílias de subestações, em MWh.

$E N D_{f}=\sum_{i=1}^{n_{\text {alim }}} E N D_{i}$

onde

$E N D_{i}$ : Energia não distribuída pelo alimentador i.

II) END f\%: $_{\text {: }}$ END da família de subestações em porcentagem, é dada pela relação entre a soma da END dos alimentadores do representante da família e a soma das energias fornecidas pelos mesmos alimentadores.

$$
E N D_{f \%}=\frac{\sum_{i=1}^{n_{a \lim }} E N D_{i}}{\sum_{i=1}^{n_{a \lim }} E A F_{i}} * 100
$$

onde

$E A F_{i}=f c_{i} * P \max _{i} * 8760$

é a energia anual fornecida pelo alimentador i.

\section{b) Total do sistema}

I) $\quad \mathrm{END}_{\mathrm{t}}[\mathrm{MWh}]$ : A END do sistema em um determinado ano será dada pela soma da END de cada família, multiplicada pelo número de SE's representadas na mesma família.

$$
E N D_{t}=\sum_{j=1}^{n_{S E}} n_{S E j} *\left[\sum_{i=1}^{n_{a \lim }} E N D_{i}\right]
$$

onde

$\mathrm{n}_{\mathrm{SE}}$ : Número total de famílias de subestações.

$\mathrm{n}_{\mathrm{SEj}}$ : Número de subestações reais representadas pela família j. 
II) END $_{\mathrm{t} \%}[\%]$ : A END total do sistema, em porcentagem, é calculada pela relação entre a END total do sistema e a energia total anual fornecida pelo sistema.

$$
E N D_{t \%}=\frac{\sum_{j=1}^{n_{S E}} n_{S E j^{*}}\left[\sum_{i=1}^{n_{a \text { lim }}} E N D_{i}\right]}{\sum_{j=1}^{n_{S E}} n_{S E j^{*}}\left[\sum_{i=1}^{n_{a \text { lim }}} E A F\right]} * 100
$$

\subsubsection{DEC - Duração Equivalente de Interrupção por Consumidor}

A duração equivalente por consumidor (DEC) de um alimentador , conforme [22], é definida como o intervalo de tempo que, em média, cada consumidor do sistema ficou privado do fornecimento de energia elétrica, em um período considerado, normalmente um ano. Para o cálculo do DEC pode-se proceder de forma análoga ao cálculo da END, com as mesmas considerações quanto a restabelecimentos dos consumidores à montante e a jusante do trecho com defeito.

O DEC por família de subestações é considerado o médio dos alimentadores da família. O mesmo procedimento foi usado para o cálculo do DEC total do sistema, sendo considerada a média aritmética dos DEC's das famílias. Os valores em porcentagem são calculados com base no valor máximo definido pelo planejador, critério adotado previamente. 
a) Valores por família de subestações

I) $\quad \mathrm{DEC}_{\mathrm{f}}[$ horas]: É o DEC médio dos alimentadores da família.

$$
D E C_{f}=\frac{1}{n_{a \lim }} * \sum_{i=1}^{n_{a \lim }} D E C_{i}
$$

II) $\quad \mathrm{DEC}_{\mathrm{f} \%}$ [\%]: É a média dos DEC's como porcentagem do valor máximo adotado como critério (DEC $\mathrm{MÁXi}_{\mathrm{i}}$.

$$
D E C_{f \%}=\frac{1}{n_{a \lim }} *\left[\sum_{i=1}^{n_{a \mathrm{lim}}} \frac{D E C_{i}}{D E C_{\text {MAXi }}}\right] * 100
$$

b) Total do sistema

I) $\mathrm{DEC}_{\mathrm{t}}$ [horas]: É o DEC médio dos alimentadores de todas as subestações do sistema.

$$
D E C_{t}=\frac{\sum_{j=1}^{n_{S E}}\left[\sum_{i=1}^{n_{a \lim }} D E C_{i}\right]}{\sum_{j=1}^{n_{S E}} n_{a \lim _{j}}}
$$

onde

$\mathrm{n}_{\mathrm{SE}}$ : Número total de famílias de subestações.

II) $\mathrm{DEC}_{t \%}$ [\%]: É a média dos DEC's percentuais dos alimentadores de todas as SE's.

$$
D E C_{t \%}=\frac{\left[\sum_{i=1}^{n_{a \text { lim }}} \frac{D E C_{i}}{D E C_{M A X i}}\right]}{\sum_{j=1}^{n_{S E}} n_{a \lim _{j}}} * 100
$$




\subsubsection{FEC - Freqüência Equivalente de Interrupção por} Consumidor

O índice freqüência equivalente por consumidor (FEC) de um alimentador, conforme [22], é definido como o número de interrupções que, em média, cada consumidor sofreu, no período considerado.

Assim como o DEC, o FEC por família de subestações é considerado o médio dos alimentadores da família. Procedimento semelhante foi usado para o cálculo do FEC total do sistema, sendo considerada a média aritmética dos FEC's das famílias. Os valores em porcentagem são calculados com base no valor máximo definido pelo planejador, critério previamente definido.

a) Valores por família de subestações

I) $\quad \mathrm{FEC}_{f}[$ vezes/ano]: É o FEC médio dos alimentadores da família.

$$
F E C_{f}=\frac{1}{n_{a \lim }} * \sum_{i=1}^{n_{a \lim }} F E C_{i}
$$

II) FEC $_{f \%}$ [\%]: É a média dos FEC's como porcentagem do valor máximo adotado como critério ( $\left.F E C_{M A ́ x i}\right)$.

$$
F E C_{f \%}=\frac{1}{n_{a \lim }} *\left[\sum_{i=1}^{n_{a \lim }} \frac{F E C_{i}}{F E C_{\text {MAXi }}}\right] * 100
$$

b) Total do sistema

I) $\quad$ FEC $_{t}$ [vezes/ano]: É o FEC médio dos alimentadores de todas as subestações do sistema.

$$
F E C_{t}=\frac{\sum_{j=1}^{n_{S E}}\left[\sum_{i=1}^{n_{a \lim }} F E C_{i}\right]}{\sum_{j=1}^{n_{S E}} n_{a \lim _{j}}}
$$


onde

$\mathrm{n}_{\mathrm{SE}}$ : Número total de famílias de subestações.

II) FEC $_{t \%}$ [\%]: É a média dos FEC's percentuais dos alimentadores de todas as SE's.

$$
F E C_{t \%}=\frac{\left[\sum_{i=1}^{n_{a l i m}} \frac{F E C_{i}}{F E C_{M A X i}}\right]}{\sum_{j=1}^{n_{S E}} n_{a \lim _{j}}} * 100
$$

\subsubsection{Queda de Tensão ( $\Delta \mathrm{V})$}

A queda de tensão máxima em cada alimentador é obtida a partir das leis estatísticas previamente avaliadas dentro do SISPAI, conforme item 2.3, e dos valores dos descritores de cada alimentador, em cada ano entre o inicial e o horizonte de estudo. Para o cálculo da queda de tensão máxima total do sistema, foi considerada a média aritmética das quedas de tensão de todos os alimentadores do sistema. Os valores em porcentagem são calculados com base no valor máximo definido pelo planejador, critério previamente definido.

a) Valores por família de subestações

I) $\Delta \mathrm{V}_{\mathrm{f}}$ [\%]: É a média da queda de tensão máxima dos alimentadores da família.

$$
\Delta V_{f}=\frac{1}{n_{a \lim }} * \sum_{i=1}^{n_{a \mathrm{lim}}} \Delta V_{i}
$$


II) $\Delta \mathrm{V}_{\mathrm{f} \%}$ [\%]: É a média da queda de tensão máxima dos alimentadores da família, em porcentagem do valor máximo adotado como critério $\left(\Delta \mathrm{V}_{\mathrm{MÁX}}=1-\mathrm{V}_{\text {Mín }}\right)$.

$$
\Delta V_{f \%}=\frac{1}{n_{a \lim }} * \frac{\left[\sum_{i=1}^{n_{a \lim }} \Delta V_{i}\right]}{1-V_{M I N}} * 100
$$

\section{b) Total do sistema}

l) $\Delta \mathrm{V}_{\mathrm{t}}$ [\%]: É a média da queda de tensão máxima dos alimentadores de todas as famílias de subestações do sistema.

$$
\Delta V_{t}=\frac{\sum_{j=1}^{n_{S E}}\left[\sum_{i=1}^{n_{a \lim }} \Delta V_{i}\right]}{\sum_{j=1}^{n_{S E}} n_{a \lim _{j}}}
$$

onde

$\mathrm{n}_{\mathrm{SE}}$ : Número total de famílias de subestações.

II) $\Delta \mathrm{V}_{\mathrm{t} \%}$ [\%]: É a média da queda de tensão máxima dos alimentadores de todas as famílias de subestações, em porcentagem da queda de tensão máxima de critério.

$$
\Delta V_{t \%}=\frac{1}{1-v_{M I N}} * \frac{\sum_{j=1}^{n_{S E}}\left[\sum_{i=1}^{n_{a l \mathrm{im}}} \Delta V_{i}\right]}{\sum_{j=1}^{n_{S E}} n_{a \lim _{j}}} * 100
$$




\subsubsection{Carregamento de Alimentadores}

O carregamento de alimentadores de uma família de subestações, assim como o DEC, é considerado como sendo a média aritmética dos carregamentos dos alimentadores da família. Para o cálculo do carregamento de alimentadores total, foi considerado o carregamento médio de todos os alimentadores do sistema. Os valores em porcentagem são calculados com base na potência instalada.

a) Valores por família de subestações

I) Salim $_{f}[K V A]$ : Carregamento médio dos alimentadores da família.

$$
S_{a \lim f}=\frac{1}{n_{a \lim }} * \sqrt{\left(\sum_{i=1}^{n_{a \lim }} P_{M A X_{i}}\right)^{2}+\left(\sum_{i=1}^{n_{a \lim }} Q_{M A X_{i}}\right)^{2}}
$$

onde

$\mathrm{P}_{\mathrm{MÁXi}}$ : potência ativa máxima do alimentador i.

$\mathrm{Q}_{\text {MÁxi }}$ : potência reativa máxima do alimentador i.

II) Salim ${ }_{f \%}$ [\%]: Média dos carregamentos percentuais dos alimentadores da família.

$$
S_{a \lim _{f \%}}=\frac{1}{n_{a \lim }} *\left[\sum_{i=1}^{n_{a \lim }} \frac{S_{i}}{S_{M_{A X}}}\right] * 100
$$

onde

$S_{i}=\sqrt{P_{M A X_{i}}^{2}+Q_{M A X_{i}}^{2}}$

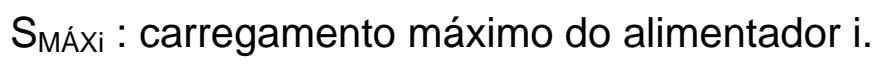


b) Total do sistema

I) Salim $\mathrm{t}$ [KVA]: Carregamento médio dos alimentadores de todas as subestações.

$$
S_{a \lim t \%}=\frac{1}{\sum_{j=1}^{n_{S E}} n_{a \lim j}} * \sqrt{\left(\sum_{j=1}^{n_{S E}} \sum_{i=1}^{n_{a \lim }} P_{M A X_{i}}\right)^{2}+\left(\sum_{j=1}^{n_{S E}} \sum_{i=1}^{n_{a \lim }} Q_{M A X_{i}}\right)^{2}}
$$

onde

$\mathrm{n}_{\mathrm{SE}}$ : Número total de famílias de subestações.

II) Salim ${ }_{\mathrm{t} \%}$ [\%]: Média dos carregamentos percentuais dos alimentadores de todas as subestações.

$$
S_{a \lim _{t} \%}=\frac{1}{\sum_{j=1}^{n_{S E}} n_{a \lim j}} * \sum_{j=1}^{n_{S E}}\left[\sum_{i=1}^{n_{a \lim }} \frac{S_{i}}{S_{M A X_{i}}}\right] * 100
$$

onde

$$
S_{i}=\sqrt{P_{M A X_{i}}^{2}+Q_{M A X_{i}}^{2}}
$$

\subsubsection{Carregamento de Subestações}

O carregamento de subestações estudado neste trabalho é o carregamento do representante da família de subestações considerada. Também é apresentado o valor como porcentagem da potência instalada. O total é calculado como a soma dos carregamentos de todos os representantes, considerando o número de subestações representadas.

a) Valores por família de subestações 
I) $\mathrm{S}_{\mathrm{SEf}}[\mathrm{MVA}]$ : Carregamento do representante da família de subestações.

$S_{S E f}=f_{\text {coinc }} * \sqrt{\left(\sum_{i=1}^{n_{a l \lim }} P_{M A X_{i}}\right)^{2}+\left(\sum_{i=1}^{n a \lim } Q_{M A X_{i}}\right)^{2}}$

onde

$\mathrm{f}_{\text {coinc }}$ : fator de coincidência das demandas dos alimentadores da subestação representante da família f.

II) S SEf\% [\%]: Carregamento em porcentagem da potência instalada.

$S_{S E_{f \%}}=\left[\frac{S_{S E f}}{S_{\text {inst }}}\right] * 100$

onde

$S_{\text {inst }}=n_{\text {traf }} * S n_{\text {traf }}$

$\mathrm{n}_{\text {traf }}$ : Número de transformadores da família f.

$\mathrm{Sn}_{\text {traf }}$ : Potência nominal de cada transformador da família f.

\section{b) Total do sistema}

I) $\mathrm{S}_{\mathrm{SEt}}$ [MVA]: Soma dos carregamentos de todas as subestações.

$S_{S E t}=\sum_{j=1}^{n_{S E}} S_{S E j} * n_{S E j}$

onde

$\mathrm{n}_{\mathrm{SE}}$ : Número total de famílias de subestações.

II) $\mathrm{S}_{\mathrm{SEt} \%}$ [\%]: Carregamento de todas as subestações do sistema como porcentagem da potência instalada total. 
$S_{S E_{t \%}}=\frac{\sum_{j=1}^{n_{S E}} S_{S E j} * n_{S E j}}{\sum_{j=1}^{n_{S E}} S_{i n s t_{j}} * n_{S E j}}$

onde

$\mathrm{n}_{\mathrm{SE}}$ : Número total de famílias de subestações.

$\mathrm{n}_{\mathrm{SEj}}$ : Número de subestações reais representadas pela família j.

$S_{\text {inst }_{j}}=n_{\text {traf }_{j}} * S n_{\text {traf }_{j}}$

\subsubsection{Relatórios de Investimento - Distribuição dos Dispêndios por Família}

Através de ferramenta para análise econômica do sistema, é possível analisar-se a evolução dos dispêndios totais e para cada família existente. Nesta opção, obtém-se o relatório com os investimentos anuais por família, em forma de tabela. Da mesma forma que os demais índices, os relatórios de investimentos também são apresentados em duas unidades: na unidade monetária adotada para os dados referentes a custos no SISPAI (por exemplo, US\$) e em porcentagem. A diferença, aqui, é que os valores para as famílias já consideram a quantidade de subestações representadas nas mesmas. A porcentagem é o volume de investimentos utilizado nas obras da família frente ao montante total de investimentos no sistema naquele ano.

\section{a) Valores por família de subestações}

I) $\mathrm{I}_{\mathrm{f}}^{\prime}[\mathrm{kUS} \$$ ]: total dos investimentos da família f. Considera-se neste valor todas as subestações representadas pela família.

$$
\mathrm{I}_{\mathrm{f}}{ }^{\prime}=n_{\text {SEf }} * I_{f}
$$


onde

$I_{f}$ : investimento no representante da família.

$\mathrm{n}_{\mathrm{SEf}}$ : número de subestações reais representadas pela família f.

II) $\mathrm{I}_{\mathrm{f} \%}$ ' [\%]: total de investimentos na família f frente ao montante total de investimentos no sistema.

$$
\mathrm{I}_{\mathrm{f} \%}{ }^{\prime}=\frac{I_{f}{ }^{\prime}}{I_{T}} * 100
$$

onde

$\mathrm{I}_{\mathrm{T}}$ : investimento total no sistema, conforme definido no próximo item.

\section{b) Total do sistema}

III) $\quad \mathrm{I}_{\mathrm{T}}[\mathrm{kUS} \$$ : investimentos totais no sistema.

$$
\mathrm{I}_{\mathrm{T}}=\sum_{f=1}^{n_{S E}} I_{f}
$$

onde

$\mathrm{n}_{\mathrm{SE}}$ : Número total de famílias de subestações.

IV) $I_{t \%}[\%]$ : e a soma dos investimentos totais nas famílias, sobre 0 valor total de investimentos no sistema. Será sempre igual a 100\% e, portanto, não é utilizado. 


\subsection{Os Índices de Qualidade Implementados}

Os índices de qualidade definidos no item 4.2 são calculados quando da geração das obras e cenários. Isso pode ser melhor observado no esquema da figura 4.3(a), que mostra sinteticamente todo o processo do planejamento agregado, da definição das famílias aos módulos de análise, isto é, os módulos SISFAMÍLIAS e SISREGIONAIS.

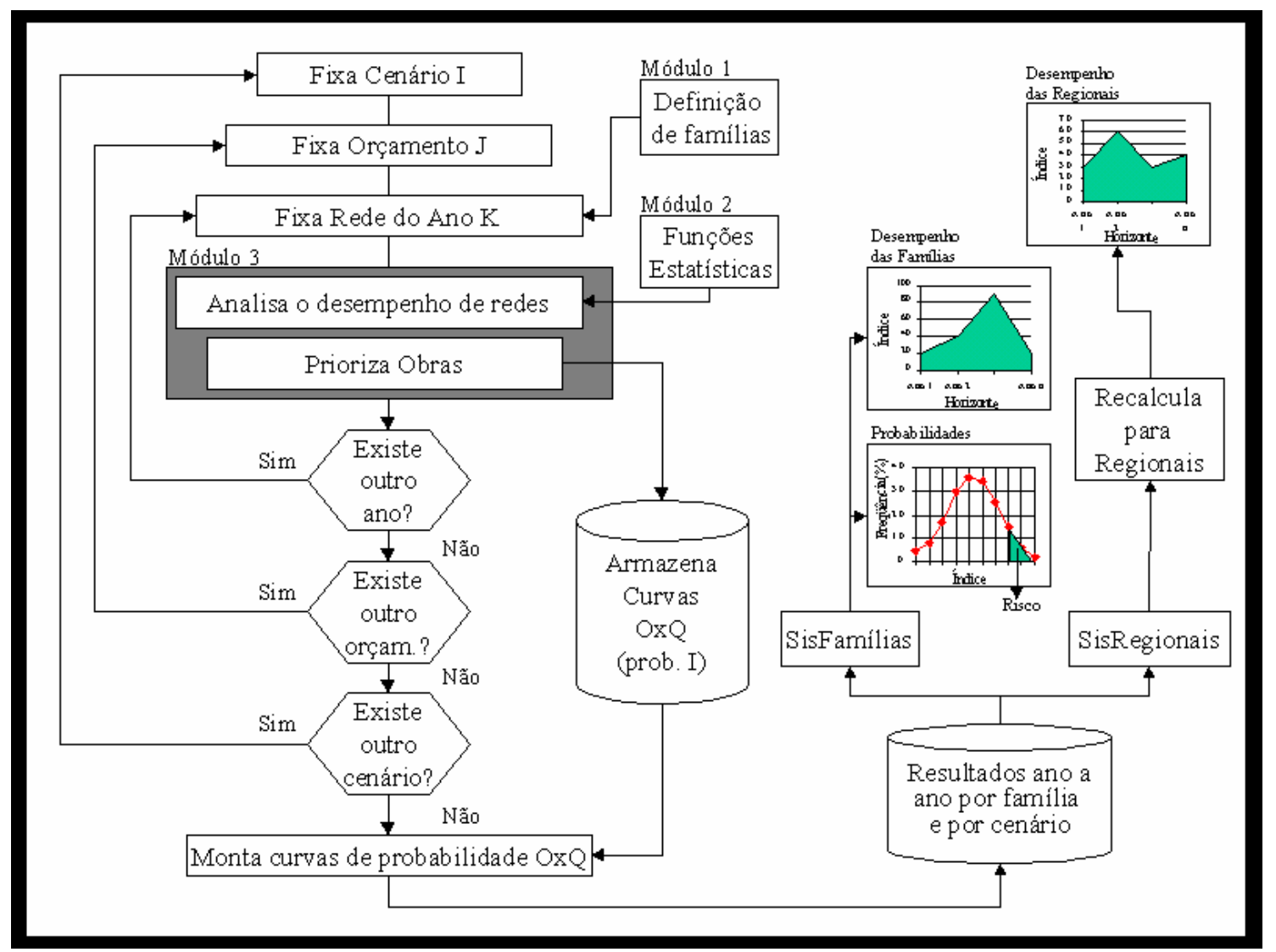

Figura 4.3(a) - Metodologia

$\mathrm{Na}$ figura 4.3(b) tem-se a tabela correspondente aos relatórios de índices de qualidade emitidos pelo sistema, onde observa-se a evolução dos índices ao longo dos anos de estudo. Para cada ano apresenta-se os valores em unidades usuais (na primeira linha de cada família ou regional) e em porcentagem (na segunda), conforme detalhado no capítulo 4.2. 
Como pode-se observar na figura, as duas últimas linhas correspondem ao total, e IQ refere-se ao índice de qualidade (ou econômico) escolhido.

\begin{tabular}{|c|c|c|c|c|c|c|}
\hline Família & Ano 1 & Ano 2 & Ano 3 & $\ldots$ & Ano $(n-1)$ & Ano $(n)$ \\
\hline 1 (unidades usuais) & $\mathrm{IQ}_{1,1}$ & $\mathrm{IQ}_{1,2}$ & $\mathrm{IQ}_{1,3}$ & $\ldots$ & $\mathrm{IQ}_{1, \mathrm{n}-1}$ & $\mathrm{IQ}_{1, \mathrm{n}}$ \\
\hline $1(\%)$ & $\mathrm{IQ}_{1,1 \%}$ & $\mathrm{IQ}_{1,2 \%}$ & $\mathrm{IQ}_{1,3 \%}$ & $\ldots$ & $\mathrm{IQ}_{1, \mathrm{n}-1 \%}$ & $I Q_{1, n \%}$ \\
\hline 2 (unidades usuais) & $\mathrm{IQ}_{2,1}$ & $\mathrm{IQ}_{2,2}$ & $\mathrm{IQ}_{2,3}$ & $\ldots$ & $\mathrm{IQ}_{2, \mathrm{n}-1}$ & $\mathrm{IQ}_{2, \mathrm{n}}$ \\
\hline $2(\%)$ & $\mathrm{IQ}_{2,1 \%}$ & $\mathrm{IQ}_{2,2 \%}$ & $\mathrm{IQ}_{2,3 \%}$ & $\ldots$ & $I Q_{2, n-1 \%}$ & $\mathrm{IQ}_{2, \mathrm{n} \%}$ \\
\hline$\ldots$ & $\ldots$ & $\ldots$ & $\ldots$ & $\ldots$ & $\ldots$ & $\ldots$ \\
\hline$\ldots$ & $\ldots$ & $\ldots$ & $\ldots$ & $\ldots$ & $\ldots$ & $\ldots$ \\
\hline f (unidades usuais) & $\mathrm{QQ}_{\mathrm{f}, 1}$ & $I Q_{f, 2}$ & $\mathrm{IQ}_{\mathrm{f}, 3}$ & $\cdots$ & $I Q_{f, n-1}$ & $\mathrm{QQ}_{\mathrm{f}, \mathrm{n}}$ \\
\hline$f(\%)$ & $I Q_{f, 1 \%}$ & $I Q_{f, 2 \%}$ & $I Q_{f, 3 \%}$ & $\ldots$ & $I Q_{f, n-1 \%}$ & $I Q_{f, n \%}$ \\
\hline Total (unidades usuais) & $I Q_{t, 1}$ & $I Q_{t, 2}$ & $I Q_{t, 3}$ & $\ldots$ & $I Q_{t, n-1}$ & $\mathrm{IQ}_{\mathrm{t}, \mathrm{n}}$ \\
\hline Total (\%) & $I Q_{t, 1 \%}$ & $I Q_{t, 2 \%}$ & $I Q_{t, 3 \%}$ & $\ldots$ & $1 Q_{t, n-1 \%}$ & $I Q_{t, n \%}$ \\
\hline
\end{tabular}

Figura 4.3(b) - Desempenho anual das famílias

A ferramenta permite analisar os índices para cada família separadamente, algumas delas conjuntamente ou o desempenho total de todas as famílias. Raciocínio análogo aplica-se às regionais, onde, uma vez definidas as mesmas, o programa calcula automaticamente os valores e apresenta os resultados. Na figura 4.3(c) observa-se um sistema com a definição de $\mathrm{n}$ regionais.

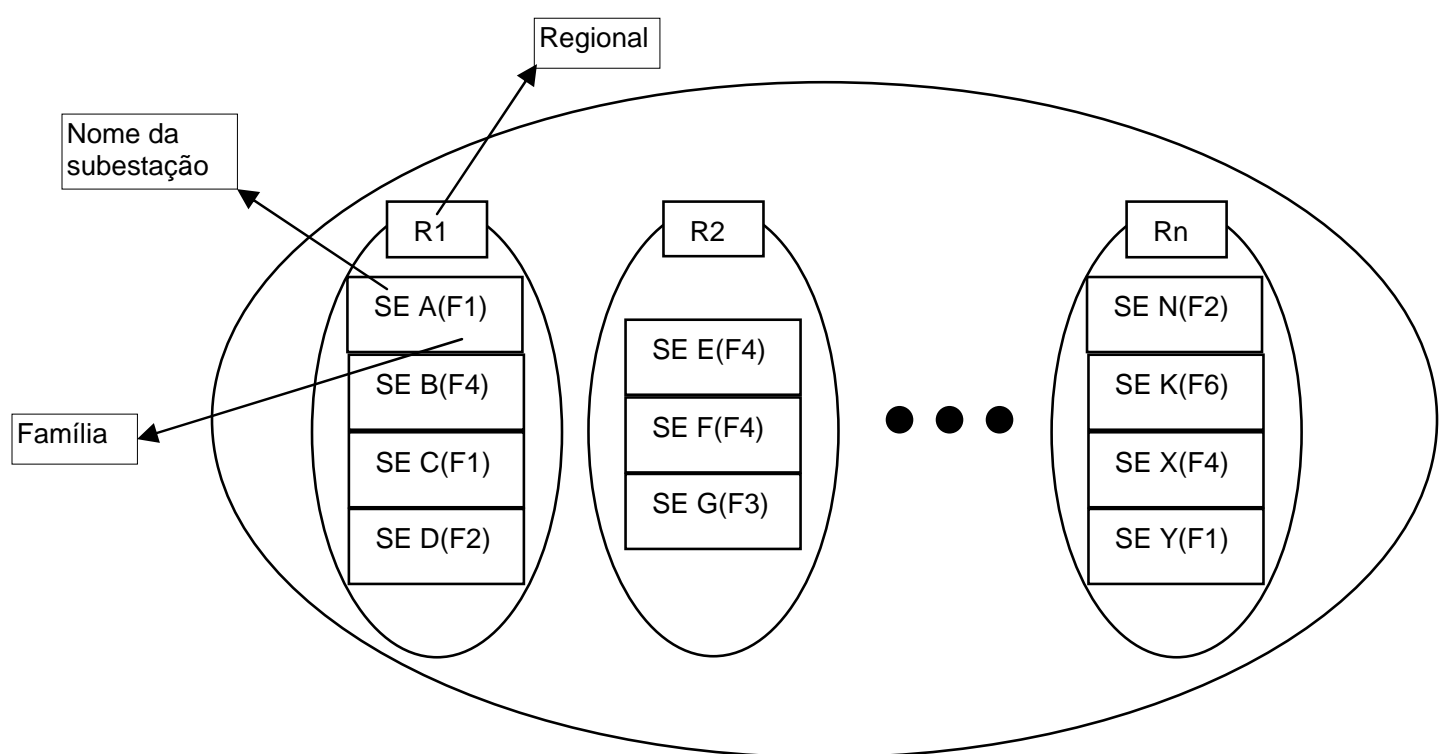

Figura 4.3(c) - Esquema demostrando a formação das regionais. 
No esquema tem-se, por exemplo, a regional R1, que conta com quatro subestações ( $A, B, C$ e D). classificadas, respectivamente, nas famílias F1, F4, F1 e F2. A partir da contabilização de índices, por famílias, fica relativamente simples a composição dos resultados para as regionais, conforme será apresentado no item 4.5.2

As tabelas são apresentadas por cenário, e, para cada um, é gerado o gráfico correspondente. Na figura 4.3(d) observa-se um gráfico genérico para análise de desempenho de índices de qualidade, válido tanto para famílias quanto para regionais.

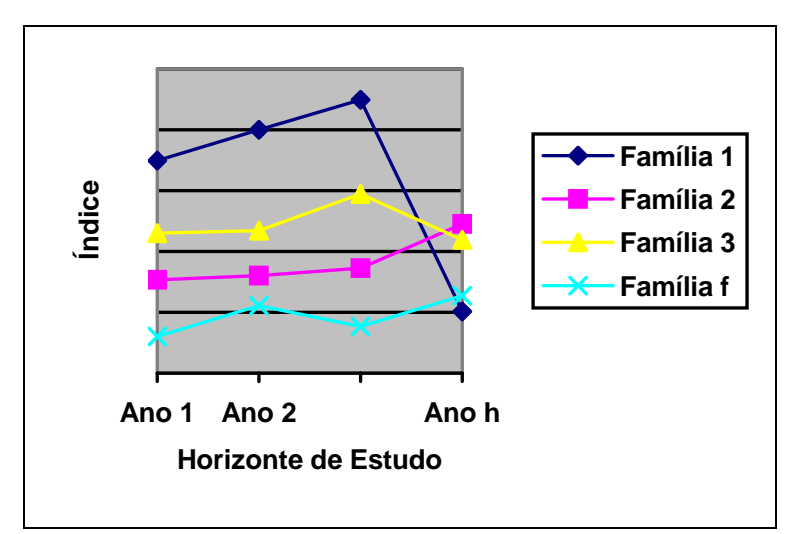

Figura 4.3(d) - Desempenho anual dos índices de qualidade.

Para a totalização, temos um gráfico semelhante ao apresentado na figura 4.3(e). Conforme visto no item 4.2, de acordo com o índice de qualidade considerado, o resultado da totalização tem um significado diferente. Assim, por exemplo, para perdas, o total refere-se às perdas globais do sistema, ao passo que, quando analisa-se FEC, os valores totais são as médias dos alimentadores de todas as subestações do sistema. 


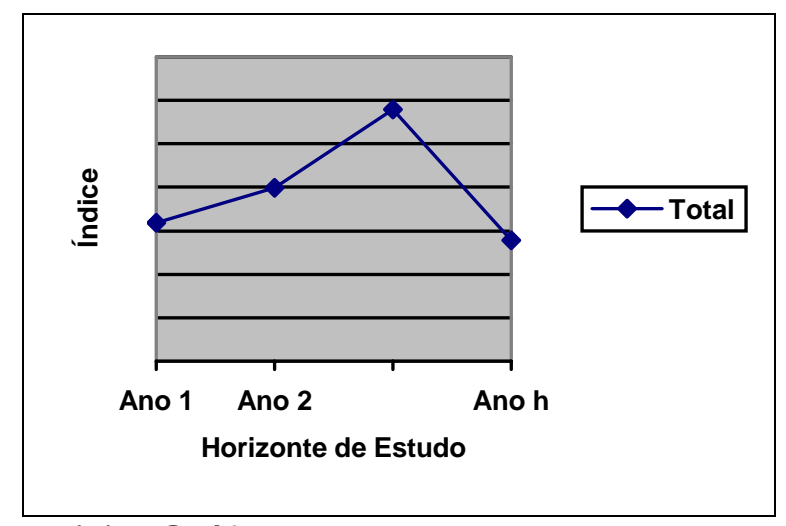

Figura 4.3(e) - Gráfico de desempenho total do sistema.

Raciocínio semelhante pode ser aplicado para o relatório de investimentos, onde pode-se escolher entre o gráfico que apresenta os custos como porcentagem do valor dispendido anualmente ou em unidade monetária, por famílias ou para todo o sistema. Para exemplificar, na figura 4.3(f) observa-se um gráfico com os dispêndios globais efetivos no sistema, em unidades monetárias.

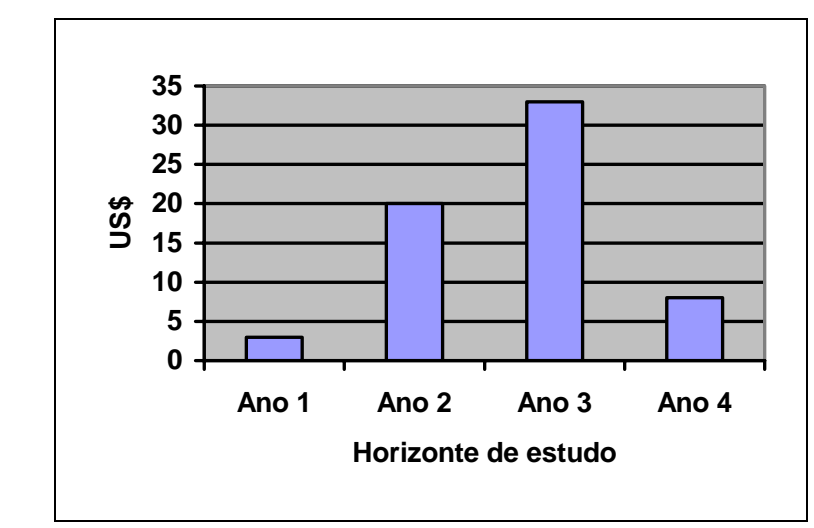

Figura 4.3(f):Relatório econômico para o sistema em dólares. 


\subsection{SisFamílias}

O aplicativo SISFAMÍLIAS, desenvolvido no âmbito deste trabalho, possui a interface apresentada na figura 4.4(a).

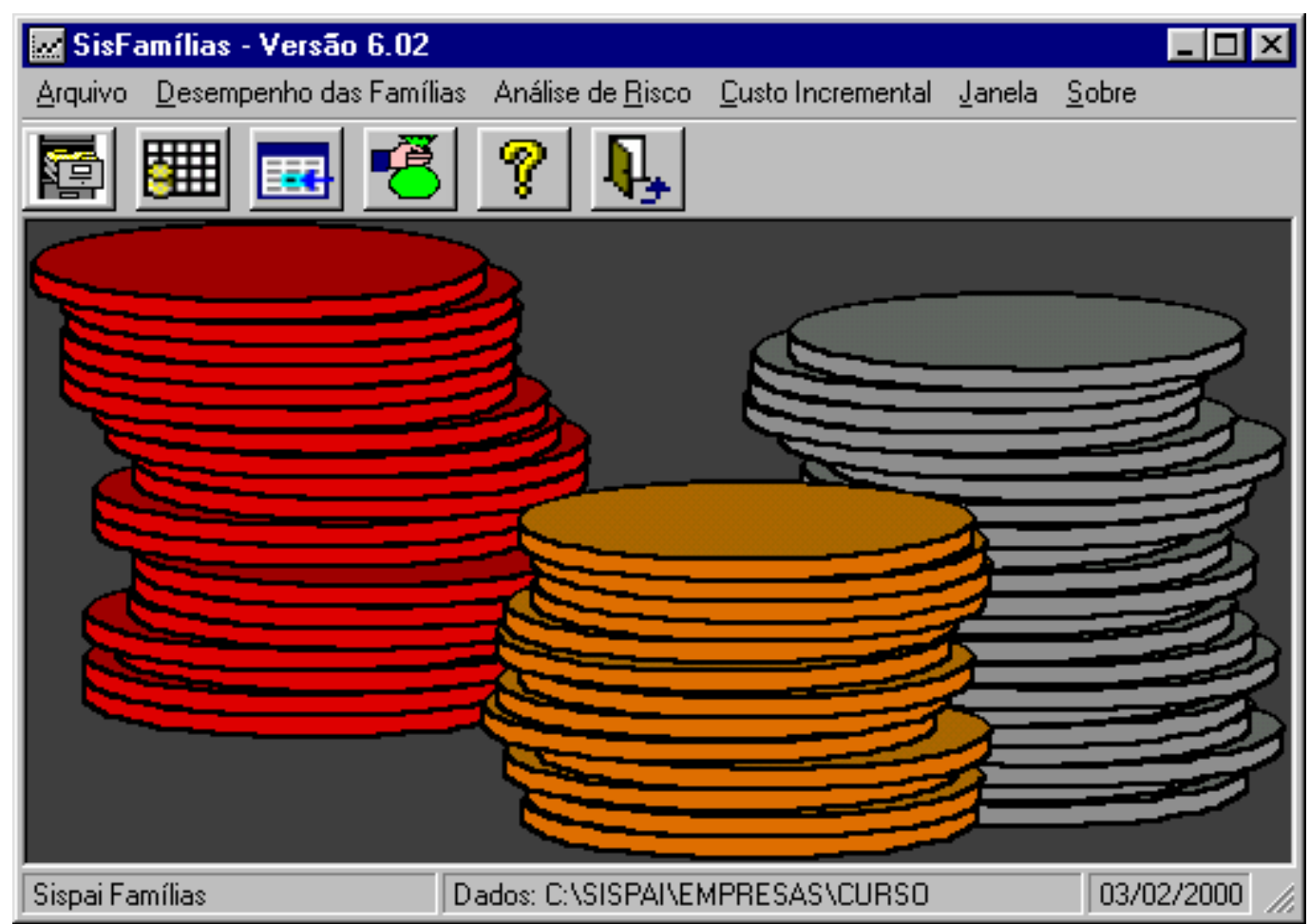

Figura 4.4(a):Tela principal do aplicativo SisFamílias.

Com esse aplicativo é possível analisar-se a evolução do sistema elétrico ao longo do horizonte de estudo. O módulo permite as seguintes análises:

- desempenho das famílias

- análise de risco

- determinação de custos incrementais médios e custos marginais

que serão objeto dos sub-itens seguintes.

Para cada índice de qualidade que deseja-se estudar, deve-se proceder a sua escolha, conforme figura 4.4(b). 


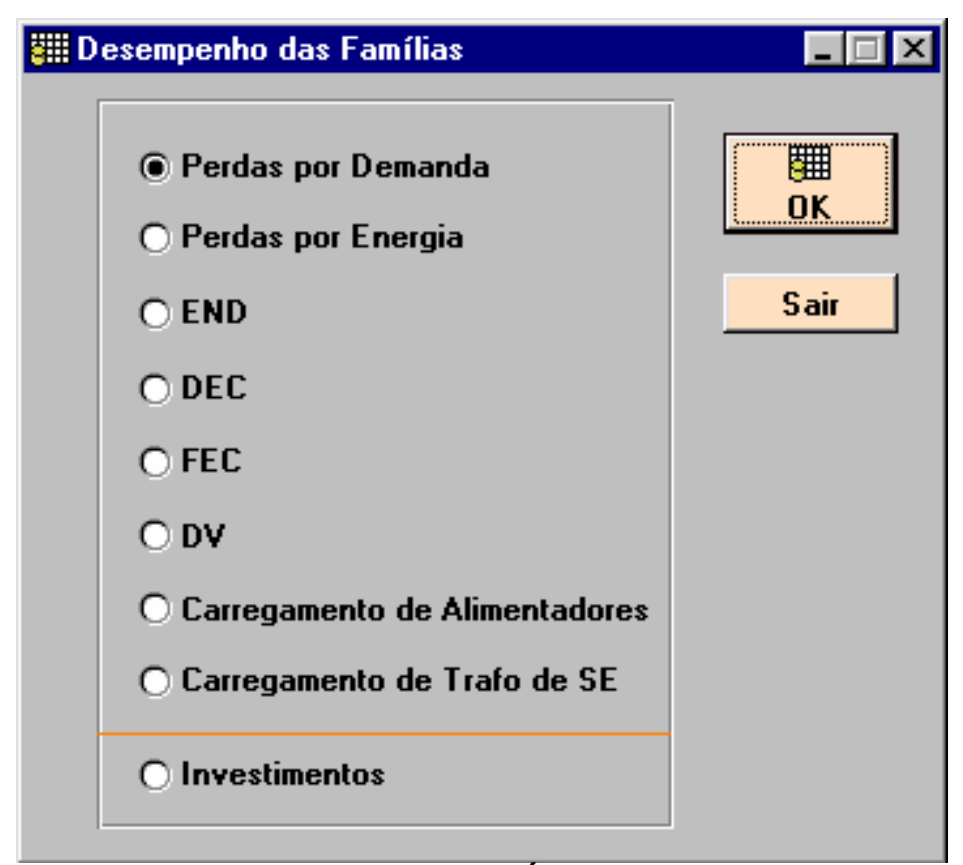

Figura 4.4(b):Escolha do Índice de Qualidade.

\subsubsection{Relatórios de Evolução dos Índices no Período de Planejamento - Desempenho das Famílias}

$\mathrm{Na}$ alternativa de análise do desempenho das famílias, o planejador tem a disposição uma poderosa ferramenta para verificar o desempenho dos índices de qualidade do seu sistema. Assim, pode-se acompanhar a evolução do DEC, por exemplo, para cada família, e a seguir comparar com o DEC total médio de todas as subestações, analisando o desempenho de cada família em relação a média (ou às demais). É possível visualizar o desempenho de cada um dos índices de qualidade apresentados anteriormente, ao longo do horizonte de estudo. Os relatórios são mostrados na forma de tabelas, uma para cada cenário proposto, para todos os anos do horizonte de estudo, em valores percentuais e nas unidades usuais, conforme descrito no item 4.2.

A seguir visualiza-se graficamente o relatório, definindo-se qual resultado deseja-se observar, em unidades usuais ou em porcentagem. 
Para evitar a poluição visual decorrente do grande número de famílias, fato comum em análises de casos reais, o sistema tem ferramentas que ajudam a contornar o problema, permitindo que observe-se apenas algumas famílias escolhidas.

Para permitir a análise dos gráficos de desempenho, algumas observações são importantes. Uma curva que sofre um forte decréscimo em algum ano do horizonte, deve ser analisada levando-se em conta a ocorrência de alguma obra para aquela família, naquele ano.

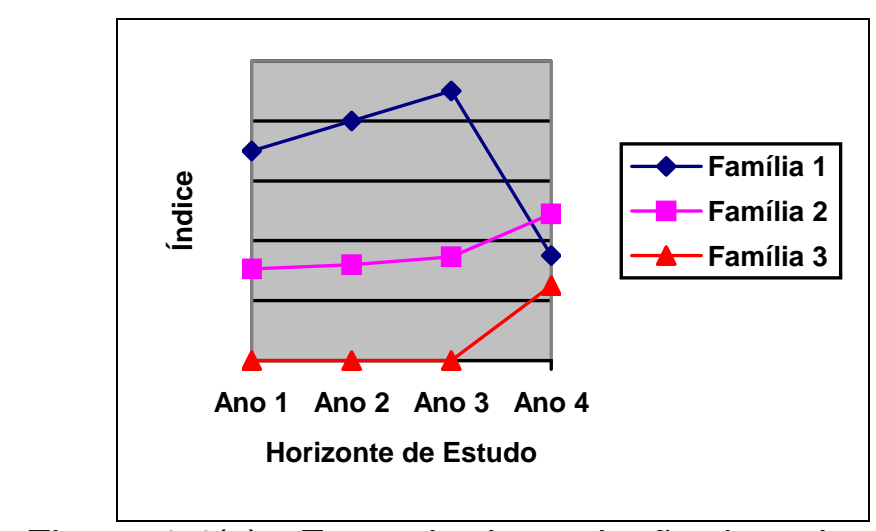

Figura 4.4(c) - Exemplo de evolução de rede.

No exemplo da figura 4.4(c) percebe-se três casos bem distintos. A curva da família 1 tem um forte decréscimo a partir do terceiro ano. Isto é certamente devido a alguma obra que auxiliou a diminuição do índice considerado. Caso o índice em estudo seja carregamento de alimentadores, por exemplo, a obra poderia ter sido uma nova subestação ou desdobramento de alimentadores. Já na família 2, percebe-se um crescimento constante do índice, demostrando que os alimentadores da família ainda não exigiram nenhum tipo de obra do sistema. Para a família 3, nota-se que a família não existia até o terceiro ano, e, portanto, foi fruto de obra em subestação nova. Do exemplo, considerando-se apenas as três famílias representadas, nota-se claramente que a família 3 é uma subestação nova, para atendimento da família 1. 
Pode-se também verificar o total, que para o exemplo sugerido seria o carregamento médio dos alimentadores de todas as subestações do sistema, conforme figura $4.4(d)$.

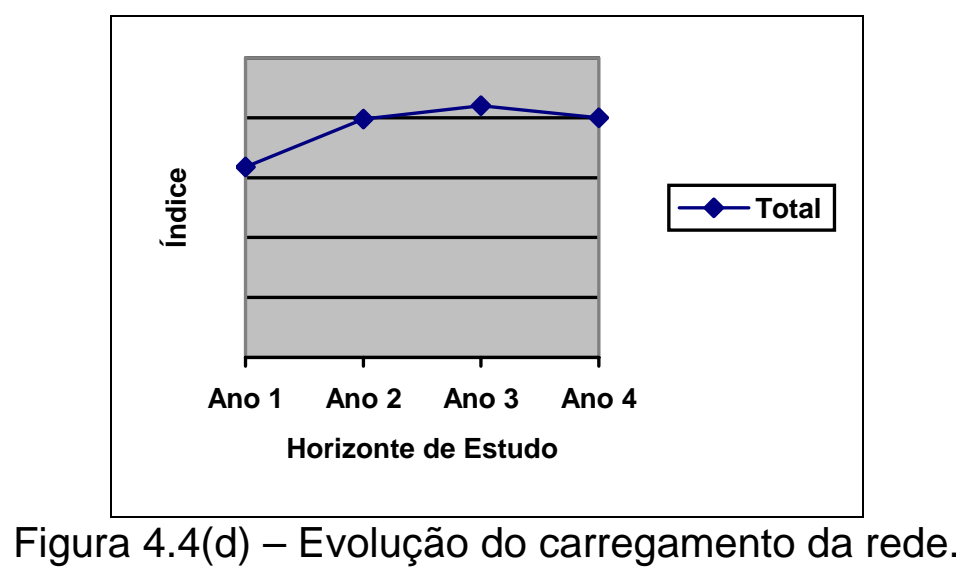

\subsubsection{Relatórios de Distribuição de Probabilidades e Análise de Risco dos Índices de Qualidade}

O tratamento de incertezas no SISPAI é realizado através de análise de cenários, isto é, análise de valores otimistas, medianos e pessimistas dos parâmetros relativos à taxa de crescimento, taxa de juros e custos unitários de equipamentos.

A cada cenário, que é uma combinação de valores dos três parâmetros acima, corresponde uma probabilidade de ocorrência dada pelo produto das probabilidades de ocorrência de cada parâmetro (hipótese de eventos independentes). Desta forma, o sistema SISPAI foi aprimorado para verificar as freqüências de ocorrência de cada um dos índices técnicos de qualidade definidos no item 4.2 em todos os cenários, para um determinado orçamento. Determina-se, portanto, a curva de distribuição de probabilidades de cada índice técnico definido, que permite análise do risco de cada índice violar determinado valor pré-fixado. 
Nota-se que nas tabelas de Desempenho das Famílias haviam duas faixas de valores: uma com as unidades usuais, e a outra em porcentagem. Para a análise de risco dos índices de qualidade foi escolhida apenas uma, a unidade mais habitualmente utilizada, conforme a tabela 4.4(a):

\begin{tabular}{|c|c|}
\hline $\begin{array}{l}\text { Índice de } \\
\text { Qualidade }\end{array}$ & Unidade \\
\hline $\begin{array}{l}\text { Perdas por } \\
\text { demanda }\end{array}$ & $\begin{array}{l}\% \text { (porcentagem da potência atendida dos } \\
\text { alimentadores) }\end{array}$ \\
\hline $\begin{array}{l}\text { Perdas por } \\
\text { energia }\end{array}$ & $\%($ porcentagem da energia anual fornecida) \\
\hline END & MWh/ano \\
\hline DEC & Horas/ano \\
\hline FEC & $\begin{array}{c}\text { Falhas/ano } \\
\end{array}$ \\
\hline $\begin{array}{l}\text { Queda de } \\
\text { Tensão }\end{array}$ & $\begin{array}{l}\% \text { (queda de tensão média dos alimentadores da } \\
\text { família) }\end{array}$ \\
\hline $\begin{array}{c}\text { Carregamento } \\
\text { de } \\
\text { Alimentadores }\end{array}$ & $\begin{array}{c}\% \text { (média dos carregamentos percentuais dos } \\
\text { alimentadores da família) }\end{array}$ \\
\hline $\begin{array}{l}\text { Carregamento } \\
\text { de subestações }\end{array}$ & $\begin{array}{l}\text { \%(carregamento como percentagem da potência } \\
\text { instalada) }\end{array}$ \\
\hline Investimentos & kUS\$ \\
\hline
\end{tabular}

Tabela 4.4(a): Unidades utilizadas.

Da figura 4.4(e) percebe-se que, para o orçamento escolhido, existe $20 \%$ de probabilidade do índice estar na Faixa1, 30\% de estar na Faixa2, e assim por diante. De maneira análoga, é fácil notar que a probabilidade do índice ser superior ao valor máximo da Faixa3 é de 10\%, que corresponde ao risco deste valor de índice ser excedido. 


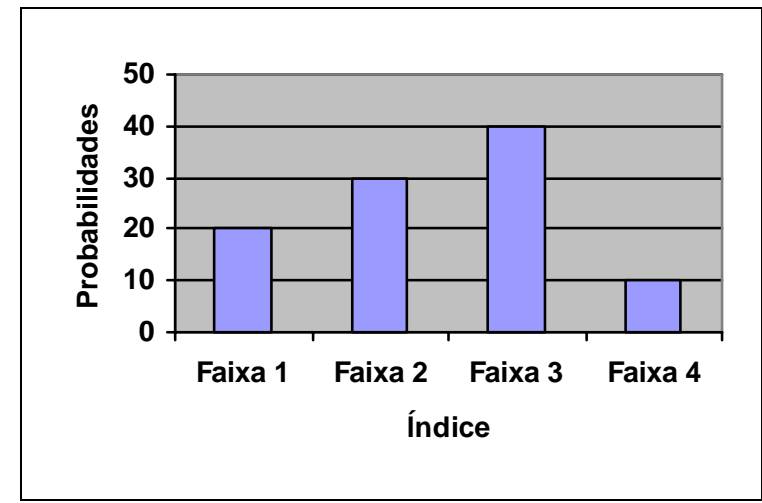

Figura 4.4(e): Gráfico de distribuição de probabilidades.

As faixas são definidas tendo-se em conta o menor e o maior valor de cada índice, nos diversos cenários em análise. Destaca-se que cada índice, em cada cenário, corresponde a uma média para todos os anos do estudo, denominado $I_{m}$. Assim, na figura 4.4(f) tem-se o índice $I_{m 1}$, que é o valor médio para o índice no cenário 1 . Na figura 4.4(g), tem-se o índice $I_{\mathrm{mn}}$, valor médio para o índice no cenário $\mathrm{n}$. Assim, o sistema verifica, dentre todos os cenários, aquele que tem o menor valor para $I_{m}$, que será o ImMín, assim como o que tem o maior, ImMáx.

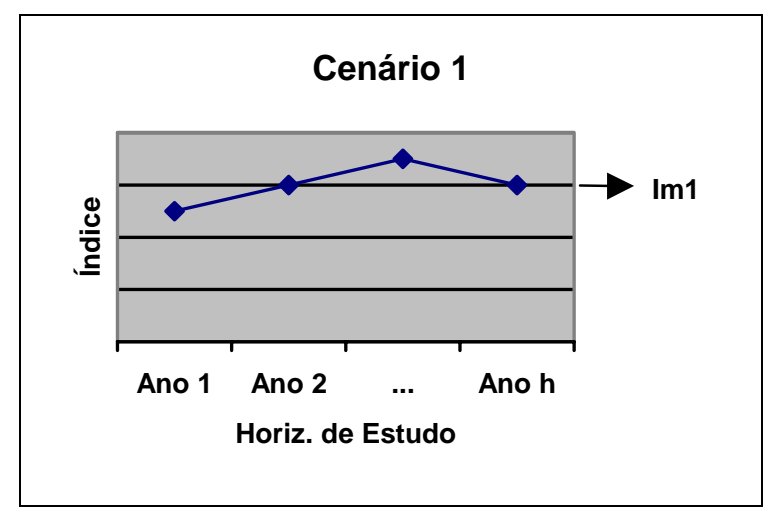

Figura 4.4(f): Gráfico de evolução do índice, com o valor médio para o cenário $1, I_{\mathrm{m} 1}$. 


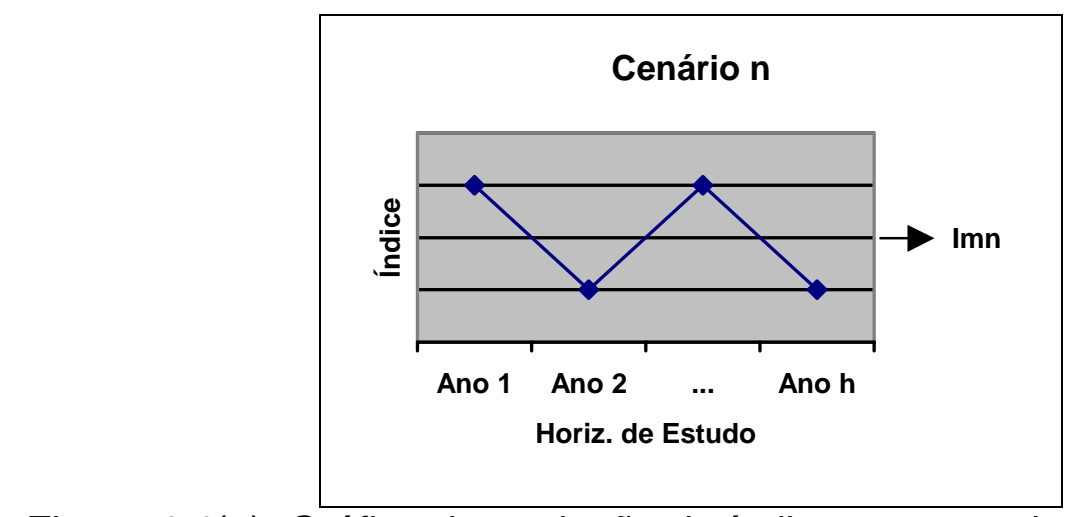

Figura 4.4(g): Gráfico de evolução do índice, com o valor médio para o cenário $\mathrm{n}, \mathrm{I}_{\mathrm{mn}}$.

O sistema define, baseado nestes limites inferior e superior, cinco faixas de valores de mesmo tamanho, dispondo os valores médios dos índices nestas faixas, e apresentando os resultados em um gráfico semelhante ao apresentado na figura 4.4(e).

A análise de cenários desenvolvida fornece, portanto, para cada orçamento considerado no estudo, a probabilidade do índice considerado encontrar-se em cada uma das faixas de valores. O mesmo raciocínio vale para o total apresentado no fim da tabela, porém aqui o sistema considera o menor e o maior valor globais, possibilitando uma visão geral do desempenho do sistema.

Cabe aqui uma discussão mais detalhada sobre o último índice definido na tabela 4.4(a), o índice de Investimentos, e como ele deve ser interpretado.

Para cada uma das famílias, tem-se o valores médios que foram investidos em obras nos diversos cenários analisados. Estes valores, assim como para todos os índices, são utilizados para definir as cinco faixas de valores para a análise de cenários. Os valores apresentados são as probabilidades de ocorrência de investimentos para cada faixa, considerando-se a soma dos investimentos de todos os anos. Para o total, o raciocínio é análogo, e os limites inferior e superior são definidos considerando-se os valores globais para todas as famílias analisadas. 


\subsubsection{Custo Incremental e Custo Marginal}

Historicamente, o custo marginal vem sendo calculado nas empresas através da Lei de Quantidade de Obras (LQO), que considera a função investimentos/demanda do passado para projetar seu Plano de Expansão futuro [2]. O problema é que a reestruturação do sistema elétrico brasileiro tem feito, mais do que nunca, que investimentos futuros não sejam reflexo de investimentos passados. Empresas que foram recentemente privatizadas, como a BANDEIRANTE ou a RGE, para citar apenas dois exemplos, não possuem esse histórico bem definido. O SISPAI encaixase perfeitamente neste modelo, pois fornece um plano de expansão que reflete a realidade dos seus investimentos futuros, que na maioria dos casos não corresponde à função investimentos/demanda do passado. Além disso, mesmo que as LQO's representassem as evoluções futuras em investimentos, não permitiriam facilmente a incorporação de aspectos da qualidade, ou seja, o quanto representa o custo adicional devido a uma melhoria de qualidade de fornecimento.

Dessa forma, para calcular-se os custos marginais de expansão da distribuição do sistema elétrico, adota-se a metodologia do Custo Incremental Médio de Longo Prazo (CIMLP), que é calculado pela seguinte fórmula [23]:

$$
C I M L P=\frac{\sum_{a=1}^{h} \Delta I_{a} *(1+j)^{-a}}{\sum_{a=1}^{h} \Delta P_{a} *(1+j)^{-a}}
$$

onde

a: ano de estudo

h: horizonte de estudo

$\Delta$ Ia: investimentos no sistema elétrico para o determinado ano "a" $\triangle \mathrm{Pa}$ : acréscimo de demanda no ano "a" 
j: taxa de atualização do capital.

Para o cálculo do Custo Marginal de Expansão, falta ainda calcular o custo de antecipação dos investimentos, uma vez que esses investimentos serão todos feitos ao longo do horizonte de estudo. Esse custo considera as despesas de capital, a depreciação e os custos referentes à manutenção e operação $(\mathrm{M} / \mathrm{O})$. Isto é feito multiplicando-se $\mathrm{O}$ custo CIMLP por uma taxa de antecipação que é o somatório das taxas correspondentes a cada uma das três despesas.

Taxa Antecipação $=$ Taxa de atualização + Taxa de Depreciação + Taxa de M/O

Assim, foi desenvolvida, nos moldes acima, uma ferramenta que determina o Custo Marginal de Expansão para cada um dos cenários considerados no planejamento, para todo o sistema elétrico considerado, que é dado por:

$\mathrm{CM}=\mathrm{CIMLP} * \mathrm{~T} . \mathrm{A}$.

onde

T.A. : taxa de antecipação. 


\subsection{SisRegionais}

No módulo SISREGIONAIS, desenvolvido no âmbito deste trabalho, o planejador pode obter os resultados do desempenho dos índices de qualidade e relatórios econômicos para alguma região em particular, ou qualquer agrupamento de subestações que se queira investigar.

O aplicativo SISREGIONAIS possui a interface apresentada na figura 4.5(a).

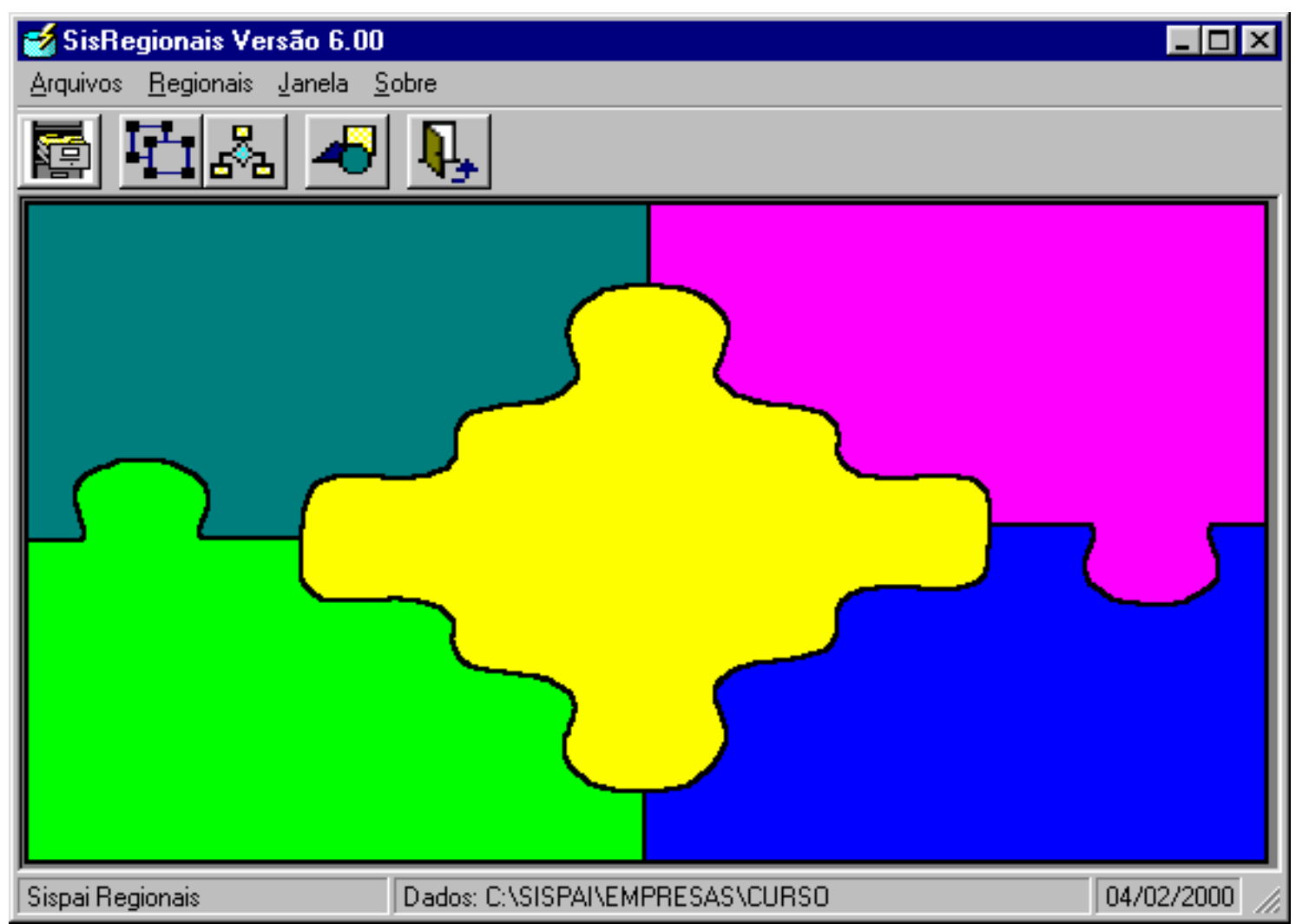

Figura 4.5(a): Tela principal do aplicativo SISREGIONAIS. 


\subsubsection{Relatórios de Evolução dos Índices no Período de Planejamento - Desempenho das Regionais}

Em uma aplicação típica do SISREGIONAIS, o planejador deseja saber o total de investimentos em uma regional do sistema (vide figura 4.3(c)), após ter processado o SISPAI para uma determinada área de concessão. Num primeiro momento, o usuário deve cadastrar as regionais em uma tela apropriada.

A seguir procede-se à associação das regionais criadas às subestações (SE's) reais. Para tal, o sistema disponibiliza uma ferramenta que pode ser vista na figura 4.5(b). No alto da figura temos a lista onde encontramse todas as regionais cadastradas até então. Na lista à esquerda (SE's existentes), são apresentadas todas as SE's reais cadastradas no sistema, para efeito de consulta. Na lista do meio (SE's remanescentes), o planejador verifica quais SE's ainda estão disponíveis para cadastramento. Na lista à direita (SE's da regional), tem-se as SE's já escolhidas para a regional atual. Assim, pode-se adicionar ou retirar SE's da regional atual.

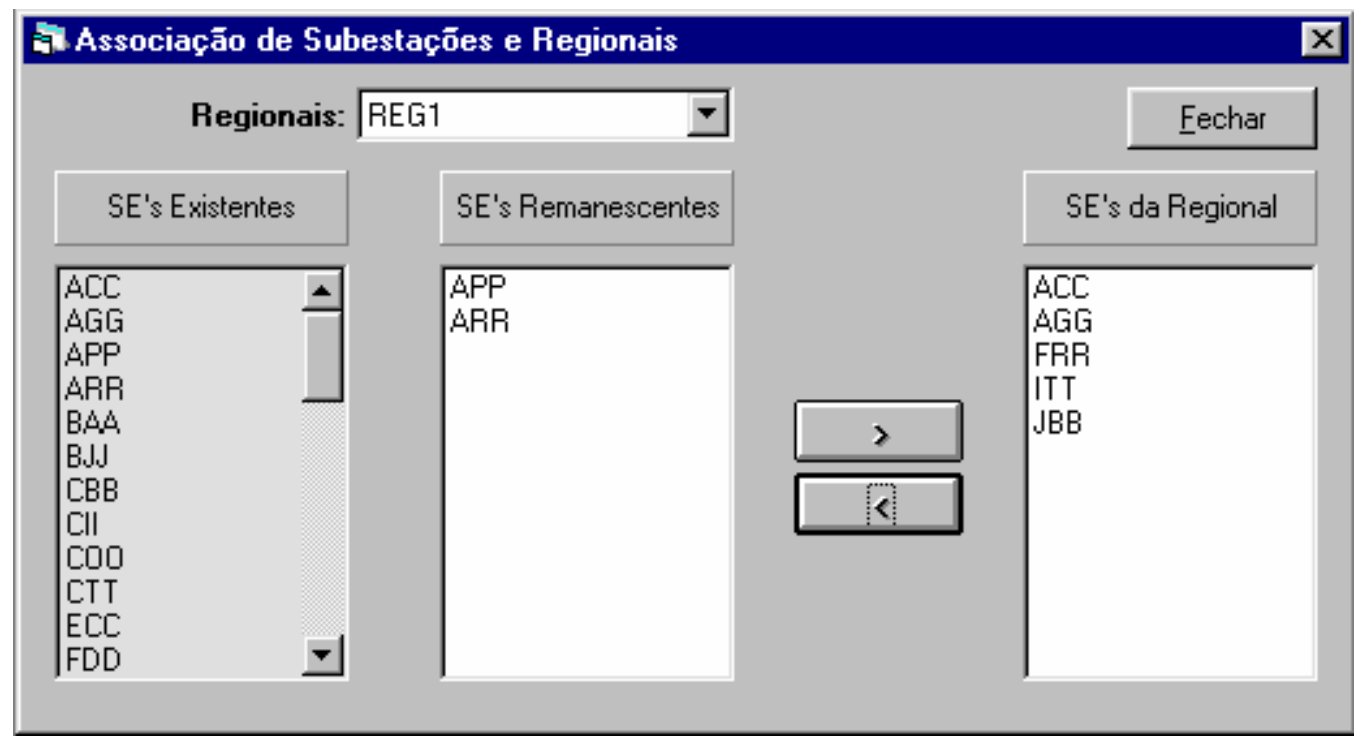

Figura 4.5(b): Tela de associação das SE's reais as regionais. 
Finalizado este processo, deve-se escolher o índice de qualidade para estudo, utilizando-se de interface ilustrada na figura 4.5(c).

Ao escolher-se o índice desejado, o programa calcula, baseado nos resultados fornecidos por família, os valores por regionais. Isso é feito considerando-se, para cada subestação real pertencente a cada regional, o número da família correspondente. Então o sistema pondera os valores por família e para cada ano, obtendo o resultado também anualizado para cada regional. Os valores são expressos em unidades usuais e em porcentagem, e, ao final, tem-se duas linhas de total, analogamente ao que ocorre com a ferramenta para análise de famílias.

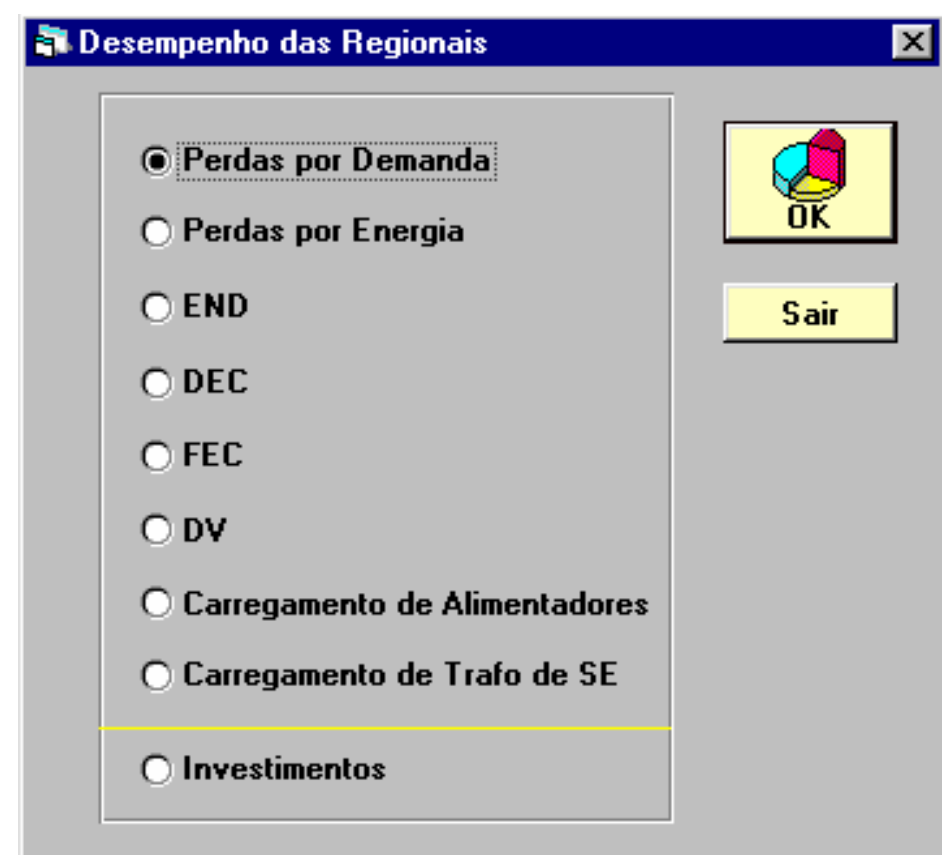

Figura 4.5(c): Tela para escolha do índice de qualidade para estudo.

Escolhendo-se a visualização gráfica na unidade desejada, obtém-se uma tela semelhante a da figura 4.5(d), que possibilita analisar a evolução do desempenho das regionais definidas. 


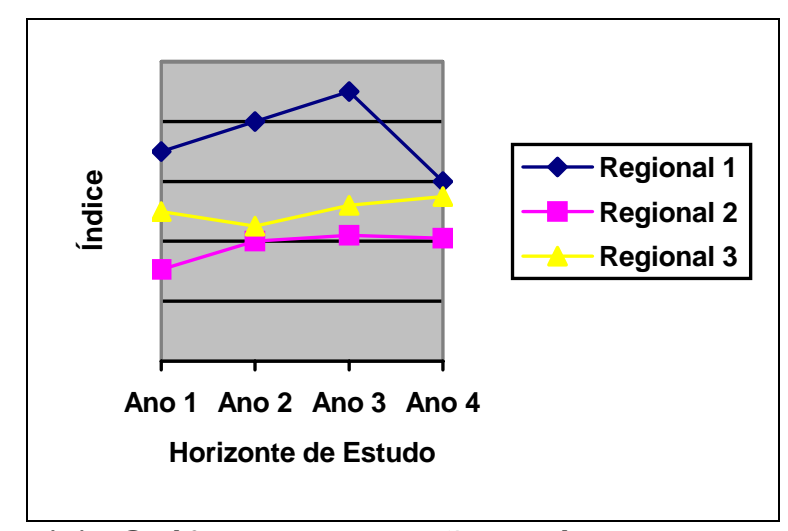

Figura 4.5(d): Gráfico de evolução de índices para regionais.

\subsubsection{Cálculo dos Índices para Regionais}

Os índices por regional são calculados a partir dos valores obtidos para as famílias de subestações formadas no SISPAI. Como o sistema conhece as subestações reais, que pertencem a uma determinada regional, e conhece também as famílias a que pertencem cada uma dessas subestações reais, ele considera para efeito de cálculo que os valores dos índices de qualidade das subestações reais são os obtidos para as famílias as quais elas pertencem. Essa aproximação é tanto mais precisa quanto melhores forem as formações de famílias no SISPAI, ou seja, quanto melhor as subestações reais estiverem sendo representadas pelo representante da família correspondente.

Desta forma, o sistema já possui os resultados para as subestações, e basta agora agregar esses resultados para as regionais formadas. Para tanto, deve-se ter em vista as características do índice considerado, que devem ser tratados separadamente. Os totais são sempre, obrigatoriamente, iguais aos totais obtidos para as famílias, pois o sistema em estudo é o mesmo, embora agrupado de maneiras diferentes. Não serão, portanto, definidos.

Para os índices Perdas por Demanda, Perdas por Energia, Energia Não Distribuída (END), Carregamento de Subestações e Investimentos, o 
cálculo é feito somando-se os valores correspondentes às famílias representantes das subestações originais. Desta forma, por exemplo, o valor de perdas por demanda de uma regional, será a soma das perdas dos representantes das subestações envolvidas. Para os valores em porcentagem, segue-se o mesmo raciocínio.

Para os demais índices, DEC, FEC, Queda de Tensão e Carregamento dos Alimentadores, o cálculo é efetuado considerando-se a média dos valores das famílias envolvidas.

Note-se que para ambos os casos, as famílias criadas ao longo do processo de expansão do sistema são consideradas para efeito de cálculo de índices para regionais. Isto deve ser feito pois, as novas famílias geradas são, na realidade, novas subestações que vão sendo incorporadas ao sistema ao longo do horizonte de estudo.

\subsubsection{Perdas por Demanda}

I) Perdas por demanda da regional em $\mathrm{kW}$.

$\operatorname{Perdas}_{R}=\sum_{f=1}^{n_{f}}$ Perdas $_{f}$

onde

Perdas $_{\mathrm{f}}$ : Perda máxima da família f, em kW.

$\mathrm{n}_{\mathrm{f}}$ : número de subestações da regional $\mathrm{R}$.

II) Perdas por demanda da regional em \%.

$$
\operatorname{Perdas}_{R \%}=\frac{\operatorname{Perdas}_{R}}{\sum_{f=1}^{n_{\text {famR }}} P_{M A X_{f}}} * 100
$$

onde

$P_{\max }$ : Demanda máxima da família f, em kW. 


\subsubsection{Perdas por Energia}

I) Energia de perdas da regional, em $\mathrm{kWh}$.

Eperdas $_{R}=\sum_{f=1}^{n_{f}}$ Eperdas $_{f}$

onde

Eperdas $_{\mathrm{f}}$ : Energia de perdas da família f, em kWh.

$\mathrm{n}_{\mathrm{f}}$ : número de subestações da regional $\mathrm{R}$.

II) Energia de perdas da regional, em porcentagem.

$$
\text { Eperdas }_{R \%}=\frac{\text { Eperdas }_{R}}{\sum_{f=1}^{n_{f}} E A F_{f}} * 100
$$

onde

$\mathrm{EAF}_{\mathrm{f}}$ : Energia anual fornecida pela família f, em $\mathrm{kWh}$.

\subsubsection{END - Energia Não Distribuída na Rede Primária}

I) END da regional, em MWh.

$$
E N D_{R}=\sum_{i=1}^{n_{f}} E N D_{f}
$$

onde

$\mathrm{END}_{\mathrm{f}}$ : Energia não distribuída pela família f.

$\mathrm{n}_{\mathrm{f}}$ : número de subestações da regional $\mathrm{R}$. 
II) END da regional, em porcentagem.

$$
E N D_{R \%}=\frac{\sum_{f=1}^{n_{f}} E N D_{f}}{\sum_{f=1}^{n_{f}} E A F_{f}} * 100
$$

onde

$E A F_{f}$ é a energia anual fornecida pela família f.

\subsubsection{DEC - Duração Equivalente de Interrupção por Consumidor}

I) DEC médio da regional, em horas/ano.

$$
D E C_{R}=\frac{\sum_{f=1}^{n_{f}} D E C_{f} * n_{a \lim f}}{\sum_{f=1}^{n_{f}} n_{a \lim _{f}}}
$$

onde

$\mathrm{DEC}_{\mathrm{f}}$ : DEC da família $\mathrm{f}$.

$\mathrm{n}_{\mathrm{f}}$ : número de subestações da regional $\mathrm{R}$.

$\mathrm{n}_{\text {alimf }}$ : número de alimentadores da família $\mathrm{f}$.

II) DEC da regional em porcentagem.

$$
D E C_{R \%}=\frac{\sum_{f=1}^{n_{f}} D E C_{f \%} * n_{a \lim f}}{\sum_{f=1}^{n_{f}} n_{a \lim _{f}}}
$$

onde

$\mathrm{DEC}_{\mathrm{f} \%}$ : DEC da família $\mathrm{f}$, em porcentagem. 


\subsubsection{FEC - Freqüência Equivalente de Interrupção por Consumidor}

I) FEC médio da regional, em vezes/ano.

$$
\mathrm{FEC}_{R}=\frac{\sum_{f=1}^{n_{f}} \mathrm{FEC}_{f} * n_{a \lim f}}{\sum_{f=1}^{n_{f}} n_{a \lim _{f}}}
$$

onde

$\mathrm{FEC}_{\mathrm{f}}$ : FEC da família f.

$\mathrm{n}_{\mathrm{f}}$ : número de subestações da regional $\mathrm{R}$.

$\mathrm{n}_{\text {alimf }}$ : número de alimentadores da família f.

II) FEC da regional em porcentagem.

$$
F E C_{R \%}=\frac{\sum_{f=1}^{n_{f}} F E C_{f \%} * n_{a \lim f}}{\sum_{f=1}^{n_{f}} n_{a \lim _{f}}}
$$

onde

$\mathrm{FEC}_{\mathrm{f} \%}$ : FEC da família $\mathrm{f}$, em porcentagem.

\subsubsection{Queda de Tensão $(\Delta V)$}

I) Média da queda de tensão máxima dos alimentadores da regional, em volts.

$$
\Delta V_{R}=\frac{\sum_{f=1}^{n_{f}} \Delta V_{f} * n_{a \lim }}{\sum_{f=1}^{n_{f}} n_{a \lim }}
$$


II) Média da queda de tensão máxima dos alimentadores da regional, em porcentagem.

$$
\Delta V_{R \%}=\frac{\Delta V_{R}}{1-V \min }
$$

\subsubsection{Carregamento de Alimentadores}

I) Carregamento médio dos alimentadores da regional.

$$
S a \lim _{R}=\frac{\sum_{f=1}^{n_{f}} \operatorname{Salim}_{f} * n_{a \lim f}}{\sum_{f=1}^{n_{f}} n_{a \lim _{f}}}
$$

II) Média dos carregamentos percentuais dos alimentadores da regional.

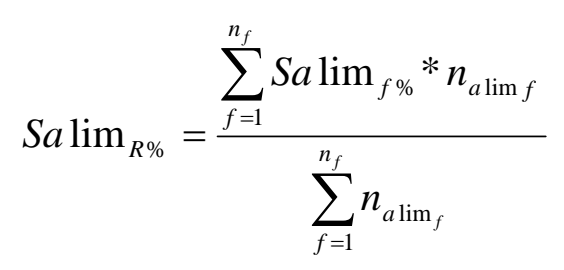

\subsubsection{Carregamento de Subestações}

I) Carregamento da regional, em MVA.

$$
S_{R}=\sum_{f=1}^{n_{f}} S_{f}
$$

onde

$\mathrm{S}_{\mathrm{f}}$ : Carregamento da família f, em MVA.

$\mathrm{n}_{\mathrm{f}}$ : número de subestações da regional $\mathrm{R}$. 
II) Carregamento da regional, em porcentagem.

$$
S_{R \%}=\frac{S_{R}}{\sum_{f=1}^{n_{f}} S_{\text {inst }_{f}}} * 100
$$

onde

$S_{\text {inst } f}$ : Potência instalada da família f, em MVA.

\subsubsection{Investimento - Distribuição dos Dispêndios por Regional}

I) Total dos investimentos na regional, em unidade monetária.

$$
\mathrm{I}_{\mathrm{R}}=\sum_{f=1}^{n_{f}} I_{f}
$$

onde

$I_{f}$ : investimento no representante da família $\mathrm{f}$.

$\mathrm{n}_{\mathrm{f}}$ : número de subestações da regional $\mathrm{R}$.

II) Total de investimentos na regional $\mathrm{R}$, em porcentagem.

$$
\mathrm{I}_{\mathrm{R} \%}=\frac{I_{R}}{I_{T}} * 100
$$

onde

$\mathrm{I}_{\mathrm{T}}$ : investimento total no sistema. 


\section{CAPÍTULO 5}

\section{CASO TESTE DE APLICAÇÃO}

\subsection{Descrição do Caso Teste}

O caso teste de aplicação foi gerado a partir de casos reais, porém com as alterações necessárias para preservar o anonimato dos dados das empresas envolvidas.

Inicialmente foi feito o processamento do sistema escolhido no SISPAI, observando-se todos os passos normalmente utilizados no planejamento agregado de investimentos. Neste capítulo são descritas todas as etapas desse processamento, passando pelo módulo 1, onde são feitos os agrupamentos de subestações e alimentadores, módulo 2, onde são criadas as leis estatísticas para evolução, e os módulos 3 e 5, onde observa-se a evolução da rede ao longo do horizonte de estudo para o caso base e para todos os cenários previamente definidos.

Esse caso teste tem por finalidade a utilização efetiva das ferramentas desenvolvidas neste trabalho, apresentando o resultado da aplicação da metodologia de planejamento agregado de investimentos em uma rede de distribuição real, com ênfase nas novas perspectivas alcançadas.

Os resultados dos investimentos obtidos neste caso teste aplicam-se aos ramais de subtransmissão associados às novas subestações, às subestações de distribuição com seus respectivos transformadores, e aos alimentadores primários. Todas as redes consideradas neste estudo são classificadas como não completamente urbanizadas. 


\subsection{Processamento do Sispai Básico}

Os dados para análise dizem respeito a um universo de 74 subestações, contendo um total de 280 alimentadores.

Nas tabelas 5.2(a) a 5.2(c), apresenta-se um resumo das principais características das subestações em estudo, relativas à distribuição por nível de tensão, número de transformadores e número de alimentadores.

\begin{tabular}{|c|c|}
\hline $\begin{array}{c}\text { Nível de Tensão } \\
(\mathbf{k V})\end{array}$ & $\begin{array}{c}\text { Quantidade de } \\
\text { SEs }\end{array}$ \\
\hline $69 / 13.8$ & 74 \\
\hline
\end{tabular}

Tabela 5.2(a) - Distribuição por Nível de Tensão

\begin{tabular}{|c|c|}
\hline $\begin{array}{c}\text { Número de } \\
\text { Transformadores }\end{array}$ & $\begin{array}{c}\text { Quantidade de } \\
\text { Subestações }\end{array}$ \\
\hline 1 & 40 \\
\hline 2 & 34 \\
\hline
\end{tabular}

Tabela 5.2(b) - Distribuição por Número de Transformadores

\begin{tabular}{|c|c|}
\hline $\begin{array}{c}\text { Número de } \\
\text { Alimentadores }\end{array}$ & $\begin{array}{c}\text { Quantidade de } \\
\text { Subestações }\end{array}$ \\
\hline \hline 1 & 3 \\
\hline 2 & 4 \\
\hline 3 & 20 \\
\hline 4 & 33 \\
\hline 5 & 10 \\
\hline 6 & 4 \\
\hline
\end{tabular}

Tabela 5.2(c) - Distribuição por Número de Alimentadores 


\subsubsection{Cadastramento de Dados}

Inicialmente foram cadastrados os dados relacionados aos equipamentos utilizados pela empresa. São eles: cabos, transformadores, subtransmissão, reguladores, custos e bays. Nas tabelas a seguir, são apresentados os dados de entrada utilizados para cada equipamento.

Os dados referentes aos parâmetros dos condutores utilizados, critérios de carregamento e custos unitários para construção da rede, são apresentados na tabela 5.2(d).

\begin{tabular}{|c|c|c|c|c|c|c|}
\hline $\begin{array}{c}\text { Número } \\
\text { de } \\
\text { Identificação }\end{array}$ & Descrição & $\begin{array}{c}\text { Resistência } \\
\text { dos Cabos } \\
(\Omega / \mathrm{km})\end{array}$ & $\begin{array}{c}\text { Reatância } \\
\text { dos } \\
\text { Cabos } \\
(\Omega / \mathrm{km})\end{array}$ & $\begin{array}{c}\text { Corrente } \\
\text { Admissível } \\
\text { (A) }\end{array}$ & $\begin{array}{l}\text { Carregamento } \\
\text { Máximo em } \\
\text { Regime (pu) }\end{array}$ & $\begin{array}{c}\text { Custo } \\
\text { da Rede } \\
\text { (US\$/km) }\end{array}$ \\
\hline 1 & 120 & 0.1672 & 0.3938 & 440 & 0.8 & 61370 \\
\hline 2 & 35 & 0.5998 & 0.4468 & 210 & 0.8 & 21792 \\
\hline 3 & 25 & 0.8863 & 0.4618 & 165 & 0.8 & 18566 \\
\hline 4 & $33 \mathrm{R}$ & 0.1902 & 0.3721 & 514 & 0.8 & 43480 \\
\hline 5 & $40 R$ & 0.3679 & 0.4529 & 340 & 0.8 & 31451 \\
\hline 6 & 10R & 0.6961 & 0.4995 & 230 & 0.8 & 17470 \\
\hline 7 & 04R & 1.5973 & 0.5014 & 140 & 0.8 & 14172 \\
\hline 8 & $33 \mathrm{~L}$ & 0.1902 & 0.3721 & 514 & 0.8 & 33333 \\
\hline 9 & $40 \mathrm{~L}$ & 0.3679 & 0.4529 & 340 & 0.8 & 16793 \\
\hline 10 & $10 \mathrm{~L}$ & 0.6961 & 0.4995 & 230 & 0.8 & 9887 \\
\hline 11 & 04L & 1.5973 & 0.5014 & 140 & 0.8 & 8020 \\
\hline 12 & 40Rr & 0.3679 & 0.4529 & 340 & 0.8 & 17300 \\
\hline 13 & $10 \mathrm{Rr}$ & 0.6961 & 0.4995 & 230 & 0.8 & 9600 \\
\hline 14 & $40 \mathrm{Lr}$ & 0.3679 & 0.4529 & 340 & 0.8 & 9236 \\
\hline 15 & $10 \mathrm{Lr}$ & 0.6961 & 0.4995 & 230 & 0.8 & 5500 \\
\hline 16 & $120 r$ & 0.1672 & 0.3938 & 440 & 0.8 & 33700 \\
\hline 17 & $02 \mathrm{~L}$ & 0.963 & 0.467 & 180 & 0.8 & 8400 \\
\hline 18 & $20 \mathrm{R}$ & 0.56 & 0.509 & 270 & 0.8 & 22500 \\
\hline 19 & $20 \mathrm{~L}$ & 0.479 & 0.441 & 282 & 0.8 & 13100 \\
\hline 20 & 02R & 1.05 & 0.524 & 180 & 0.8 & 15600 \\
\hline 21 & 70 & 0.2964 & 0.4362 & 370 & 0.8 & 49300 \\
\hline
\end{tabular}

Tabela 5.2(d) - Dados dos cabos utilizados 
Os dados de transformadores de subestações são apresentados na tabela 5.2(e).

\begin{tabular}{|c|c|c|c|c|c|c|c|c|}
\hline Índice & $\begin{array}{c}\text { Potência } \\
\text { Nominal } \\
(\text { MVA) }\end{array}$ & $\begin{array}{c}\text { Fator de } \\
\text { Sobrecarga } \\
(\mathbf{p u})\end{array}$ & $\begin{array}{c}\text { Perdas } \\
\text { no } \\
\text { Ferro } \\
\mathbf{( \% )}\end{array}$ & $\begin{array}{c}\text { Perdas } \\
\text { no } \\
\text { Cobre } \\
\mathbf{( \% )}\end{array}$ & $\begin{array}{c}\text { Custo } \\
\mathbf{( U S \$ )}\end{array}$ & $\begin{array}{c}\text { Valor } \\
\text { Residual } \\
\mathbf{( \% )}\end{array}$ & $\begin{array}{c}\text { Tensão } \\
\text { AT } \\
(\mathbf{k V})\end{array}$ & $\begin{array}{c}\text { Tensão } \\
\text { MT } \\
\mathbf{( k V )}\end{array}$ \\
\hline \hline 1 & 12.5 & 1.2 & 0.12 & 0.55 & 289000 & 33 & 69 & 13.8 \\
\hline 2 & 20 & 1.2 & 0.11 & 0.51 & 336925 & 33 & 69 & 13.8 \\
\hline 3 & 9.75 & 1.2 & 0.14 & 0.57 & 250000 & 33 & 138 & 13.8 \\
\hline 4 & 20 & 1.2 & 0.14 & 0.57 & 384000 & 33 & 138 & 13.8 \\
\hline 5 & 10 & 1.2 & 0.12 & 0.55 & 267000 & 33 & 69 & 13.8 \\
\hline 6 & 2.5 & 1.2 & 0.12 & 0.55 & 115000 & 33 & 69 & 13.8 \\
\hline 7 & 5 & 1.2 & 0.12 & 0.55 & 153000 & 33 & 69 & 13.8 \\
\hline 8 & 25 & 1.2 & 0.12 & 0.55 & 426000 & 33 & 69 & 13.8 \\
\hline 9 & 7.5 & 1.2 & 0.12 & 0.55 & 237000 & 33 & 69 & 13.8 \\
\hline 10 & 6.25 & 1.2 & 0.12 & 0.55 & 222000 & 33 & 69 & 13.8 \\
\hline 11 & 30 & 1.2 & 0.12 & 0.55 & 1426000 & 33 & 69 & 13.8 \\
\hline
\end{tabular}

Tabela 5.2(e) - Dados dos Transformadores Utilizados

Os dados do sistema de subtransmissão são apresentados na tabela $5.2(f)$.

\begin{tabular}{|c|c|c|}
\hline Índice & Tensão (kV) & $\begin{array}{c}\text { Custo da LT } \\
\text { (US\$/km) }\end{array}$ \\
\hline \hline 1 & 69 & 45000 \\
\hline 2 & 69 & 36000 \\
\hline 3 & 138 & 55500 \\
\hline 4 & 69 & 94500 \\
\hline 5 & 69 & 89550 \\
\hline
\end{tabular}

Tabela 5.2(f) - Dados de Subtransmissão 
Os dados de reguladores de tensão são apresentados na tabela 5.2(g).

\begin{tabular}{|c|c|c|c|}
\hline Índice & $\begin{array}{c}\text { Potência Nominal } \\
\text { (kVA) }\end{array}$ & $\begin{array}{c}\text { Ganho de } \\
\text { Tensão } \\
\text { (\%) }\end{array}$ & $\begin{array}{c}\text { Custo do } \\
\text { Regulador } \\
\text { (US\$) }\end{array}$ \\
\hline \hline 1 & 4780 & 10 & 50000 \\
\hline
\end{tabular}

Tabela 5.2(g) - Dados de Reguladores de Tensão

Os dados de custos de subestações são apresentados na tabela 5.2(h).

\begin{tabular}{|c|c|c|c|}
\hline Índice & $\begin{array}{c}\text { Tensão } \\
\mathbf{( k V )}\end{array}$ & $\begin{array}{c}\text { Custo de Conexão } \\
\text { do Trafo (kUS\$) }\end{array}$ & $\begin{array}{c}\text { Custo de Entrada } \\
\text { da LT (kUS\$) }\end{array}$ \\
\hline 1 & 69 & 156 & 156 \\
\hline 2 & 138 & 577.5 & 577.5 \\
\hline
\end{tabular}

Tabela 5.2(h) - Dados de Custo de subestações

Os dados de bays de alimentadores são apresentados tabela 5.2(i).

\begin{tabular}{|l|l|l|}
\hline Índice & Descrição & Custo do Bay (US\$) \\
\hline 1 & EL13.8kV & 35000 \\
\hline
\end{tabular}

Tabela 5.2(i) - Dados de Bays de Alimentadores

Em seguida é necessário fornecer os dados referentes às subestações e aos alimentadores. Como citado anteriormente, foram estudadas 74 subestações contendo 280 alimentadores, todas consideradas como não completamente urbanizadas. As duas figuras a seguir, 5.2(a) e 5.2(b), demostram, respectivamente, as interfaces usadas para cadastramento: 


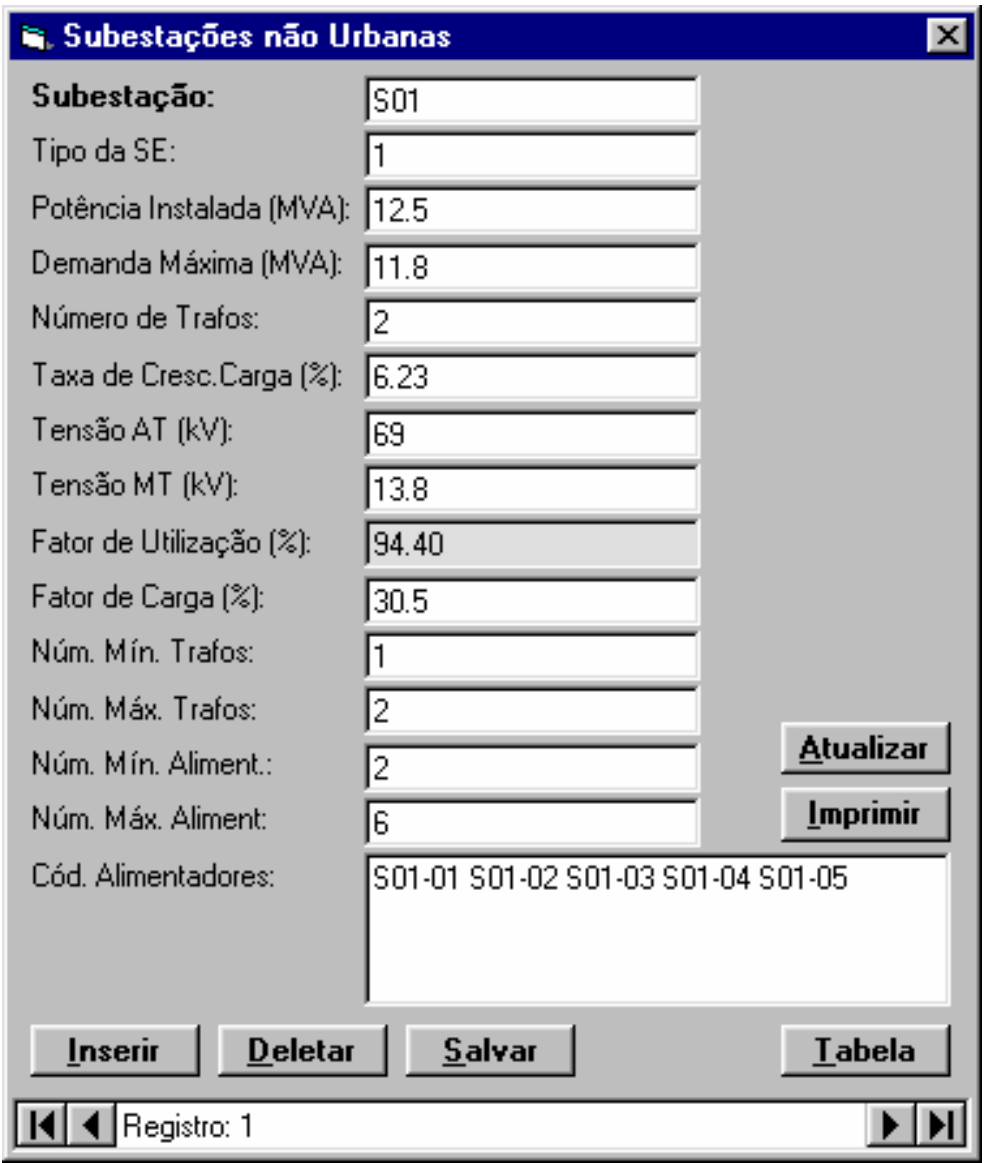

Figura 5.2(a): Tela de entrada de dados de subestações.

\begin{tabular}{|c|c|c|}
\hline \multicolumn{3}{|c|}{ a, Alimentadores de Subestaçōes não Urbanas } \\
\hline Alimentador: $\quad \mid$ & $501-01$ & Atualizar \\
\hline Comprimento $(\mathrm{Km})$ : & 6.2 & Imprimir \\
\hline Número de Pontos: & 35 & \\
\hline Condutor Tronco: & 10R & \\
\hline Condutor Ramal: & 04R & \\
\hline Ângulo de Ação (Graus): & 40 & \\
\hline Demanda Máxima (MVA): | & 2.5 & \\
\hline Fator de Potência (pu): & 0.92 & \\
\hline Fator de Carga [\%]: & 30.5 & \\
\hline Taxa Cresc Vertical (\%): & 6.23 & \\
\hline Taxa Cresc. Horiz. (\%): & 0 & \\
\hline Coef. Dens. Pts (Alpha): & 0 & \\
\hline Deletar & S-alvar & Iabela \\
\hline \begin{tabular}{|l|l|l|}
$\mathbf{A}$ & $\mathbf{4}$ & Registro: 1 \\
\end{tabular} & & $D \mid$ \\
\hline
\end{tabular}

Figura 5.2(b): Tela de entrada de dados de alimentadores. 


\subsubsection{Módulo 1 - Formação de Famílias}

Para a formação das famílias de subestações, ou seja, do agrupamento das subestações existentes, é utilizado o método de classificação hierárquica, conforme detalhado em [13]. Foram então definidos os dados para processamento do agrupamento de SE's, conforme podemos observar na figura 5.2(c).

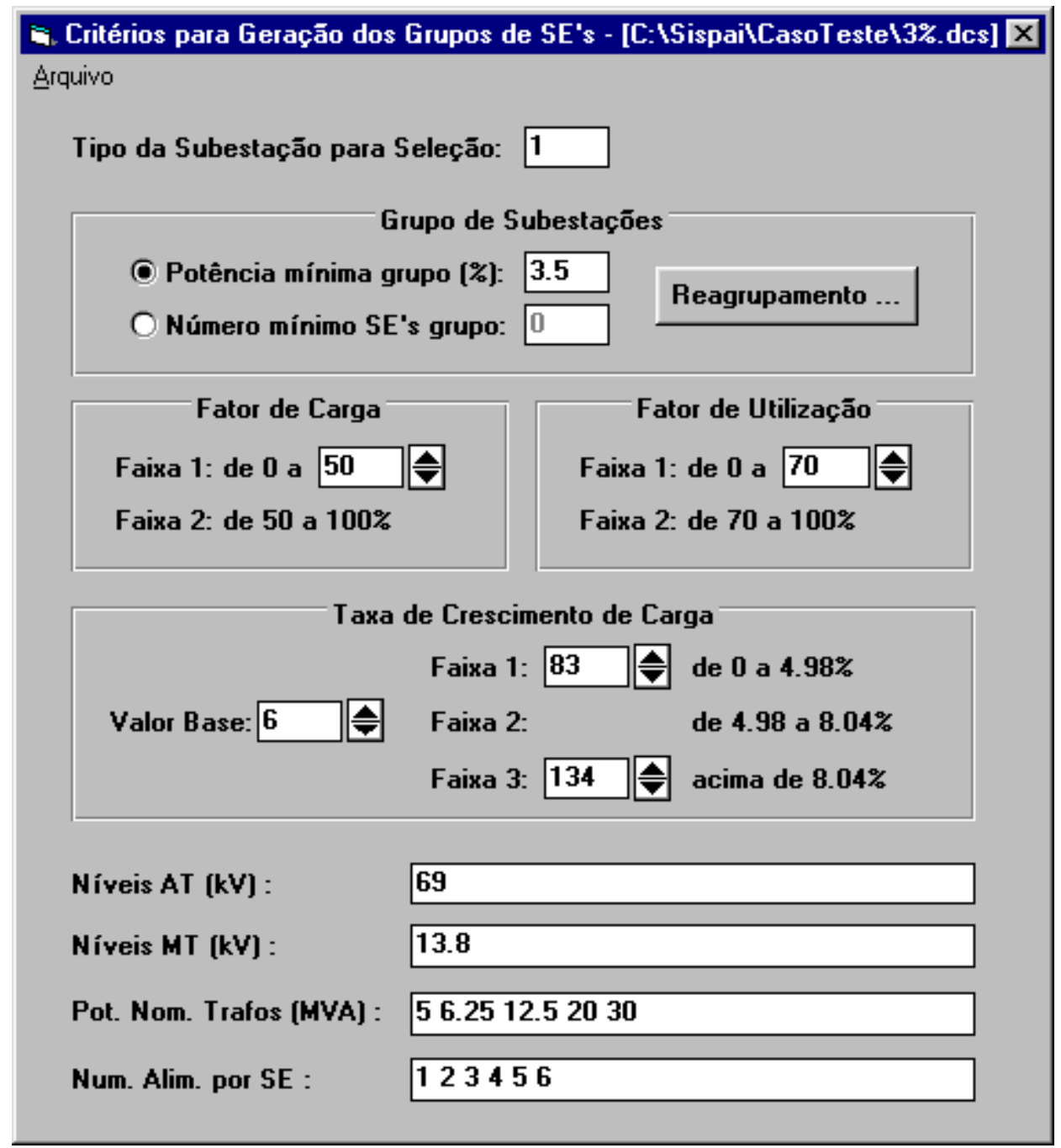

Figura 5.2(c): Dados gerais para agrupamento de SE's.

$\mathrm{Na}$ metodologia do planejamento agregado, é exigido um "tamanho mínimo" que cada família deve atingir, de modo a evitar-se a formação de famílias excessivamente "pequenas", sem representatividade face ao universo de subestações. 
Assim, muitos casos foram efetuados preliminarmente e, após cuidadosa análise dos resultados, considerou-se para referência dos processamentos a formação de famílias de subestações com no mínimo $3,5 \%$ da potência total instalada que cada uma deve conter para ser considerada representativa. Quando da necessidade de reagrupamento, o critério de menor distância dos valores dos atributos normalizados é utilizado para ponderação. Para este caso teste, os valores adotados foram os apresentados na figura 5.2(d).

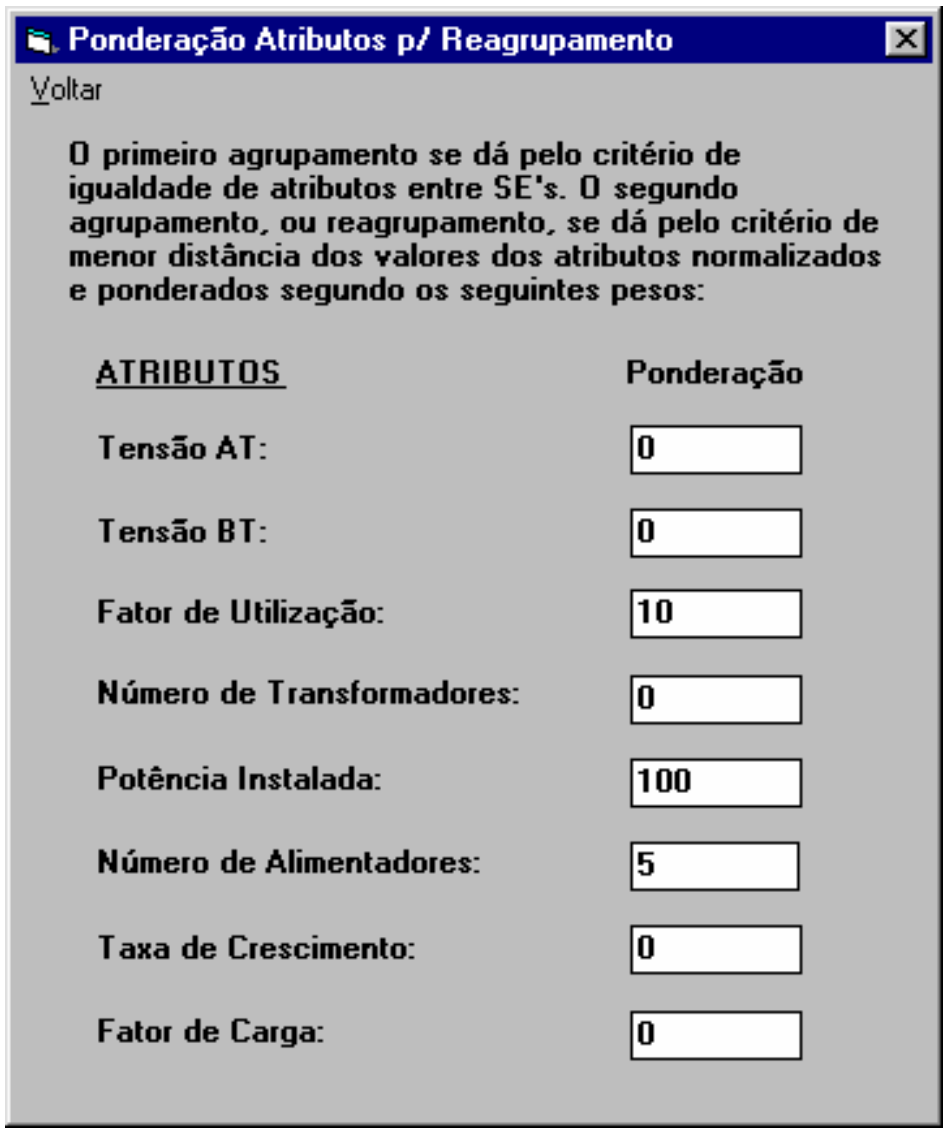

Figura 5.2(d): Critérios para reagrupamento de famílias de subestações.

Com estes dados foram geradas 15 famílias de subestações, como podese observar no anexo A, onde observa-se o relatório do agrupamento de subestações. Os principais resultados relativos às famílias formadas são apresentados na tabela 5.2(j). 


\begin{tabular}{|c|c|c|c|c|c|}
\hline $\begin{array}{l}\text { Número da } \\
\text { Família }\end{array}$ & $\begin{array}{c}\text { Tensões } \\
\text { (KV) }\end{array}$ & $\begin{array}{l}\text { Trafos } \\
\text { (MVA) }\end{array}$ & $\begin{array}{c}\text { Número de } \\
\text { Alimentadores }\end{array}$ & $\begin{array}{c}\text { Fator de } \\
\text { Utilização (\%) }\end{array}$ & $\begin{array}{l}\text { No. de SEs } \\
\text { representadas }\end{array}$ \\
\hline 1 & $69 / 13.8$ & $2 * 6.25$ & 4 & 48.6 & 10 \\
\hline 2 & $69 / 13.8$ & $2 * 6.25$ & 4 & 83.2 & 5 \\
\hline 3 & $69 / 13.8$ & $1 * 12.5$ & 4 & 50.3 & 5 \\
\hline 4 & $69 / 13.8$ & $1 * 6.25$ & 4 & 52.8 & 9 \\
\hline 5 & $69 / 13.8$ & $1 * 12.5$ & 3 & 35.7 & 3 \\
\hline 6 & 69 / 13.8 & $2 * 12.5$ & 4 & 38.9 & 3 \\
\hline 7 & $69 / 13.8$ & $1 * 5.00$ & 2 & 53.6 & 8 \\
\hline 8 & 69 / 13.8 & $1 * 20.0$ & 4 & 53.0 & 3 \\
\hline 9 & $69 / 13.8$ & $2 * 5.00$ & 4 & 40.0 & 6 \\
\hline 10 & 69 / 13.8 & $2 * 12.5$ & 5 & 81.4 & 2 \\
\hline 11 & $69 / 13.8$ & $1 * 30.0$ & 4 & 31.3 & 2 \\
\hline 12 & 69 / 13.8 & $1 * 5.00$ & 3 & 83.5 & 6 \\
\hline 13 & $69 / 13.8$ & $2 * 12.5$ & 6 & 51.6 & 2 \\
\hline 14 & $69 / 13.8$ & $2 * 5.00$ & 4 & 76.6 & 6 \\
\hline 15 & $69 / 13.8$ & $1 * 12.5$ & 2 & 25.8 & 4 \\
\hline
\end{tabular}

Tabela 5.2(j) - Resultados do Agrupamento de Subestações

O próximo passo foi o agrupamento de alimentadores. Os alimentadores são agrupados através da metodologia conhecida como "Cluster Analysis".

Os parâmetros definidos para formação das famílias foram os apresentados na figura 5.2(e): 


A. Critérios para Grupos de Alimentadores
Árquivo
Arquivo: C: ISispaiłCasoT estel3\%.dca
ATRIBUTOS
Extensão da rede:
Número de pontos:
Ângulo de açāo:
Demanda de ponta:
Fator de carga:
Taxa de crescimento vertical:
Taxa de crescimento horizontal:
Fator de potência:
Coef. de Densidade de
Pontos :

Figura 5.2(e): Dados gerais para cluster de alimentadores.

Com esses dados foram formadas 44 famílias de alimentadores, representando os 280 alimentadores considerados. Os resultados obtidos a partir do agrupamento de alimentadores podem ser observados no relatório do anexo $B$, onde estão detalhadas as famílias de alimentadores formadas.

\subsubsection{Módulo 2 - Leis Estatísticas}

Para os processamentos do módulo 2, correspondentes à formação das leis estatísticas para evolução das redes, foram determinados quatro conjuntos de leis, correspondentes a quatro valores diferentes de $\alpha(0,2$, 4 e 8), que é o expoente da função densidade de pontos, conforme item 2.2. Os dados de entrada utilizados são definidos em duas telas 
desenvolvidas para este fim. Na primeira, representada na figura 5.2(f), os dados são os mesmos para todos os valores de $\alpha$. Na segunda, os dados variaram conforme valores definidos para cada tipo de rede considerada. Portanto, para cada valor do expoente da função densidade de pontos $(\alpha)$, utiliza-se dados coerentes para os demais parâmetros, conforme representado pelas figuras 5.2(g), 5.2(h), 5.2(i) e 5.2(j).

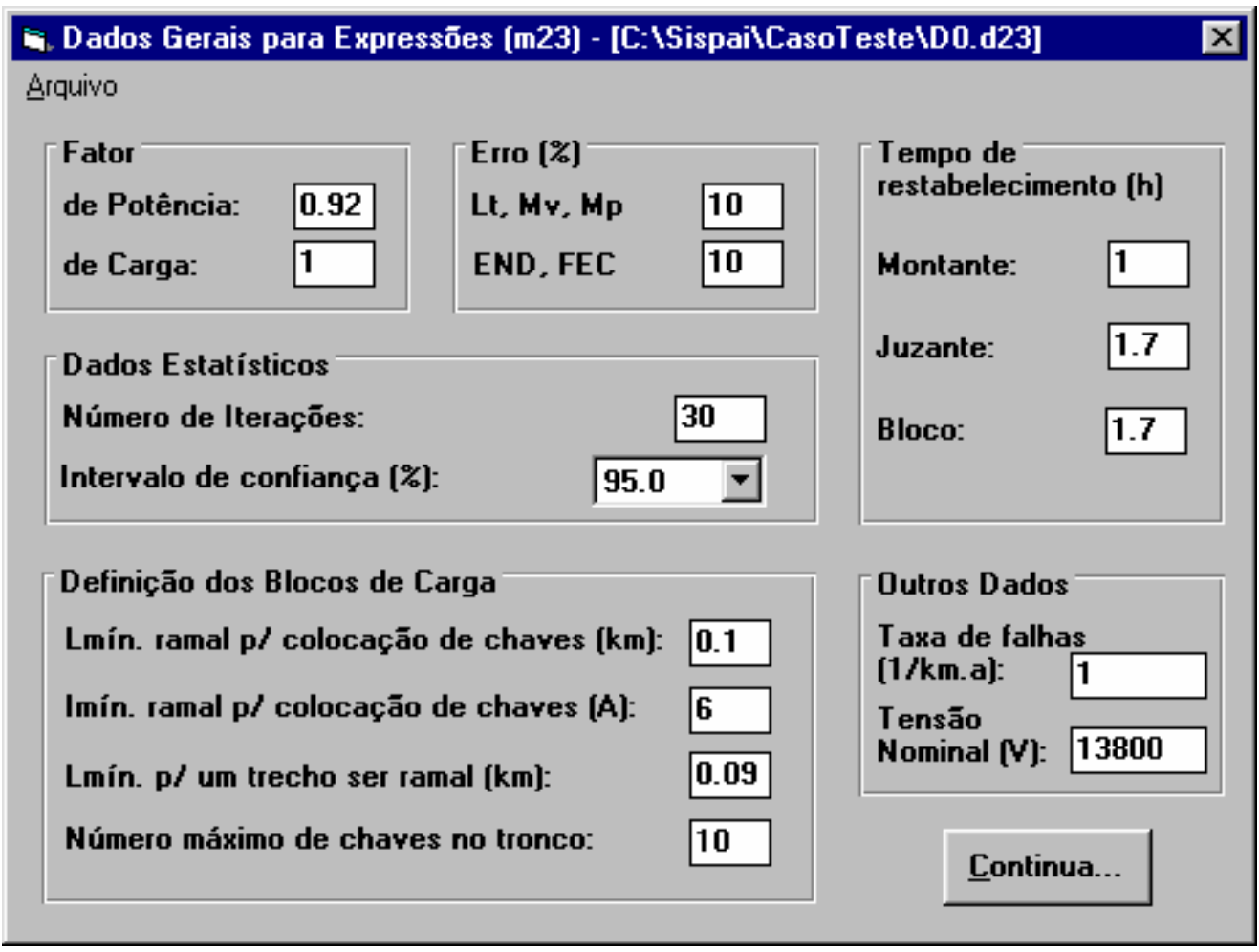

Figura 5.2(f): Dados gerais para o módulo 2 
Dados para Análise [m23]

Demandas do alimentador $\mathrm{p} /$ análise (kVA]: 100030005000

Número de pontos de carga para análise :

45115185

Areas para análise $\left(\mathrm{km}^{\wedge} 2\right)$ :

10100400

Ângulos para análise [graus]:

3060120

Distâncias entre chaves no tronco $[\mathbf{k m}]$ :

4.5

Expoentes da funçāo densidade de pontos: 0

Índices do cabo do tronco:

56

Índices do cabo do ramal:

77

\section{Yolta}

Figura 5.2(g): Continuação dos dados gerais para o módulo 2, $\operatorname{com} \alpha=0$.

Dados para Análise (m23)

Demandas do alimentador $\mathrm{p} /$ análise [kVA]:

100030005000

Número de pontos de carga para análise :

45115250

Areas para análise $\left(\mathrm{km}^{\wedge} 2\right)$ :

1003009001500

Ângulos para análise [graus]:

1050130

Distâncias entre chaves no tronco $[\mathbf{k m}]$ :

4.5

Expoentes da funçāo densidade de pontos: 2

Índices do cabo do tronco:

56

Índices do cabo do ramal:

77

Yolta

Figura 5.2(h): Continuação dos dados gerais para o módulo 2, $\operatorname{com} \alpha=2$. 
Dados para Análise (m23]

Demandas do alimentador $\mathrm{p} /$ análise (kVA]: 50020004000

Número de pontos de carga para análise :

50130210290

Areas para análise $\left[\mathrm{km}^{\wedge} 2\right]$ :

1003009001500

Ângulos para análise [graus]:

3060120

Distâncias entre chaves no tronco $[\mathbf{k m}]$ :

4.5

Expoentes da funçāo densidade de pontos:

4

Índices do cabo do tronco:

56

Índices do cabo do ramal:

77

\section{Yolta}

Figura 5.2(i): Continuação dos dados gerais para o módulo 2, $\operatorname{com} \alpha=4$.

\section{Dados para Análise (m23)}

Demandas do alimentador $\mathrm{p} /$ análise [kVA]: 50020004000

Número de pontos de carga para análise :

50130210290

Areas para análise $\left(\mathrm{km}^{\wedge} 2\right)$ :

1003009001500

Ângulos para análise [graus]:

3060120

Distâncias entre chaves no tronco $[\mathbf{k m}]$ :

4.5

Expoentes da funçāo densidade de pontos: 8

Índices do cabo do tronco:

56

Índices do cabo do ramal:

77

$$
\text { Yolta }
$$

Figura 5.2(j): Continuação dos dados gerais para o módulo 2, $\operatorname{com} \alpha=8$. 
Após a execução do módulo de regressão para os diferentes valores de $\alpha$, obteve-se as leis estatísticas apresentadas no anexo $C$.

\subsubsection{Módulo 3 - Evolução de Redes}

Segue-se o processamento do módulo de evolução de redes, conhecido como módulo 3. Este módulo utiliza os resultados do módulo 1 (formação de famílias) para representação da rede, do módulo 2 (leis estatísticas) para verificação do correspondente desempenho operacional, e dos dados de entrada complementares que estabelecem os critérios técnicos, econômicos e de qualidade que devem ser respeitados durante o período de planejamento, para proceder à determinação da evolução do sistema elétrico.

Para realização do estudo, foram executados diversos casos, referentes à variações de valores como a TRII mínima (taxa de rentabilidade do investimento inicial mínima desejada, usada para definição de obras de melhoria no sistema), horizonte de estudo, tensões mínimas para critério e para penalização, valores de orçamento, etc. No caso de referência apresentado, os dados escolhidos para análise foram os apresentados na Figura 5.2(k). Nestes dados, é importante notar que: não existe restrição orçamentária ativa (os valores anuais de investimentos são elevados, permitindo que o sistema escolha as melhores obras para atendimento aos critérios, não obstante o seu valor), a TRII mínima é muito alta (impedindo obras de melhoria no sistema - todas as obras propostas serão as estritamente necessárias para o atendimento aos critérios técnicos), horizonte de estudo 10 anos e os valores estabelecidos pela empresa para os critérios de tensão, custos, vida útil dos equipamentos e taxa de juros. 


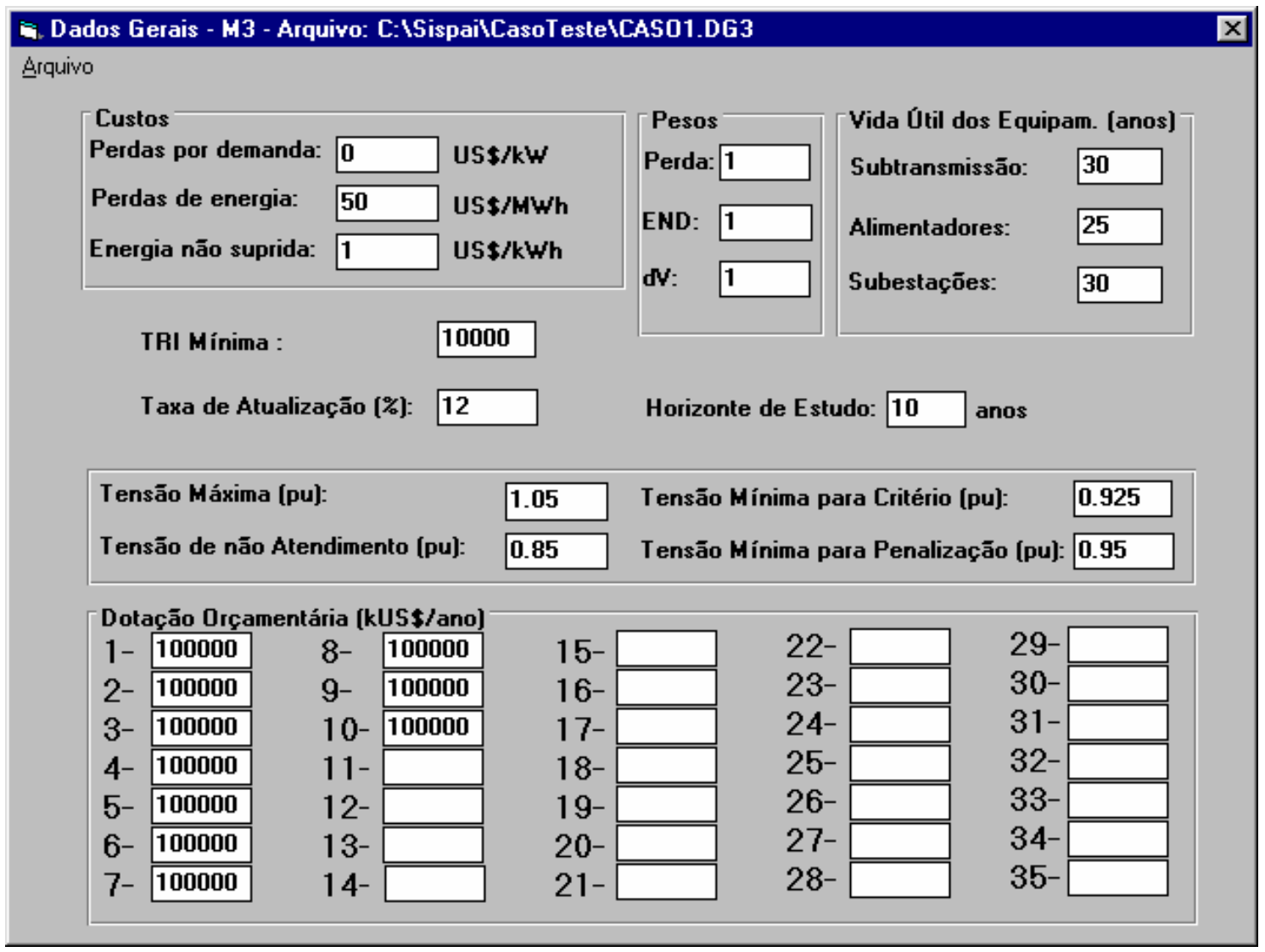

Figura 5.2(k): Dados gerais para o caso de referência.

No processamento definido para este caso teste, utilizou-se apenas um cenário. Nele considerou-se os valores de referência para as taxas de juros, de crescimento de carga, dos custos unitários dos equipamentos e do orçamento anual disponibilizado para investimentos, conforme figura $5.2(1)$. 
a. Dados de Cenários - [C: \SispaiłCasoT estełCENARIO.DAT] Arquivo

Fatores Multiplicativos da Taxa de Juros

Fator 1: 1

Fator 2: 0

Fator 3: 0
Probabilidade: 100

Probabilidade: 0

Probabilidade: 0
Fatores Multiplicativos da Taxa de Cresc.

Fator 1: 1

Probabilidade: 100

Fator 2: 0

Probabilidade: 0

Fator 3: 0

Fatores Multiplicativos dos Custos Unitários
Fator 1: $\mathbf{1}$
Fator 2: $\mathbf{0}$
Fator 3: $\mathbf{0}$

Fator Multiplicativo do Orçamento

Fator: 1

Passo: 0.01

Número de Simulaçōes: 1

Taxa de Crescimento do Orçamento

Taxa: 0

Passo: 0.01

Número de Simulaçōes: 1

Figura 5.2(I): Cenário definido para processamento do caso base.

Para o correto processamento do módulo 3, existem três arquivos que devem ser customizados segundo padrões da empresa, e dizem respeito a valores das famílias de subestações e alimentadores, permitindo um ajuste fino nos dados. Os dados utilizados estão a seguir.

\subsubsection{Dados Complementares de Redes Representantes}

Correspondem aos dados das famílias de subestações formadas com as respectivas famílias de alimentadores associadas. 


\section{a-) Comprimento Médio da Linha de Subtransmissão}

O comprimento das linhas de subtransmissão na área não urbana foi considerado único para todas as famílias consideradas:

Tensão de 69 kV: comprimento médio do ramal de subtransmissão igual a $12 \mathrm{~km}$.

\section{b-) Potência Transferida por Subestação Vizinha}

Considerou-se a transferência de carga entre subestações vizinhas. Atribuiu-se 0,3 para este parâmetro a todas as famílias, de forma que cada subestação só pode ser carregada até $70 \%$ da sua capacidade nominal. Considerando-se o fator de sobrecarga de $20 \%$ definido para os transformadores da empresa, tem-se que as subestações poderão ser carregadas a até $90 \%$ de sua capacidade, a partir da qual serão sugeridas obras.

\subsubsection{Dados Complementares de Famílias de Subestações}

Correspondem aos dados das famílias de subestações formadas.

\section{a-) Número Mínimo e Máximo de Transformadores \\ O número de transformadores nas subestações foram padronizados conforme apresentado na tabela 5.2(k):}




\begin{tabular}{|c|c|c|}
\hline Número da Família & $\begin{array}{c}\text { Número Mínimo de } \\
\text { Trafos }\end{array}$ & $\begin{array}{c}\text { Número Máximo de } \\
\text { Trafos }\end{array}$ \\
\hline 11 & 1 & 1 \\
\hline Demais & 1 & 2 \\
\hline
\end{tabular}

Tabela 5.2(k) - Número Mínimo e Máximo de Transformadores

\section{b-) Transformadores Alternativos}

Os transformadores que devem ser privilegiados no processo de evolução de redes (no caso de substituição dos transformadores por outros de maior potência) são estabelecidos com base na potência nominal dos transformadores a serem substituídos, conforme apresentado na tabela 5.2(I).

\begin{tabular}{|c|c|}
\hline $\begin{array}{c}\text { Transformador Original } \\
\text { (Potência Nominal - MVA) }\end{array}$ & $\begin{array}{c}\text { Transformador Priorizado } \\
\text { (Potência Nominal - MVA) }\end{array}$ \\
\hline 5 & 12.5 \\
\hline 6.25 & 12.5 \\
\hline 12.5 & 12.5 \\
\hline 20 & 20 \\
\hline
\end{tabular}

Tabela 5.2(I) - Evolução de Transformadores

\section{c-) Número Mínimo e Máximo de Alimentadores}

Os números mínimos e máximos de alimentadores nas subestações são padronizados e foram definidos por família, conforme apresentado na tabela $5.2(\mathrm{~m})$. 


\begin{tabular}{|l|c|c|}
\hline \multicolumn{1}{|c|}{ Família } & $\begin{array}{c}\text { Número Mínimo de } \\
\text { Alimentadores }\end{array}$ & $\begin{array}{c}\text { Número Máximo de } \\
\text { Alimentadores }\end{array}$ \\
\hline $1,3,4,7,9,12,14$ & 2 & 4 \\
\hline $\begin{array}{l}2,5,6,8,10,11, \\
13,15\end{array}$ & 2 & 6 \\
\hline
\end{tabular}

Tabela 5.2(m): Número Mínimo e Máximo de Alimentadores

\subsubsection{Dados Complementares de Alimentadores}

Correspondem aos dados das famílias de alimentadores formadas

\section{a-) Taxa de Falhas (falhas / km * ano) do Alimentador}

Para as 44 famílias de alimentadores formadas atribuiu-se o valor padrão de 0,55 falhas / Km * ano.

\section{b-) Índices de DEC e FEC de cada Família}

No âmbito do programa SISPAI, definem-se conjuntos de DEC's e FEC's onde, para cada ano do período de planejamento, são estabelecidos os valores máximos admitidos para cada um destes parâmetros.

Para cada uma das famílias de alimentadores formadas foram atribuídos os índices relativos ao conjunto DEC / FEC correspondentes.

\section{c-) Tipo e Número de Bancos de Reguladores}


A formação de famílias de alimentadores efetuada no módulo M1 não inclui, como parte de seus atributos (parâmetros que regem a formação das famílias), o número de bancos de reguladores associados a cada alimentador. Logo, a existência de bancos de reguladores em cada alimentador não é contemplada no processo de agrupamento. Este aspecto deve ser levado em consideração na evolução da rede, devendo-se ajustar cada família de alimentadores de modo a espelharem, o mais fielmente possível, os alimentadores reais existentes.

Como o SISPAI considera que o limite de queda de tensão não é transgredido no ano inicial, a definição do número de bancos de reguladores em cada família de alimentadores no ano inicial do período de planejamento é regida conforme o seguinte critério :

- Executa-se o módulo M3 para o primeiro ano do período de planejamento considerando-se a inexistência de reguladores de tensão nas famílias de alimentadores;

- São determinados, a partir dos relatórios de saída do programa, as famílias de alimentadores que excederam o limite de queda de tensão previamente estabelecido;

- Para estas famílias considera-se que já possuem bancos de reguladores operando no ano inicial do planejamento, atualizandose o campo correspondente neste arquivo.

A evolução será efetuada com base nesta nova caracterização de alimentadores (parte deles operando com banco de reguladores já no primeiro ano do período de planejamento, sem custo adicional). 


\section{d-) Índice dos Cabos para Desdobramento e Recondutoramento}

Em relação ao recondutoramento, cabe aqui uma importante consideração. Alguns cabos utilizados para tal fim foram recadastrados com os mesmos parâmetros dos originais, porém com custos reduzidos. Isto foi feito para que se pudesse considerar o real custo de uma obra de recondutoramento, onde não há dispêndio com postes e demais equipamentos, apenas com a obra e os cabos propriamente ditos. Assim, na tabela 5.2(n) a seguir, tem-se a definição final dos cabos utilizados, considerando-se os originais e os utilizados para as obras.

\begin{tabular}{|c|c|c|}
\hline Cabo Original & $\begin{array}{c}\text { Cabo } \mathrm{p} \text { l } \\
\text { Desdobramento }\end{array}$ & $\begin{array}{c}\text { Cabo } \mathrm{p} \text { / } \\
\text { Recondutoramento }\end{array}$ \\
\hline $5(40 \mathrm{R})$ & $5(40 \mathrm{R})$ & - \\
\hline $6(10 \mathrm{R})$ & $5(40 \mathrm{R})$ & $12(40 \mathrm{Rr})$ \\
\hline $9(40 \mathrm{~L})$ & $9(40 \mathrm{~L})$ & - \\
\hline $10(10 \mathrm{~L})$ & $10(10 \mathrm{~L})$ & $14(40 \mathrm{Lr})$ \\
\hline $11(04 \mathrm{~L})$ & $10(10 \mathrm{~L})$ & $15(10 \mathrm{Lr})$ \\
\hline $17(02 \mathrm{~L})$ & $10(10 \mathrm{~L})$ & $15(10 \mathrm{Lr})$ \\
\hline $19(20 \mathrm{~L})$ & $9(40 \mathrm{~L})$ & $14(40 \mathrm{Lr})$ \\
\hline
\end{tabular}

Tabela 5.2(n) - Cabos para desdobramento e recondutoramento.

\section{e-) Índice do Bay}

Índice que aponta para o arquivo de bays de alimentadores, identificando os custos de saída de novos alimentadores de cada família considerada. No caso em estudo, para todas as famílias foi considerado um único padrão de saída de novos alimentadores, com índice 1 no arquivo "bay.dat", com o seguinte valor : US\$35000,00. 


\subsubsection{Resultados para o Caso Base}

O relatório geral resultante para o caso de referência está impresso no anexo $\mathrm{D}$, onde podemos observar todas as obras sugeridas ano a ano ao longo da evolução.

O relatório de obras realizadas pode ser observado na figura $5.2(\mathrm{~m})$. Nele tem-se uma visão geral das obras sugeridas, assim como o investimento, ano a ano. No final tem-se o valor do investimento total, como somatória dos investimentos anuais e em valor presente.

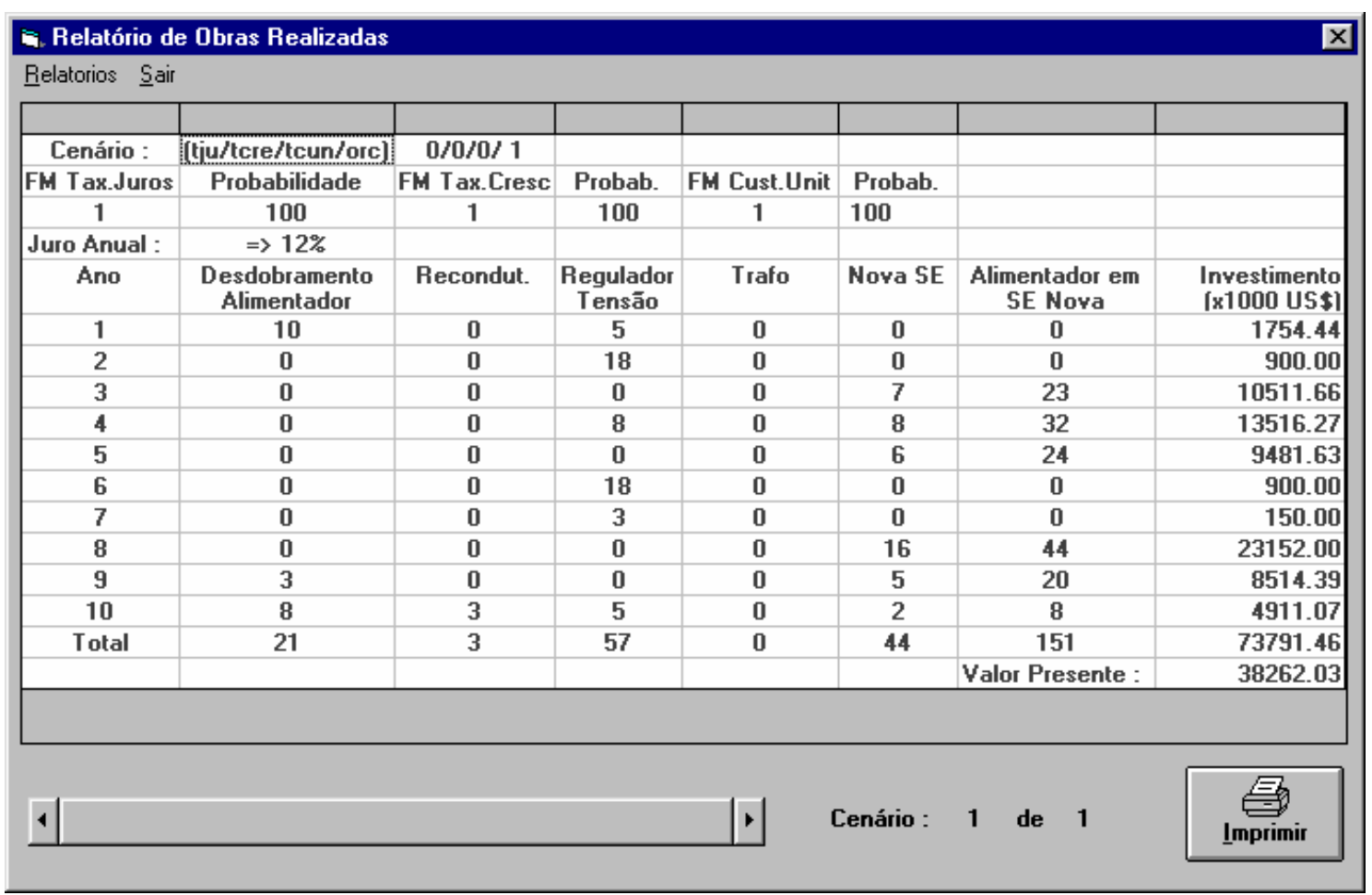

Figura 5.2(m): Resultado resumido do processamento do caso base.

\subsubsection{Análise de Cenários}

Adicionalmente, foi efetuado um caso com diversos cenários para evolução da rede durante o período de planejamento. A figura 5.2(n) mostra o arquivo de cenários definido. 
Fatores Multiplicativos da Taxa de Juros

Fator 1: 1

Fator 2: 1.5

Fator 3: 0.8
Probabilidade: 50

Probabilidade: 30

Probabilidade: 20
Fatores Multiplicativos da Taxa de Cresc.

Fator 1: 1

Probabilidade: 50

Fator 2: 1.5

Probabilidade: 30

Fator 3: 0.8 Probabilidade: 20

Fatores Multiplicativos dos Custos Unitários
Fator 1: 1
Fator 2: 1.5
Fator 3: 0.8

Fator Multiplicativo do Drçamento

Fator: 1

Passo: 0.01

Número de Simulaçōes: 1

Taxa de Crescimento do Drçamento

Taxa: 0

Passo: 0.01

Número de Simulaçōes: 1

Figura 5.2(n): Cenários definidos para processamento.

O programa SISPAI apresenta ferramentas que permitem aferir a qualidade e os benefícios econômicos decorrentes das obras propostas.

A figura 5.2(o) mostra a distribuição de benefícios econômicos anuais, em valor presente, e a respectiva probabilidade associada, para o nível orçamentário inicial. Nesta figura observa-se, através do gráfico de barras, que há, por exemplo, uma probabilidade de cerca $30 \%$ dos benefícios econômicos propiciados pelas obras superarem US\$14.090.000,00. Essa curva é conhecida como Probabilidades dos Benefícios. 
Erobabilidade dos Benefícios

Volta Imprimir

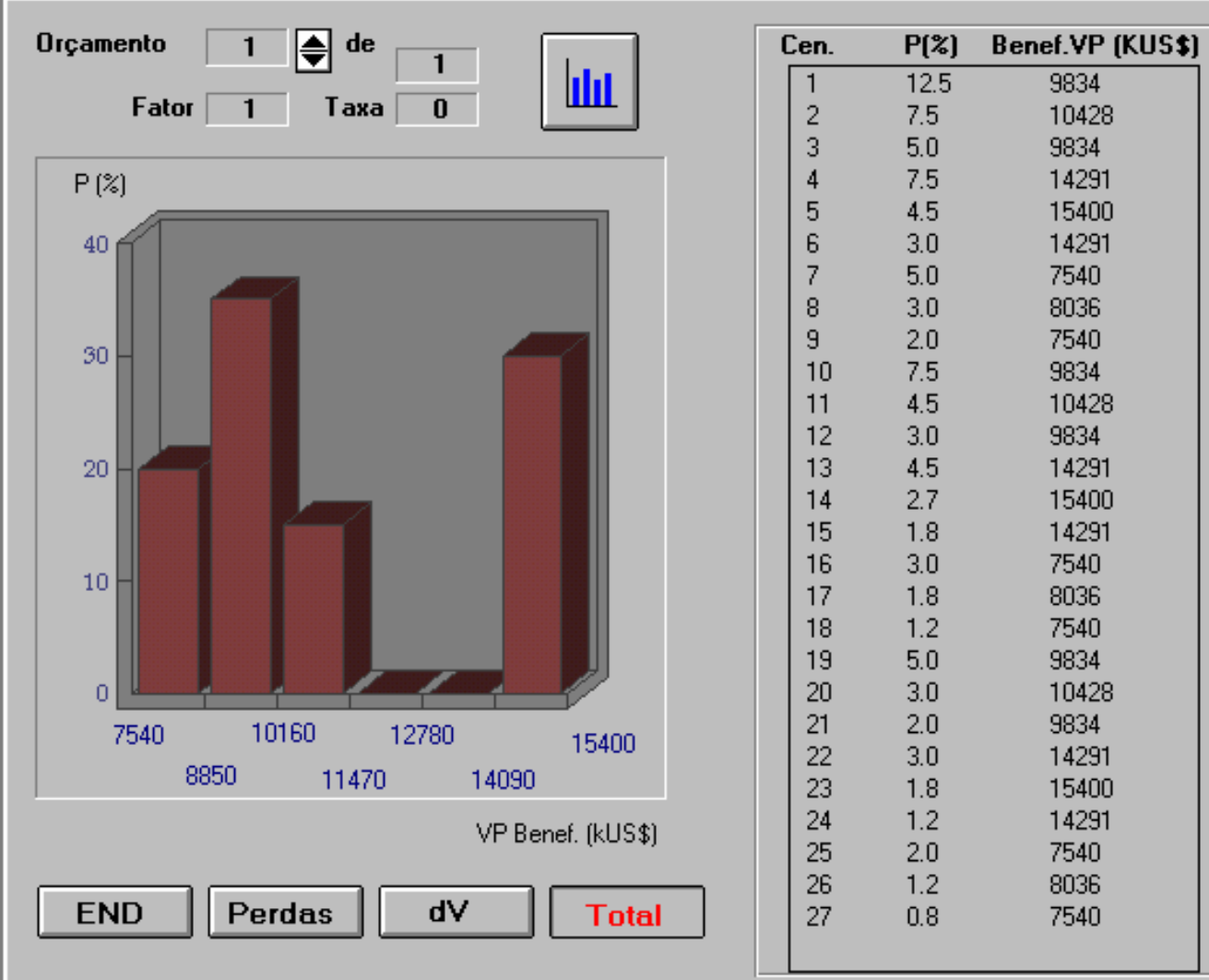

Figura 5.2(o): Curva de probabilidade dos benefícios. 


\subsection{Relatórios de Evolução de Índices para o Caso de Referência}

O próximo passo é analisar o desempenho dos índices ao longo do tempo, através do módulo SISFAMÍLIAS, desenvolvido no âmbito deste trabalho. Para tanto, utiliza-se a opção de desempenho das famílias e, escolhendo-se o índice desejado, obtem-se o relatório correspondente. A título de exemplo, para o DEC será feita a análise por famílias e por total. Para os demais índices, apenas o total.

\section{a) Perdas por Demanda}

Na figura 5.3(a), tem-se o gráfico correspondente à evolução das perdas por demanda do sistema, como porcentagem do que está sendo fornecido ao sistema.

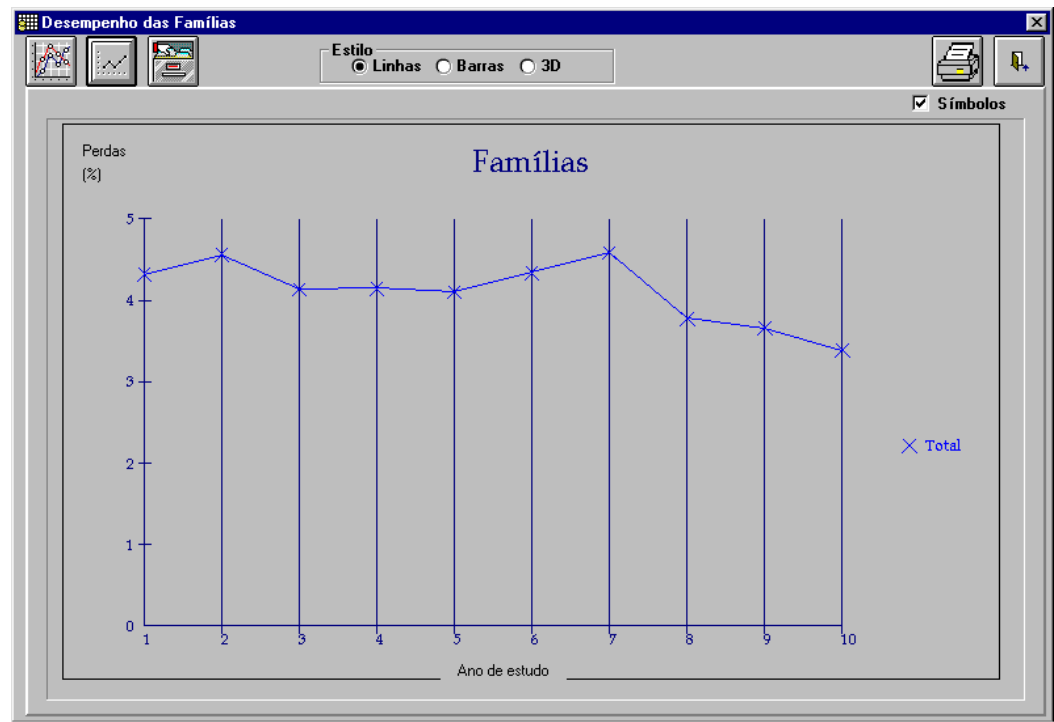

Figura 5.3(a): Perdas por demanda do sistema em \%.

\section{b) Perdas por Energia}

Na figura 5.3(b), tem-se o gráfico correspondente à evolução das perdas por energia do sistema, como porcentagem da energia anual fornecida ao sistema. 


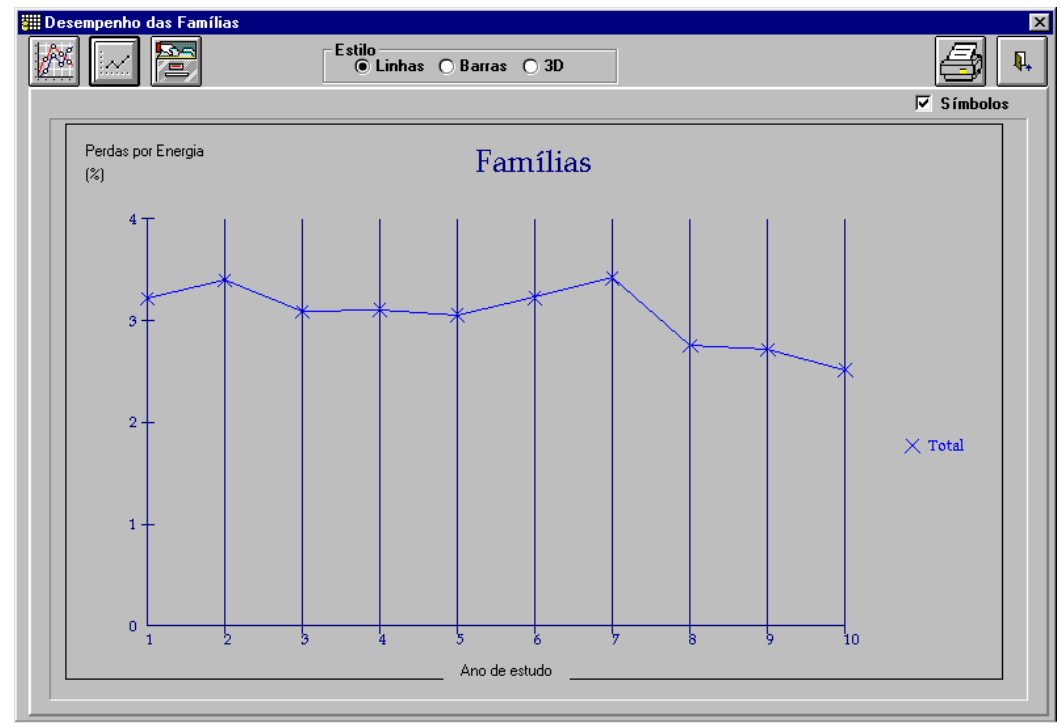

Figura 5.3(b): Perdas por energia do sistema em \%.

Observa-se que os valores percentuais de perdas em energia são inferiores aos de perda em demanda, pois este último índice leva em conta as perdas máximas do sistema (período de ponto do sistema). No entanto, nota-se que as curvas seguem exatamente a mesma tendência, como resultado das obras realizadas ao longo do período de planejamento.

\section{c) END}

Na figura 5.3(c), tem-se o gráfico correspondente à evolução da END, em MWh, para o sistema. 


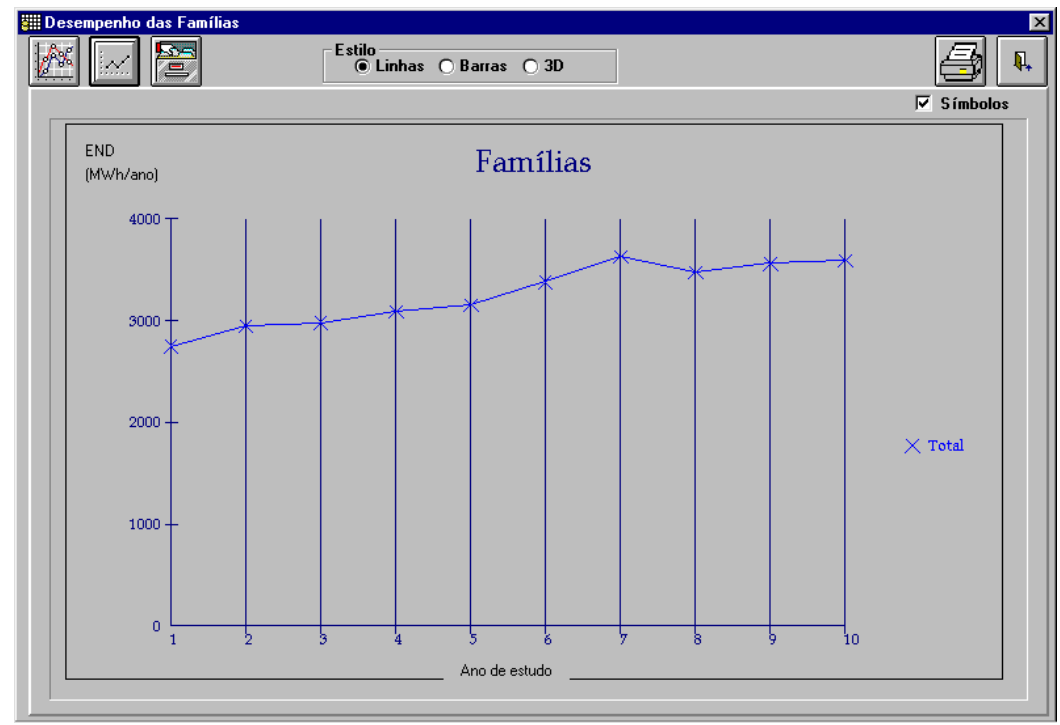

Figura 5.3(c): END média do sistema durante o horizonte de estudo.

\section{d) DEC}

1)Por família: verifica-se, pela figura 5.3(d1), a evolução do DEC para todas as famílias do sistema. Nas curvas verifica-se a ascensão e queda dos índices para todas as famílias. Numa condição normal, onde a rede evolui com taxas positivas de crescimento de carga, é intuitivo que os valores de DEC também cresçam, pois a medida que a rede se expande, os níveis de DEC também crescem, pois dependem do comprimento e da carga dos alimentadores (número de consumidores). Porém, quando da execução de uma obra em um determinado alimentador, ou ainda a criação de uma subestação nova, os níveis de DEC decaem abruptamente de um ano para outro. É também importante notar pelas curvas que muitos índices estavam com valor zero até determinado ano, e passam a ter valores de DEC positivos a partir de então. A interpretação, nesses casos, é que as famílias correspondentes foram criadas devido a obra de subestação nova, e portanto tais famílias realmente não existiam. Nota-se, entretanto, uma queda no índice de DEC na família que originou a obra. Do gráfico infere-se, por exemplo, que no quarto ano do período de planejamento, a família 12 teve uma queda abrupta no índice de 
DEC. Consultando o relatório geral de obras do SISPAI, verifica-se uma obra de subestação nova para essa família nesse ano. Pelo gráfico, é fácil notar que a família 19 surgiu como decorrência dessa obra.

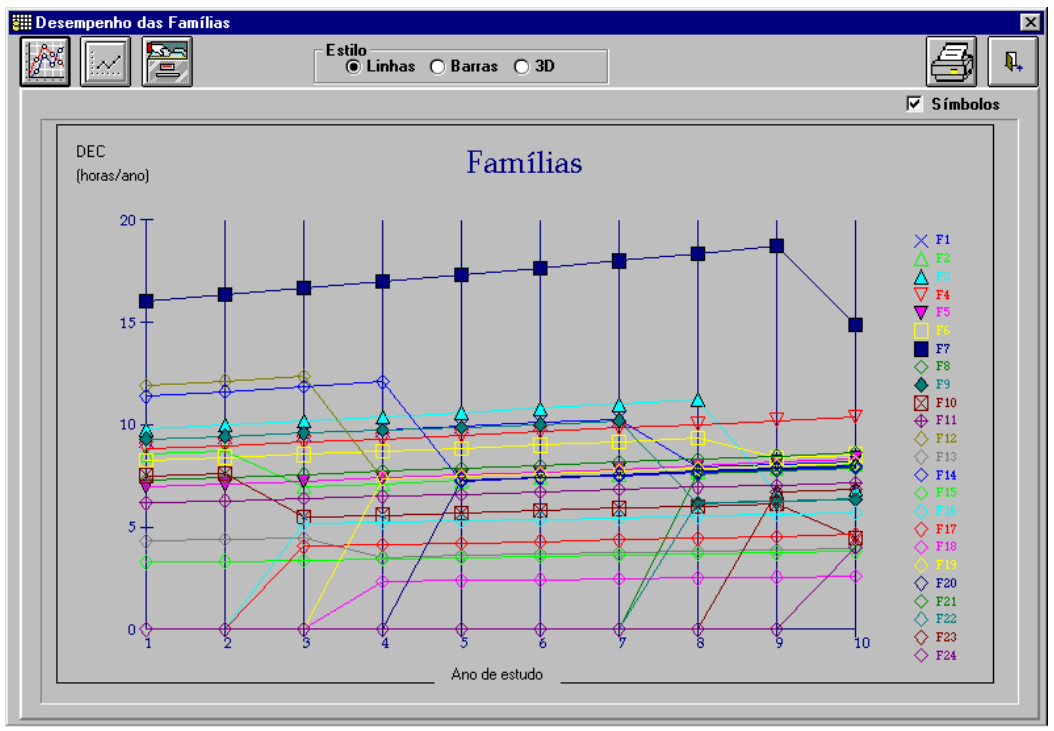

Figura 5.3(d1): Evolução do DEC.

2)Total: Para ter-se uma idéia do comportamento do sistema como um todo, pode-se verificar a média global do DEC. Neste caso, obtem-se um gráfico como o da figura 5.3(d2), a seguir. Verifica-se, da figura, uma leve tendência de queda no índice de DEC, pois o efeito da diminuição do índice do DEC devido às obras sugeridas pelo SISPAI é mais prevalecente do que a sua evolução natural, por crescimento de carga e aumento do comprimento das redes. 


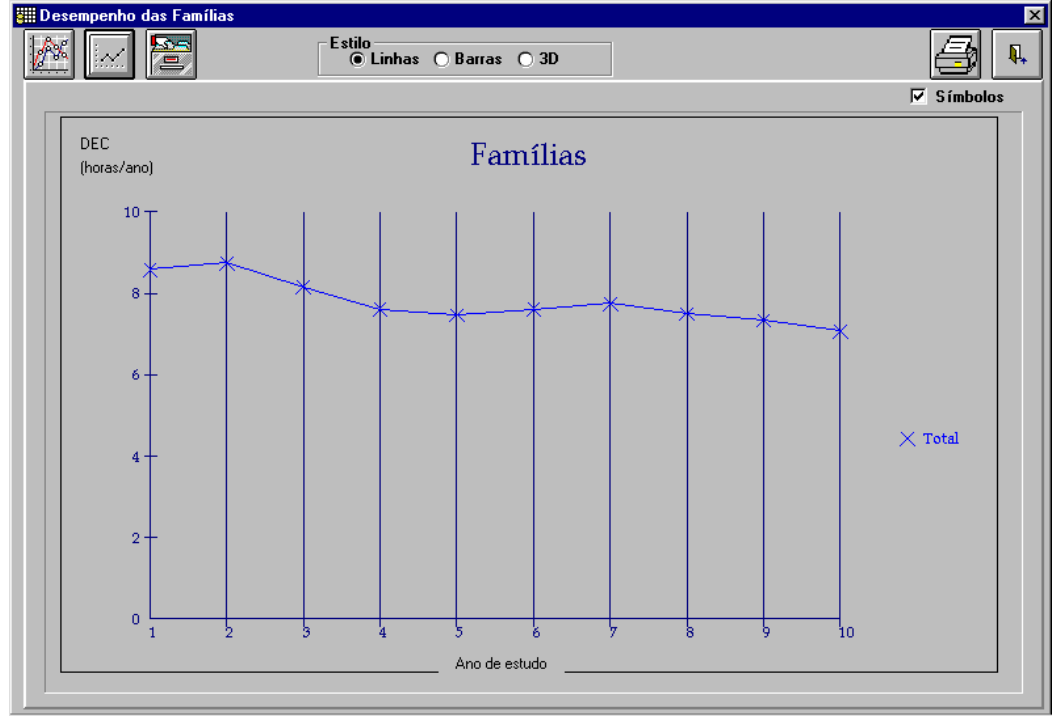

Figura 5.3(d2): DEC médio do sistema durante o horizonte de estudo.

e) FEC

Na figura 5.3(e), tem-se o gráfico correspondente à evolução do FEC, em número de interrupções por ano, para o sistema. Nota-se que segue a mesma tendência, para este caso, que o valor do DEC.

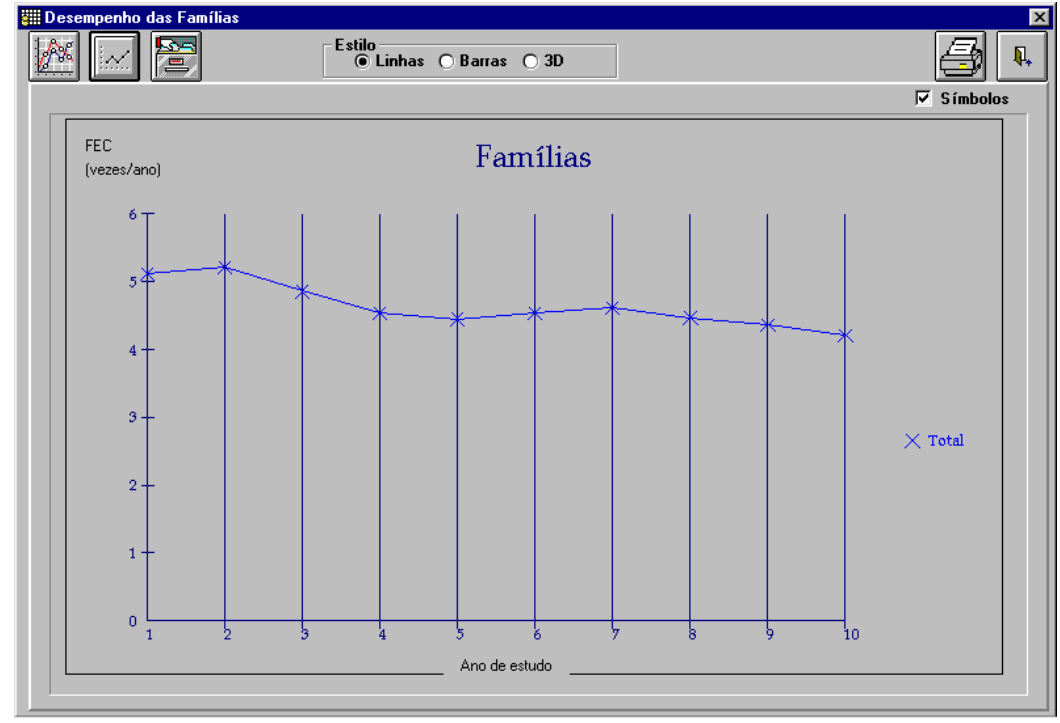

Figura 5.3(e): FEC médio do sistema durante o horizonte de estudo. 


\section{f) Queda de Tensão}

Na figura 5.3(f), tem-se o gráfico correspondente à evolução da queda de tensão, em \%, para o sistema. Nota-se um valor bastante baixo para a queda de tensão (inferior a 1,5\%) durante todo o período de planejamento. Deve-se destacar que este índice (assim como DEC e FEC) representa uma média global do sistema. Para análise mais detalhada, pode-se verificar os relatórios por família.

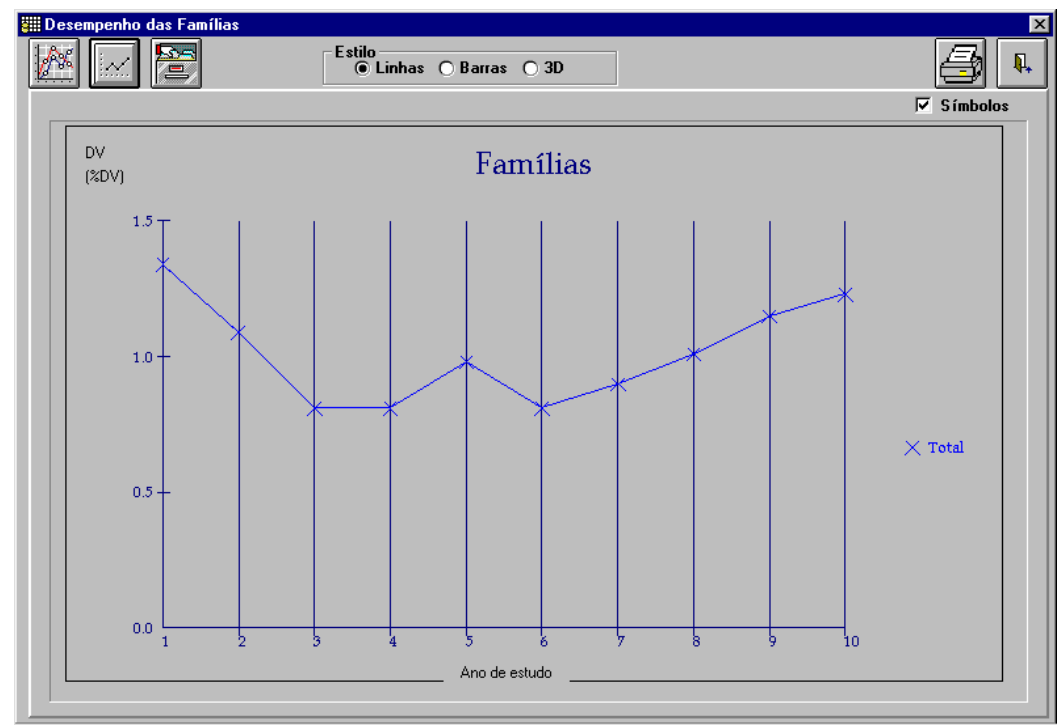

Figura 5.3(f): queda de tensão média do sistema durante o horizonte de estudo.

\section{g) Carregamento dos Alimentadores}

Na figura 5.3(g), tem-se o gráfico correspondente à evolução do carregamento dos alimentadores do sistema, que mostra uma média inferior a 40\% em relação à capacidade admissível dos alimentadores. 


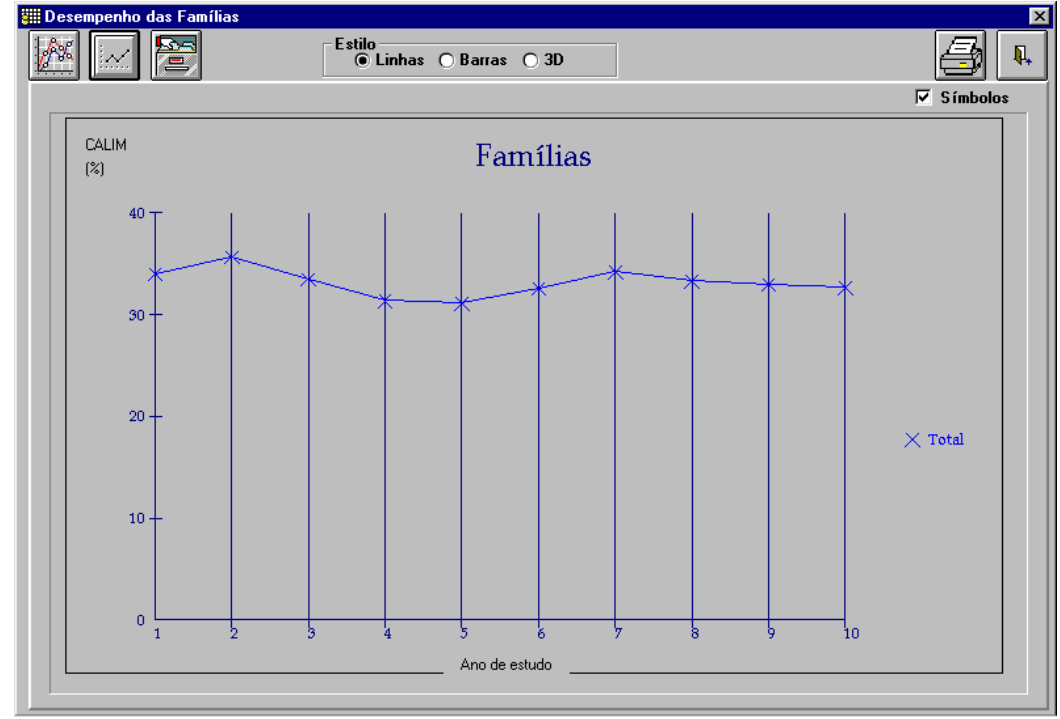

Figura 5.3(g): Carregamento médio dos alimentadores do sistema.

\section{h) Carregamento dos Transformadores das Subestações}

$\mathrm{Na}$ figura 5.3(h), tem-se o gráfico correspondente à evolução do carregamento percentual dos transformadores das subestações do sistema. Nota-se, diferentemente ao caso de carregamento dos alimentadores, uma evolução do índice médio de carregamento de subestações, pois o efeito de diminuição do carregamento por obras em subestações não prevalece sobre a evolução da demanda do sistema.

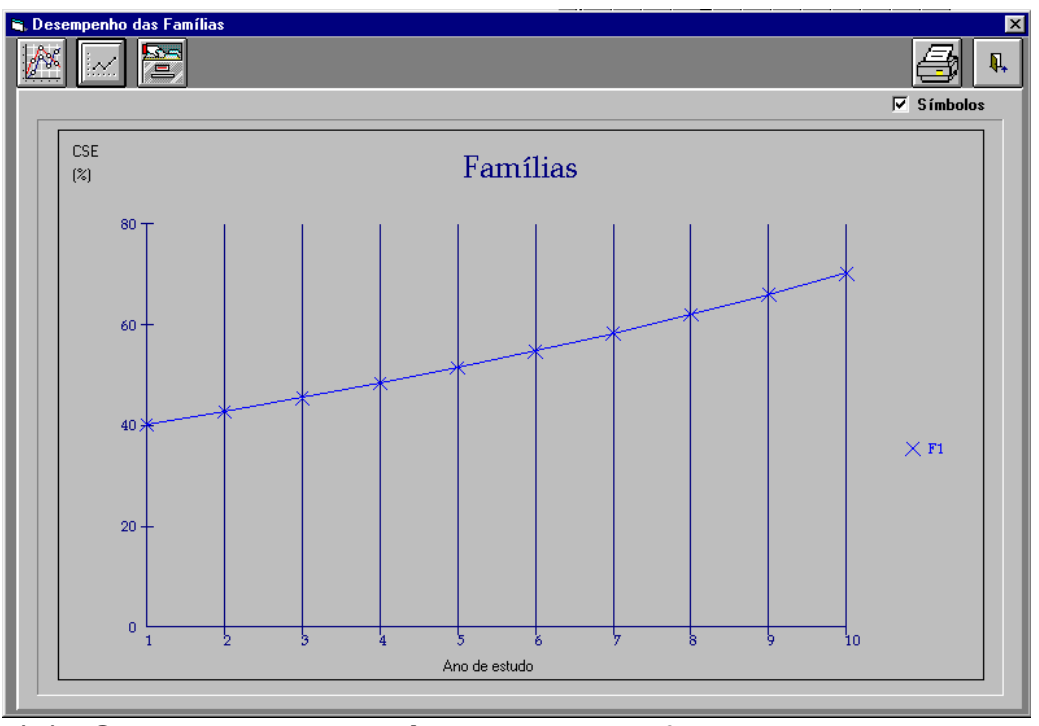

Figura 5.3(h): Carregamento médio dos transformadores das subestações. 


\section{i) Investimentos}

$\mathrm{Na}$ figura 5.3(i), tem-se o gráfico correspondente à evolução dos investimentos anuais no sistema, em milhares de dólares americanos.

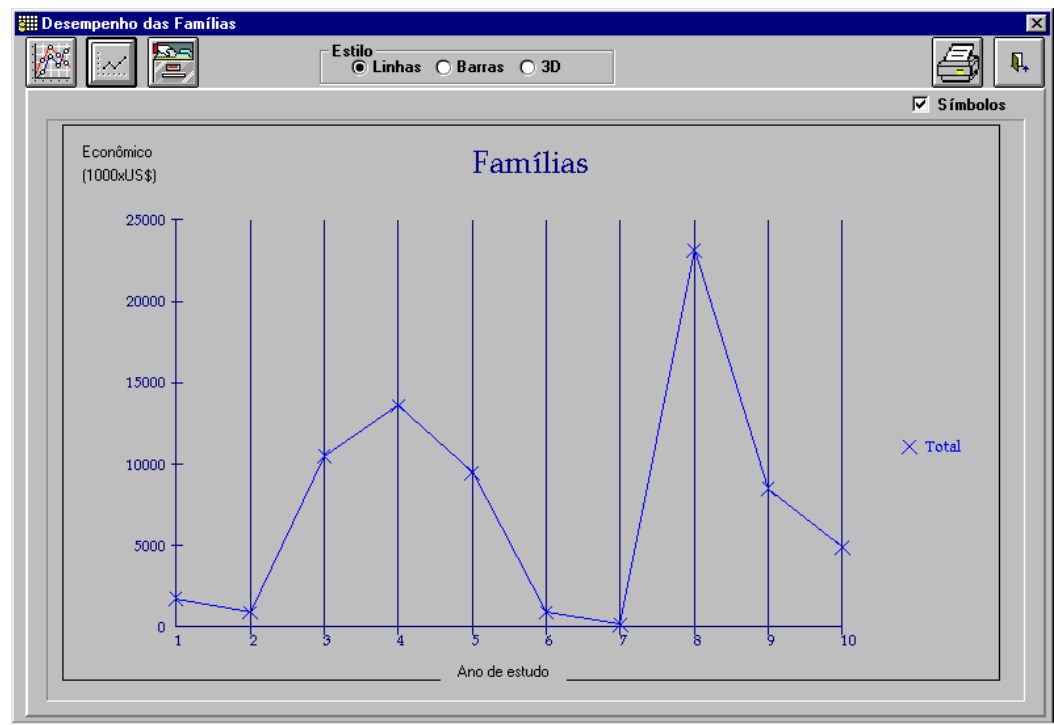

Figura 5.3(i): Investimentos no sistema ao longo do horizonte de estudo, em $1000 x U S \$$. 


\subsection{Custo Marginal}

Neste item, procede-se a análise do Custo Marginal de Expansão do caso em questão. Verifica-se, da figura 5.5(a), o gráfico referente ao investimento acumulado para cada ano (desde o ano inicial) em função da variação de demanda total do sistema. Tem-se ainda, na mesma figura, os resultados obtidos para o Custo Incremental Médio de Longo Prazo (CIMLP) e para o Custo Marginal de Expansão do sistema.

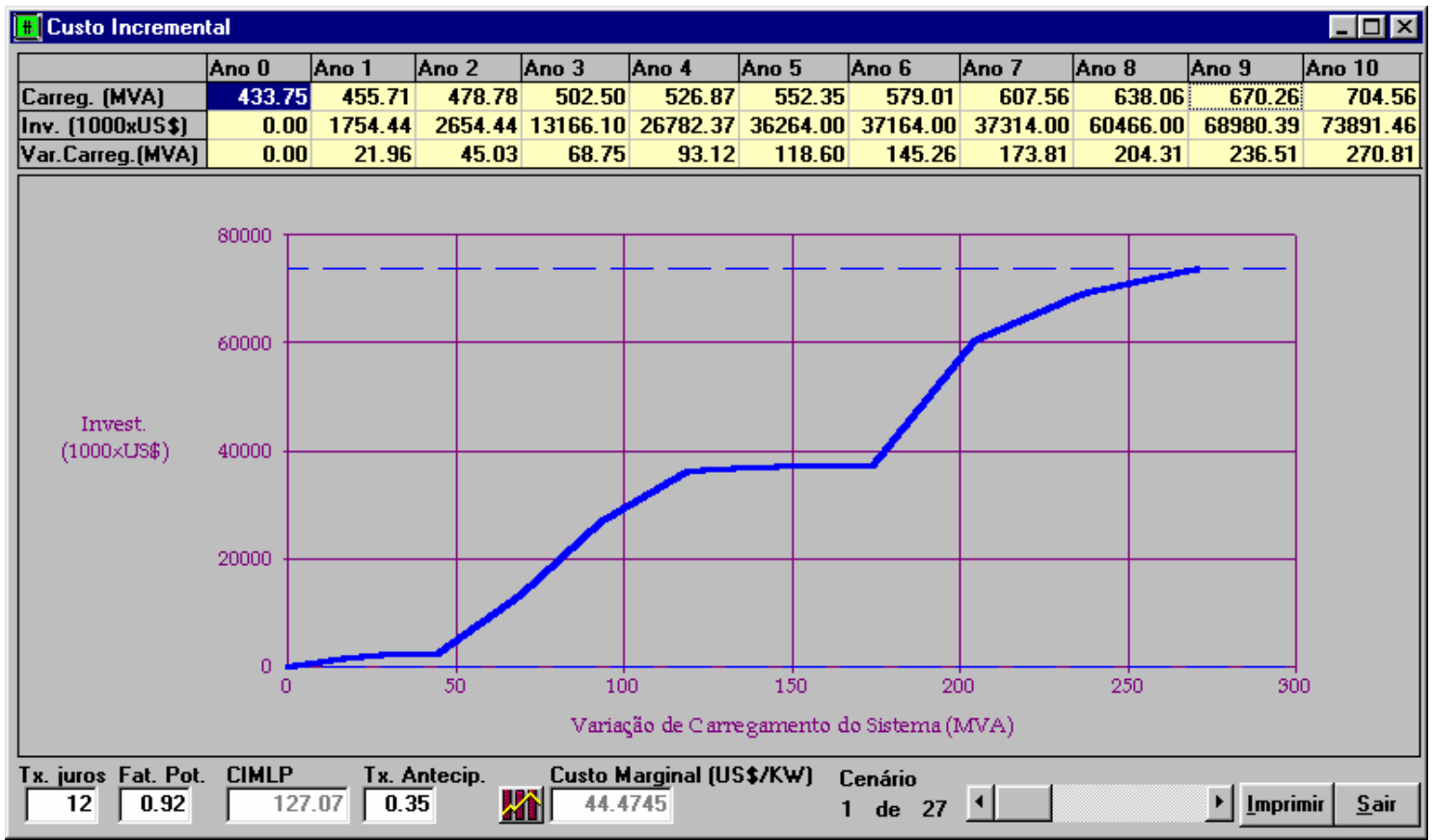

Figura 5.5(a): Gráfico do CIMLP, e o Custo Marginal para o sistema em estudo.

Para o cálculo do CIMLP, utiliza-se a expressão:

$$
\text { CIMLP }=\frac{\sum_{a=1}^{n} \Delta I_{a} *(1+j)^{-a}}{\sum_{a=1}^{n} \Delta P_{a} *(1+j)^{-a}}
$$


Tal expressão utiliza os valores anuais de carregamento e de investimentos, resultantes do processamento do caso teste no SISPAI. De posse dos valores de carregamento, procede-se ao cálculo da variação de carregamento, que será sempre crescente ao longo do horizonte de estudo, dados os valores positivos da Taxa de Crescimento de Carga. Procedimento análogo é utilizado para os valores dos investimentos anuais. Trazendo os resultados para valores presentes, conforme a fórmula acima, chega-se ao valor do CIMLP.

O custo marginal de expansão, como visto no Capítulo 4, é o resultado da multiplicação do CIMLP pela Taxa de Antecipação, que é dada pela soma das taxas de Atualização do Capital, de Depreciação e de Manutenção/Operação. Essas valores são fornecidos pelo planejador, e podem ser alterados a qualquer momento, assim obtendo-se o novo Custo Marginal de Expansão. 


\subsection{Relatórios para Análise de Incertezas e Cenários}

Através do aplicativo SISFAMÍLIAS, procede-se à análise de cenários dos índices de qualidade no caso em estudo. O processamento descrito no item 5.2.6, onde foram processados 27 cenários, será utilizado para esta análise.

a) Perdas por demanda: Verifica-se, pela figura 5.4(a), as freqüências de ocorrências para as perdas por demanda do sistema, em porcentagem. Da figura pode-se inferir, por exemplo, que existe $30 \%$ de probabilidade das perdas totais do sistema estarem em uma faixa inferior a 3,81\% da demanda atendida dos alimentadores. Nota-se que essa probabilidade refere-se a todos os cenários do orçamento escolhido, e considera todas as famílias do sistema, inclusive as criadas durante o processo de evolução. É também importante salientar que estão aí considerados todos os anos do período de planejamento, e os valores apresentados são médios para este período, desde que executadas as obras propostas pelo sistema.

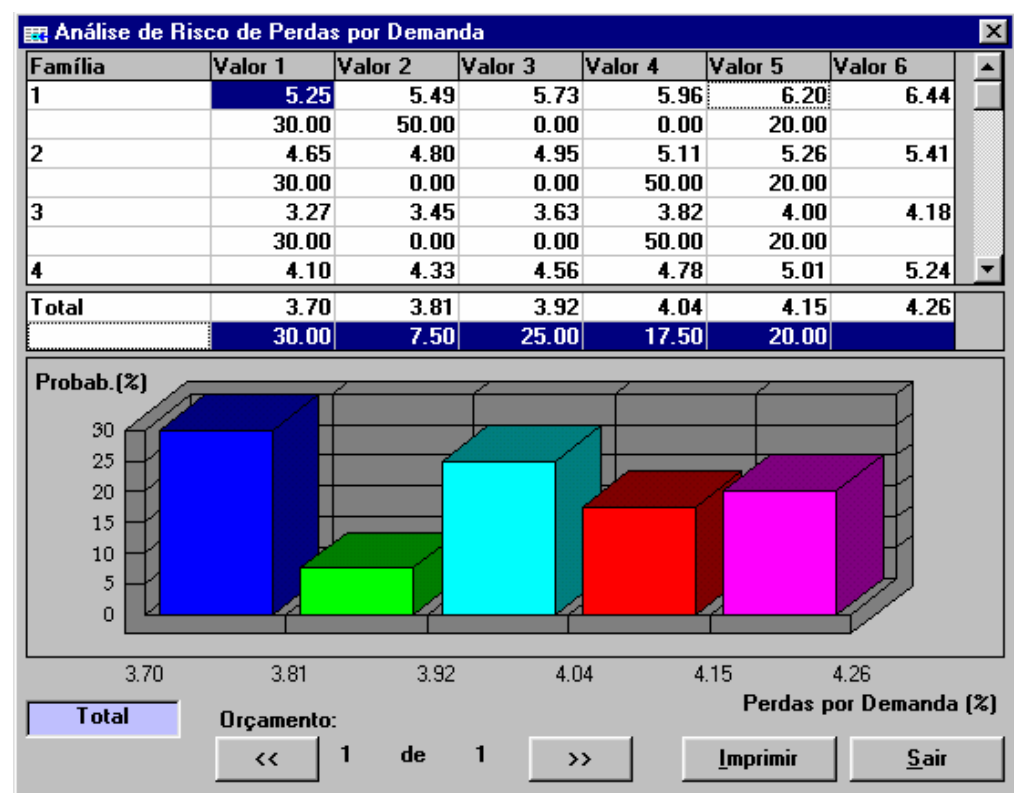

Figura 5.4(a): Análise de risco para as perdas por demanda dos alimentadores do sistema. 
b) Perdas por energia: Verifica-se, pela figura 5.4(b), as freqüências de ocorrências para as perdas por energia do sistema, em porcentagem. Da figura pode-se inferir, por exemplo, que existe $37,50 \%$ de probabilidade das perdas por energia totais do sistema estarem em uma faixa superior a 3,01\% da energia anual fornecida.

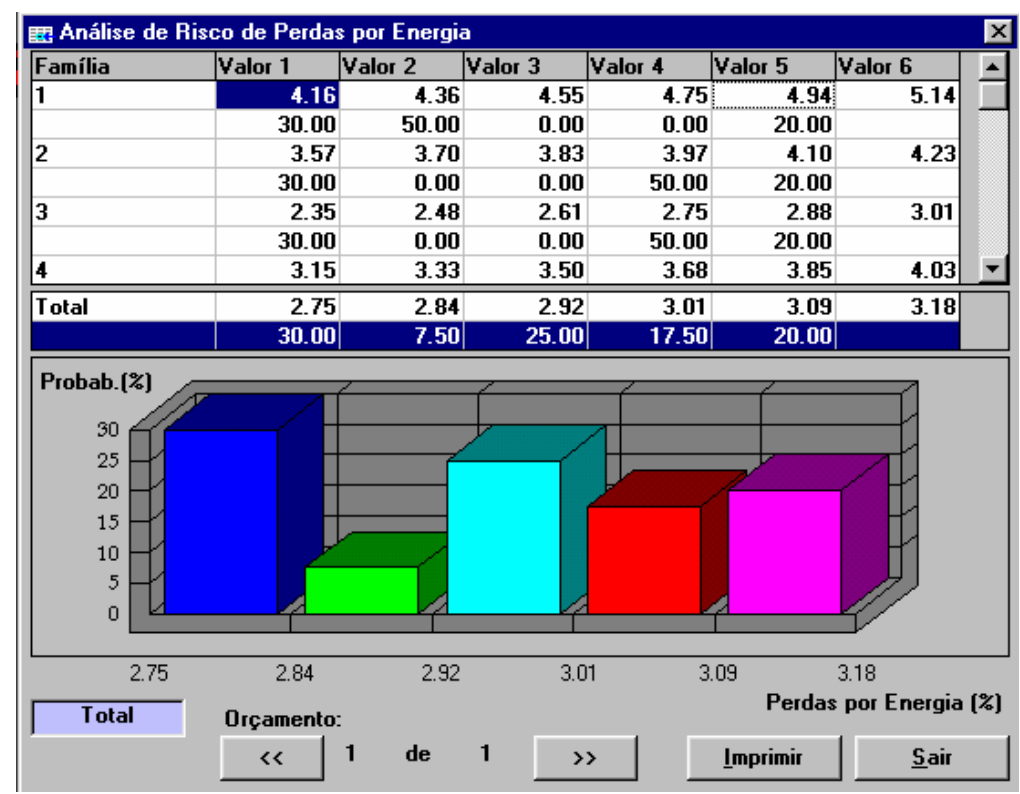

Figura 5.4(b): Análise de risco para as perdas por energia dos alimentadores do sistema. 
c) END: Verifica-se, pela figura 5.4(c), as freqüências de ocorrências para a energia não distribuída do sistema, em MWh. Da figura podese inferir, por exemplo, que o risco da END ser superior a $3370 \mathrm{MWh}$ é de $30 \%$.

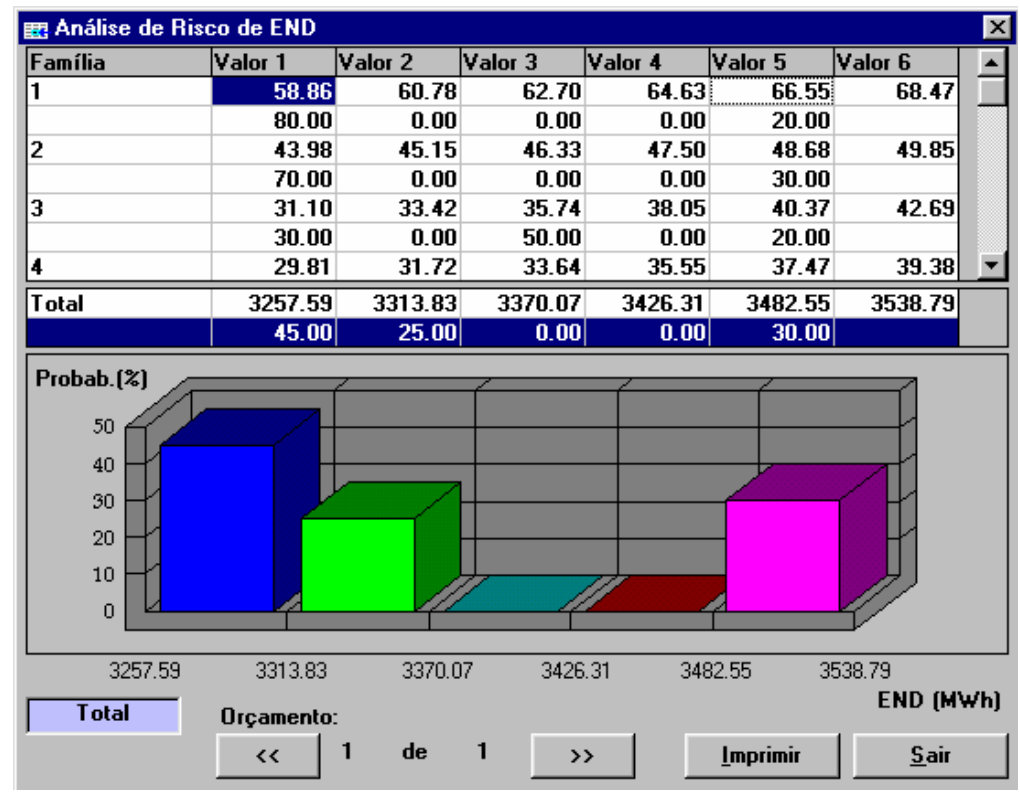

Figura 5.4(c): Análise de risco para a END média dos alimentadores do sistema. 
d) DEC: Verifica-se, pela figura 5.4(d1), as freqüências de ocorrências para o DEC médio do sistema. Da figura pode-se inferir, por exemplo, que o risco do DEC ser superior a 7,44 horas/ano é de $20 \%$.

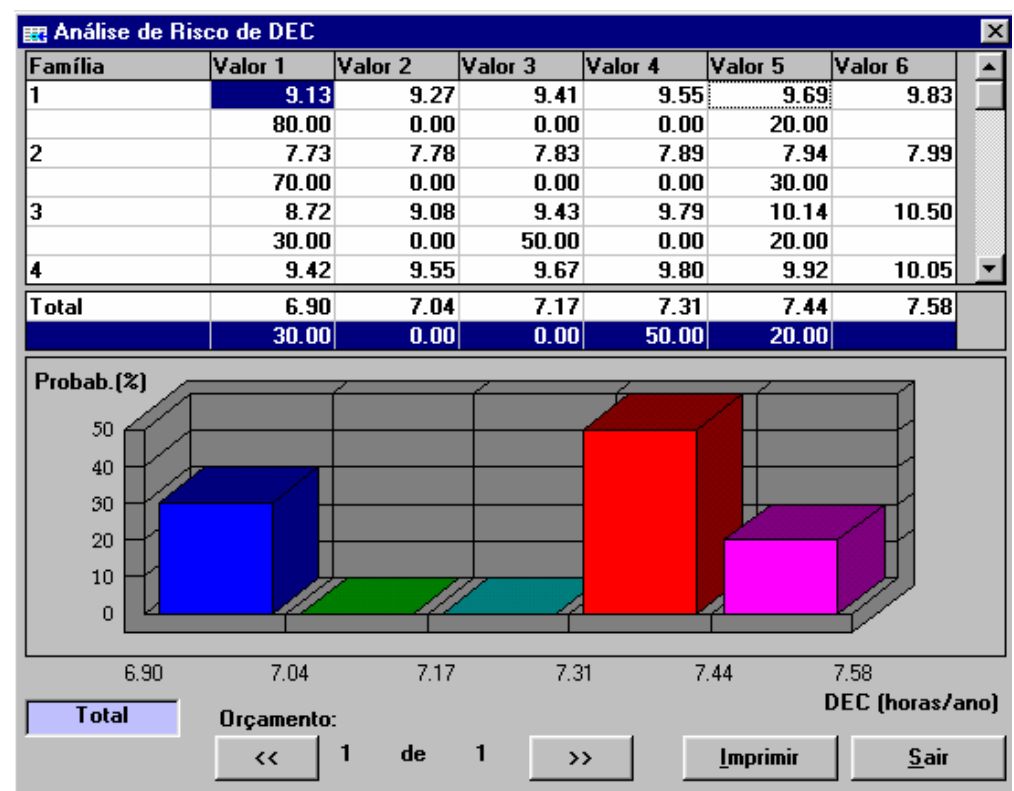

Figura 5.4(d1): Análise de risco para o DEC médio dos alimentadores do sistema.

Para o DEC, também foi processado um caso que, embora com os mesmos cenários que o caso em estudo, teve seu orçamento reduzido. Assim, ao invés dos US\$100 milhões anuais (sem restrição orçamentária), o orçamento foi reduzido para US\$14 milhões por ano, e US\$56 milhões no oitavo ano (nesse ano o orçamento teve que ser revisto para atender às necessidades de obras do sistema). Assim, conforme o gráfico da figura 5.4(d2), observa-se um deslocamento da curva para a direita, assinalando um aumento nos níveis de DEC, decorrentes da diminuição orçamentária. Por exemplo, o risco do DEC ser superior a 7,54 horas/ano é de 44\%. 


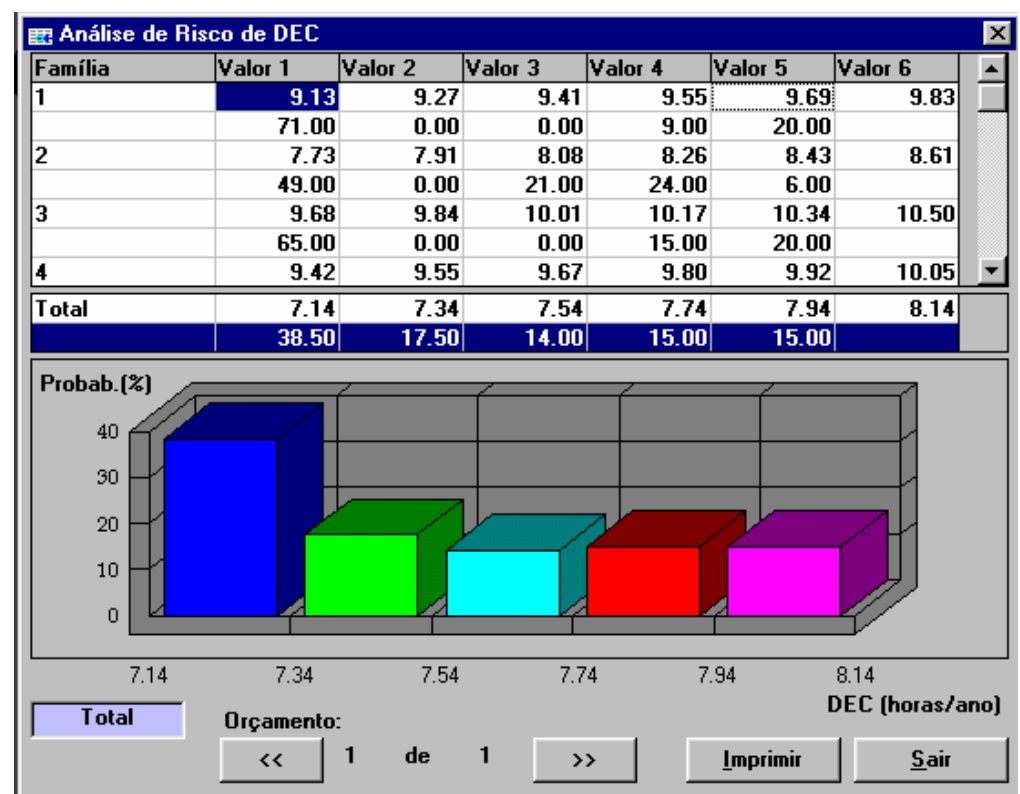

Figura 5.4(d2): Análise de risco para o DEC médio dos alimentadores do sistema, com restrição orçamentária.

e) FEC: Verifica-se, pela figura 5.4(e), as freqüências de ocorrências para o FEC médio do sistema. Da figura pode-se inferir, por exemplo, que o risco do FEC ser superior a 4,43 ocorrências/ano é de 20\%.

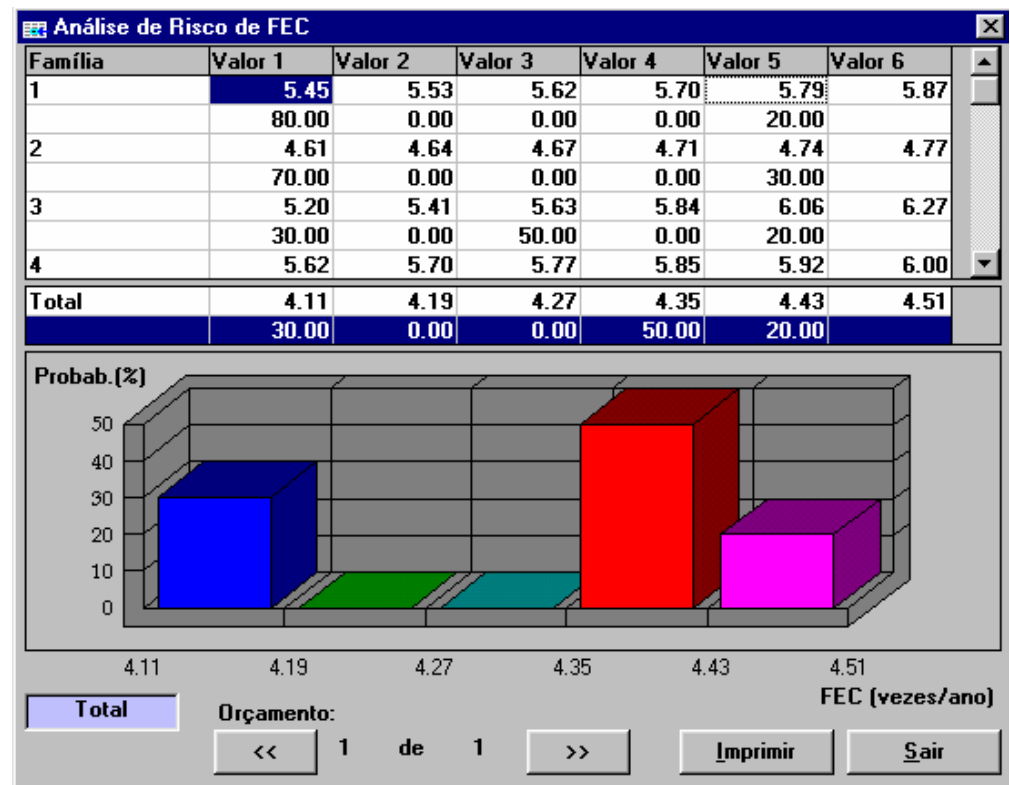

Figura 5.4(e): Análise de risco para a FEC média dos alimentadores do sistema. 
f) Queda de Tensão: Verifica-se, pela figura 5.4(f), as freqüências de ocorrências para a queda de tensão média do sistema, em \%. Da figura pode-se inferir, por exemplo, que a probabilidade da queda de tensão estar entre 2,32 e 2,44\% é de 36\%.

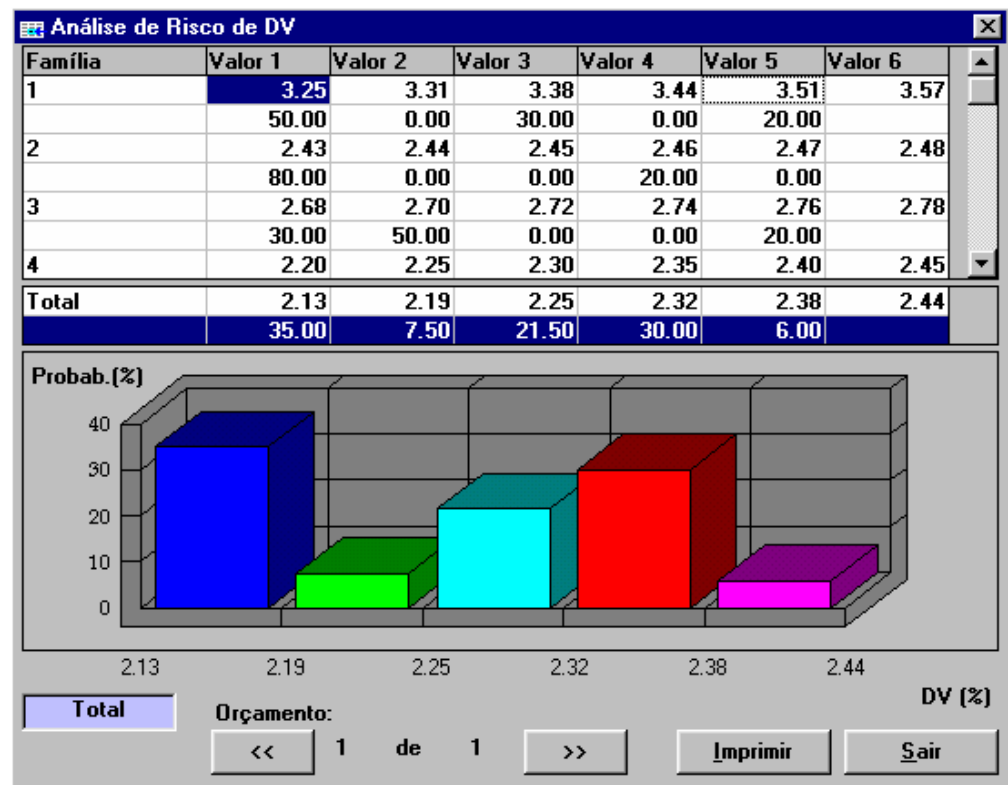

Figura 5.4(f): Análise de risco para a queda de tensão dos alimentadores do sistema. 
g) Carregamento de alimentadores: Verifica-se, pela figura $5.4(\mathrm{~g})$, as freqüências de ocorrências para o carregamento médio dos alimentadores do sistema, em \%. Da figura pode-se inferir, por exemplo, que o carregamento médio dos alimentadores do sistema é em torno de $31 \%$.

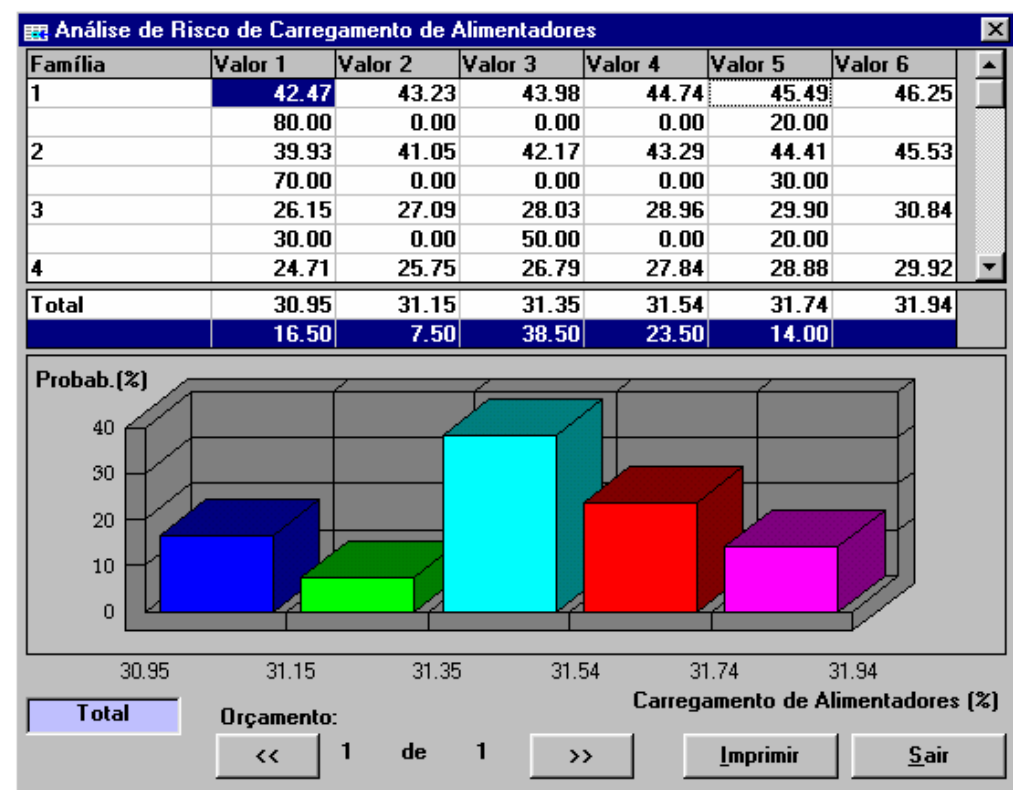

Figura 5.4(g): Análise de risco para o carregamento dos alimentadores do sistema.

h) Carregamento de subestações: Verifica-se, pela figura 5.4(h), as freqüências de ocorrências para o carregamento médio dos transformadores das subestações do sistema, em \%. Da figura pode-se inferir, por exemplo, que a faixa mais provável para o carregamento médio dos transformadores das subestações é entre 52,76 e 53,05\%, com probabilidade 50\%. 


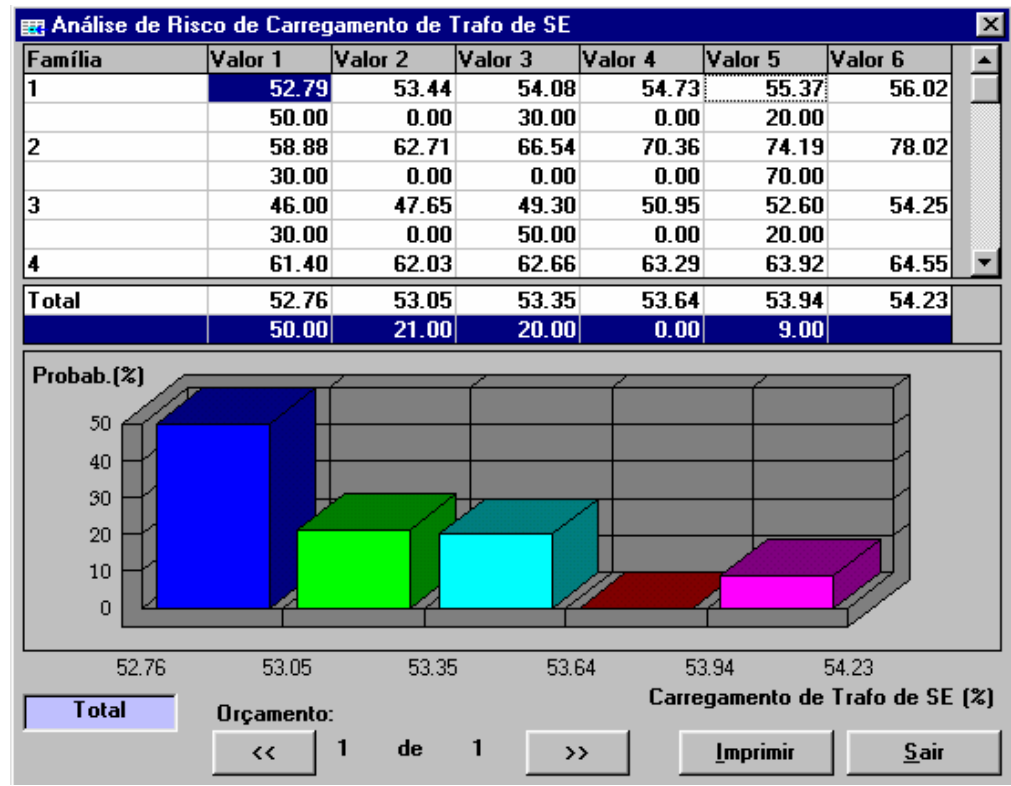

Figura 5.4(h): Análise de risco para o carregamento médio das subestações do sistema.

i) Investimentos Totais em Valor Presente: verifica-se, pela figura 5.4(i), as freqüências de ocorrências para os investimentos nas famílias do sistema, em milhares de dólares americanos. Da figura, pode-se dizer que os investimentos no sistema ao longo do horizonte de estudo, tem $24 \%$ de probabilidade de serem inferiores a aproximadamente US\$ 64,5 milhões.

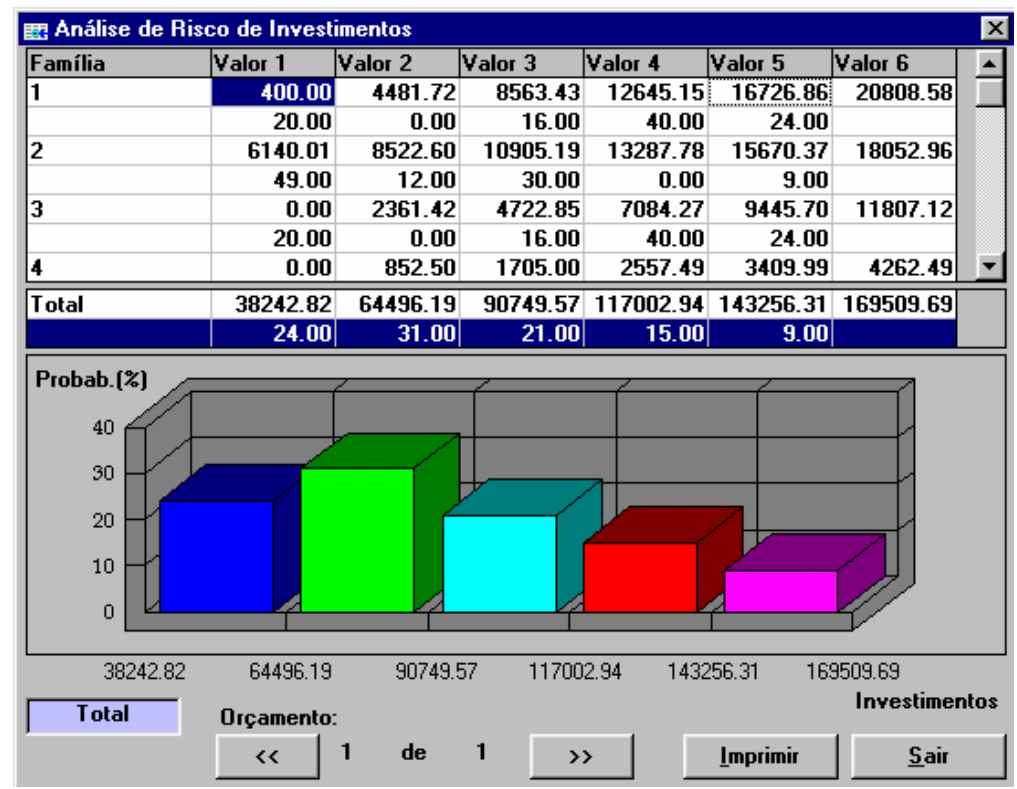

Figura 5.4(i): Análise de risco para os investimentos no sistema. 


\subsection{Resultados por Regional}

Finalmente, procede-se ao agrupamento das subestações reais para formação das regionais, obtendo-se assim resultados para cada região da empresa. Foram criadas 8 regionais, de nomes fictícios REG1, REG2 e assim por diante, conforme figura 5.6(a).

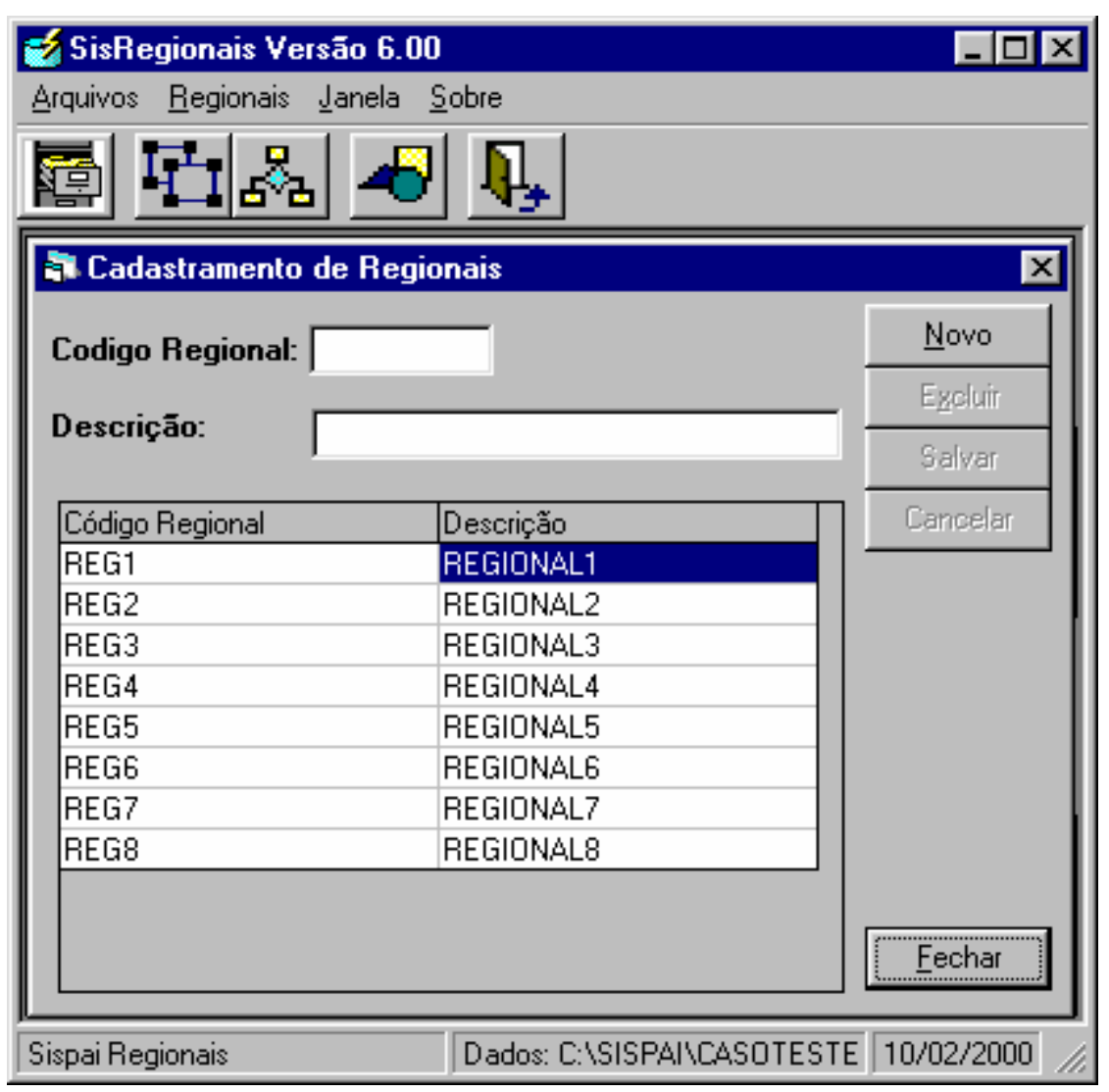

Figura 5.6(a): Regionais do sistema.

A seguir é necessário proceder-se à associação das subestações reais do sistema às regionais correspondentes. No anexo $\mathrm{E}$ tem-se a relação das regionais formadas para este caso, com as subestações correspondentes a as famílias as quais elas pertencem. 
Com tal formação de regionais, é possível obter-se basicamente os mesmo relatórios que foram obtidos por família. Para o índice END, em MWh/ano, tem-se a evolução para do índice para todas as regionais definidas conforme figura $5.6(\mathrm{~b})$.

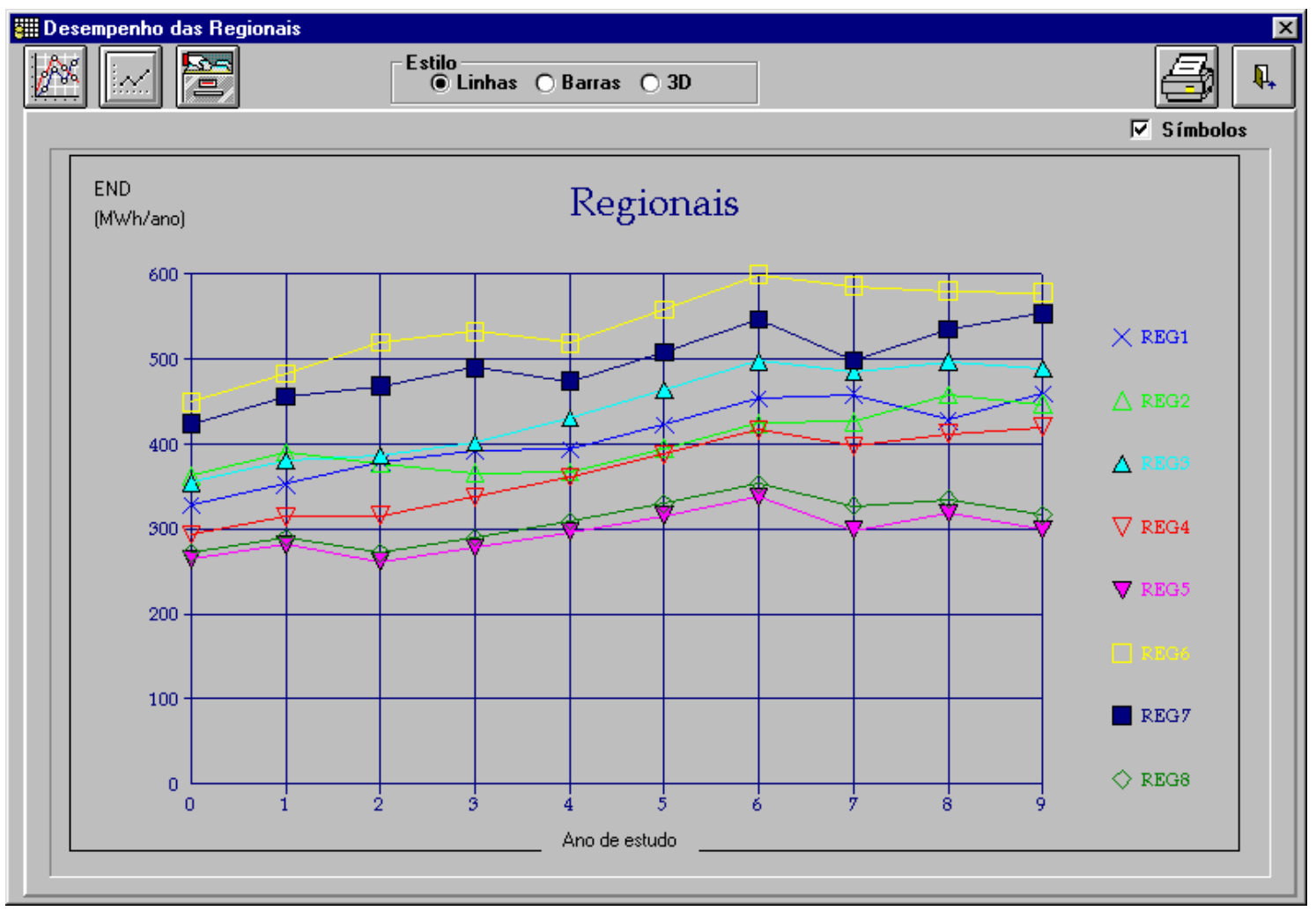

Figura 5.6(b): Curvas de END para as regionais do sistema.

As regionais foram formadas considerando-se as divisões das regionais da própria empresa. Nota-se, por exemplo, que a regional Reg6 é a que tem os piores índices de END - quase o dobro, por exemplo, da regional Reg5. Porém, quando considera-se os índices de END como porcentagem da energia anual fornecida, nota-se que a regional Reg3 é a que tem piores índices. Isso é facilmente observável pela figura 5.6(c), que apresenta os resultados da END em porcentagem para todas as famílias. 


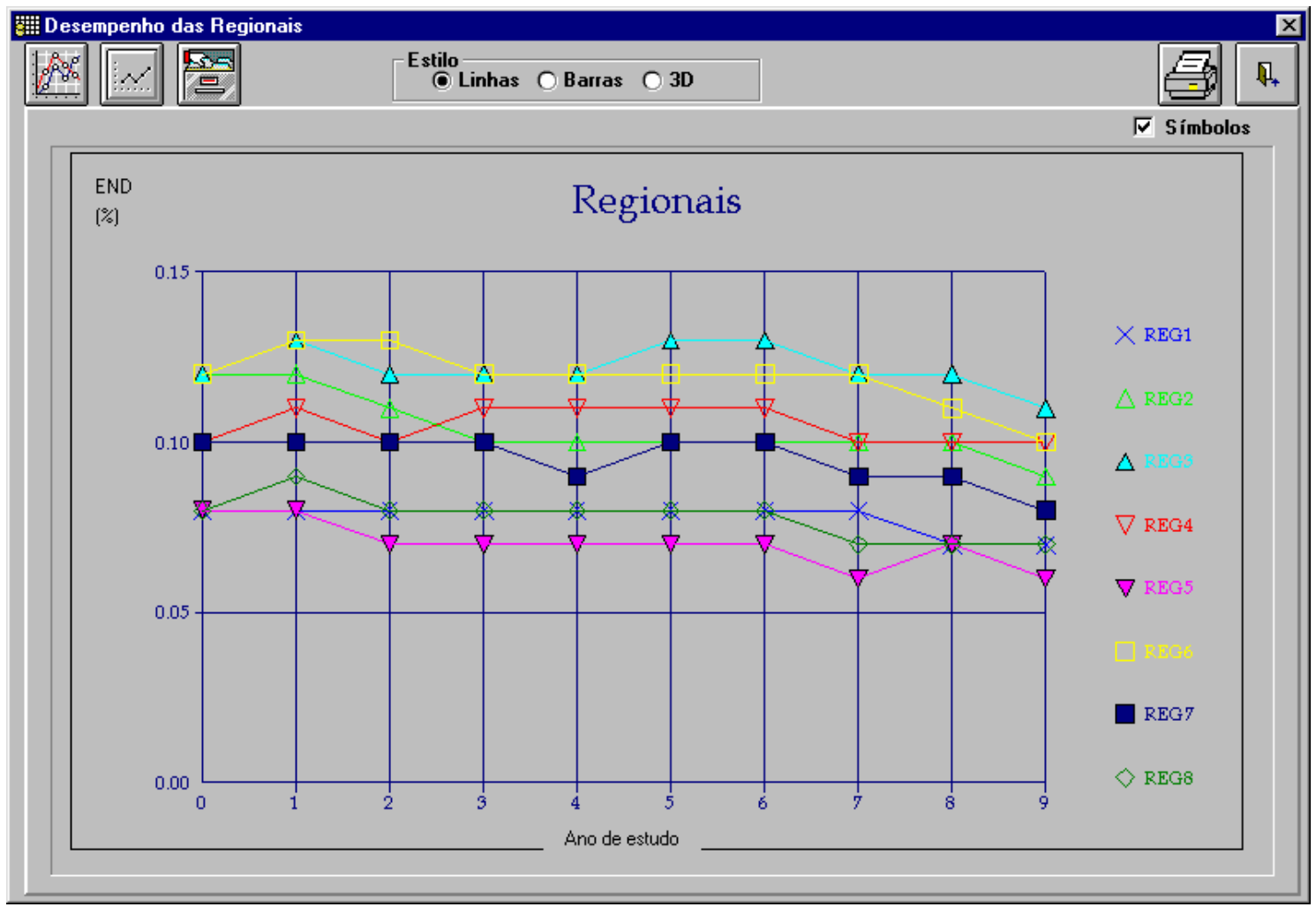

Figura 5.6(c): Curvas de END em \% para as regionais do sistema.

Outro índice de grande interesse para análise são as perdas. As perdas por demanda em KW na regional Reg7 são aproximadamente o dobro das perdas na regional Reg5, conforme figura 5.6(d). Em porcentagem, porém, essa diferença não é tão acentuada, pois a demanda atendida da regional Reg7 é bem maior, como apresentado na figura 5.6(e). 


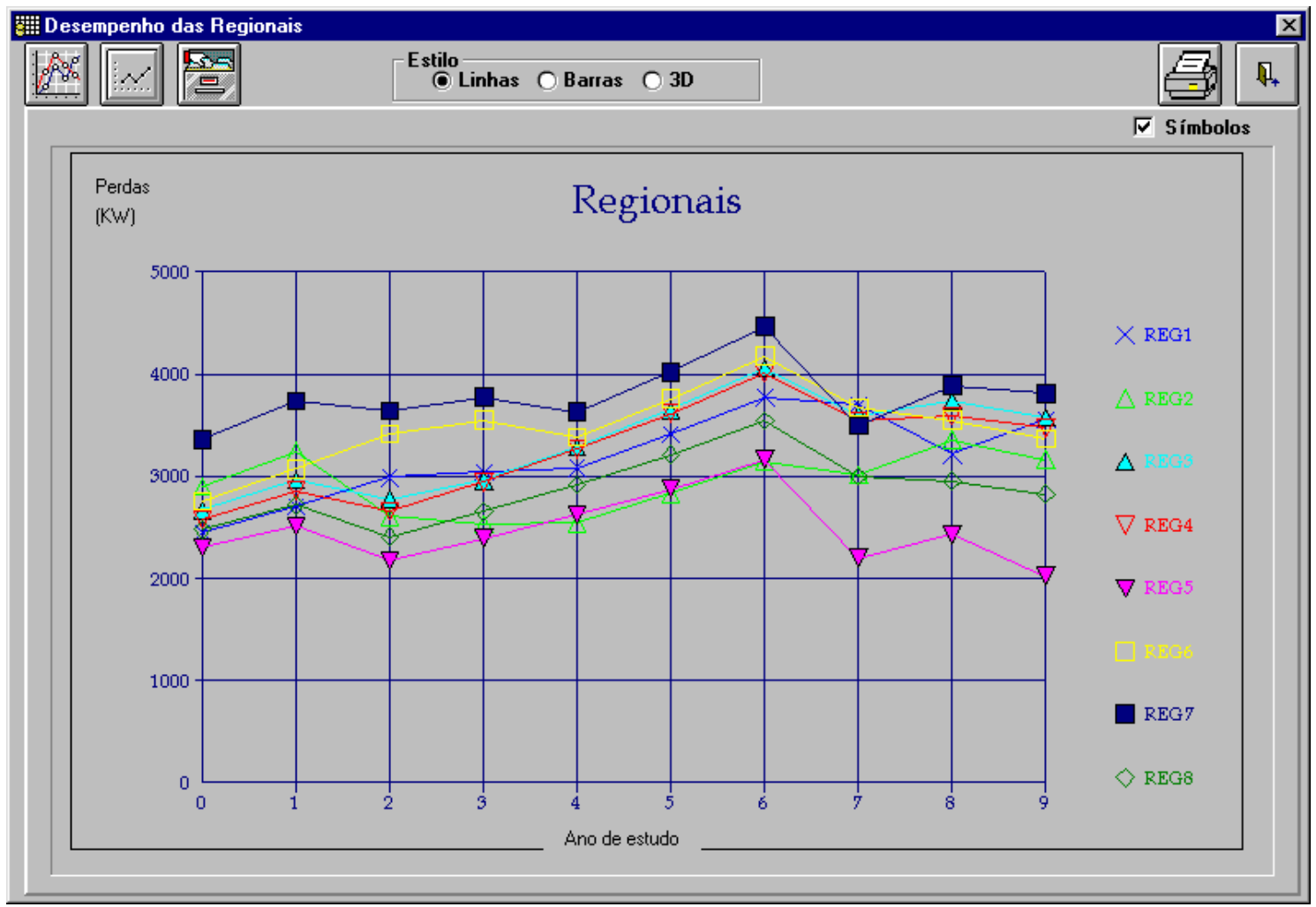

Figura 5.6(d): Curvas de perdas em kW para as regionais do sistema.

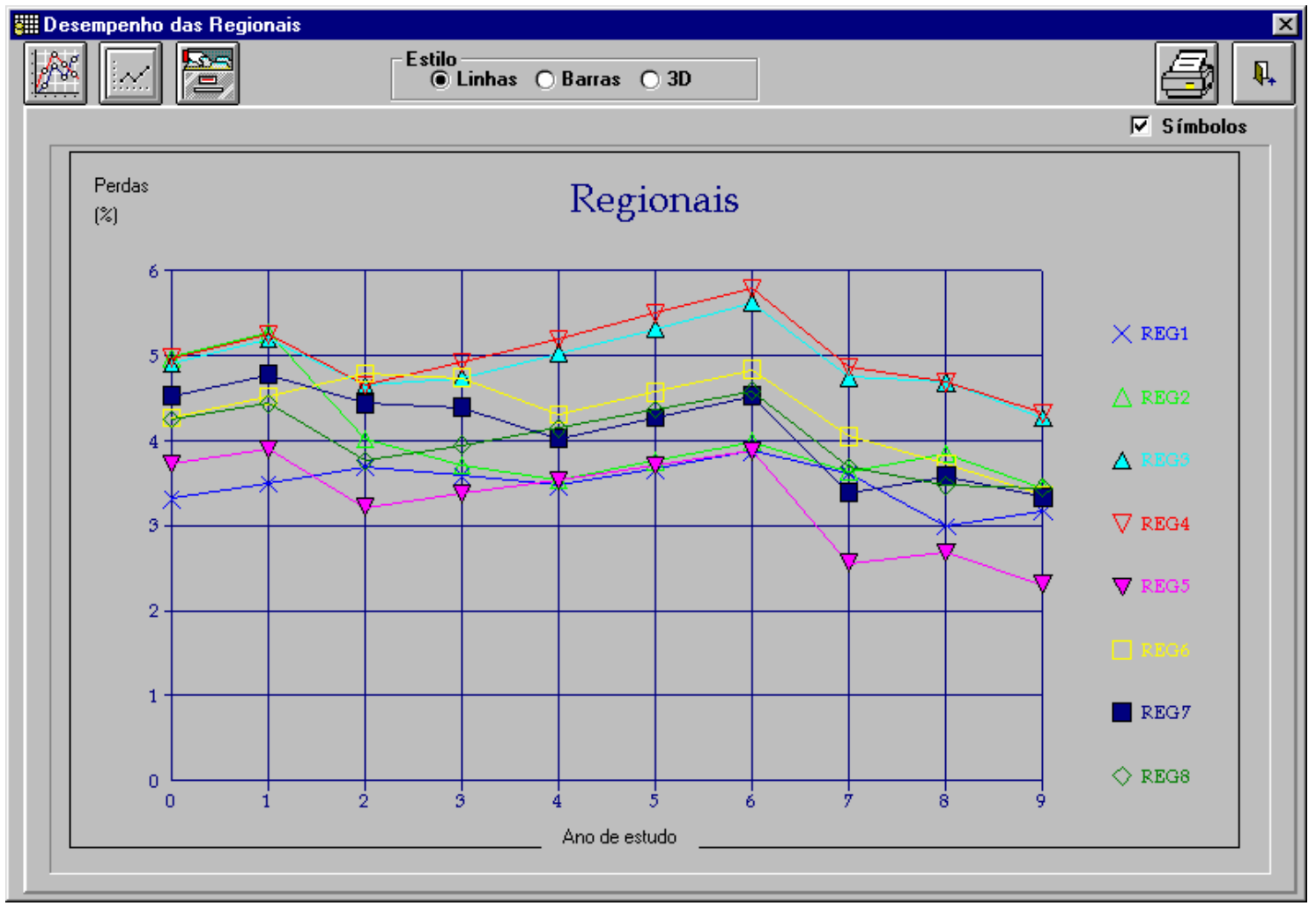

Figura 5.6(e): Curvas de perdas em \% para as regionais do sistema. 
Como último exemplo, é apresentada na figura 5.6(f) a distribuição de recursos por regional. Esse gráfico permite, por exemplo, a análise das regionais onde concentram-se os maiores dispêndios ao longo do horizonte de estudo.

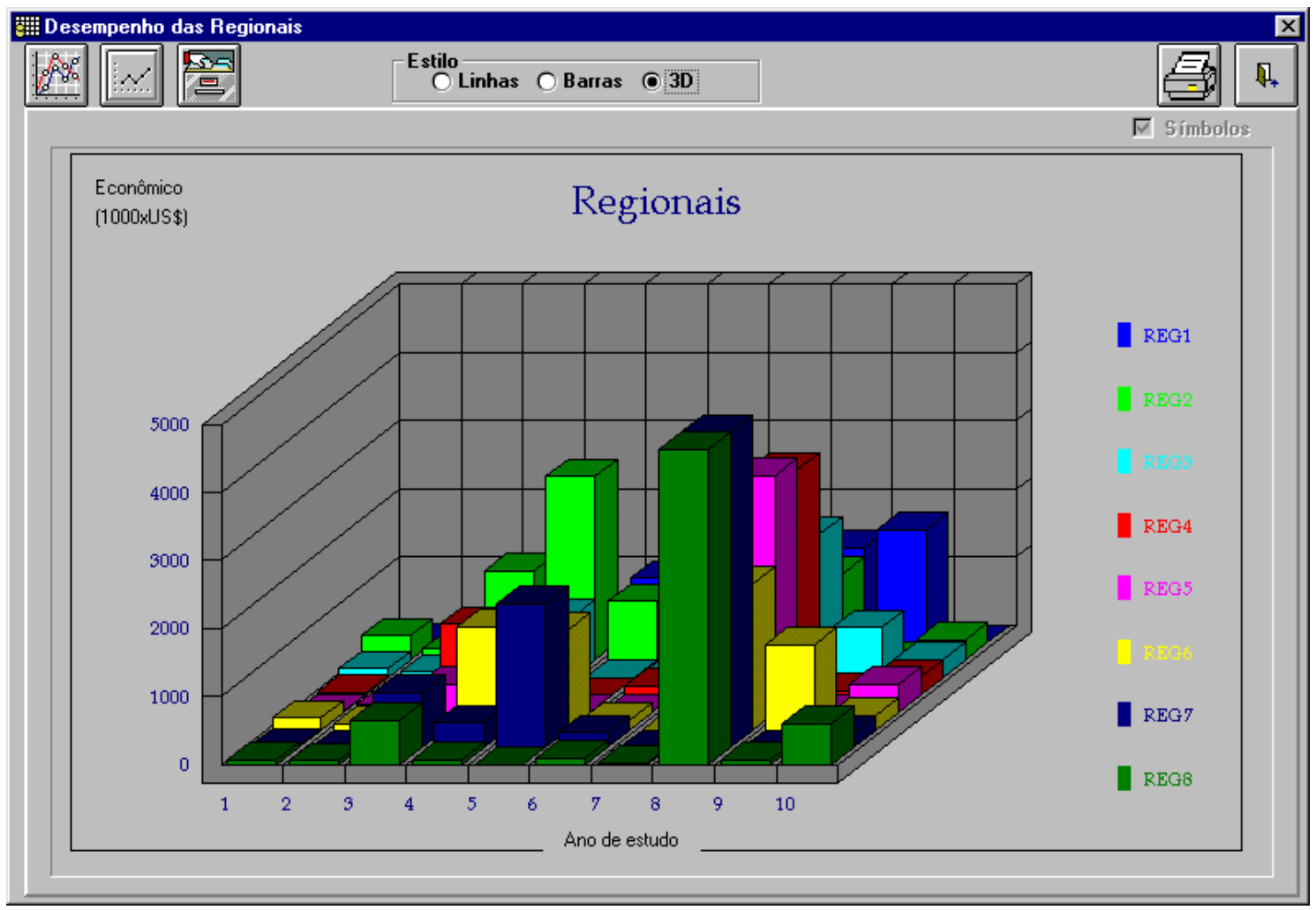

Figura 5.6(f): Distribuição de recursos por regional. 


\subsection{Discussão dos Resultados}

Como resultado deste caso teste, conseguiu-se mostrar:

- os resultados do processamento do SISPAI para um caso real;

- todos os resultados desse processamento em um caso de referência, sem restrição orçamentária e com geração apenas de obras de melhoria;

- um caso complementar com 27 cenários, onde observou-se a curva de Probabilidade dos Benefícios;

- $\quad$ a evolução dos índices de qualidade por família;

- a evolução dos índices de qualidade por regional;

- a evolução dos índices de qualidade para todo o sistema em estudo;

- a análise de risco para os diversos índices considerados;

- os custos CIMLP e o Custo Marginal de Expansão para o caso de referência, além da curva de investimento acumulado para cada ano em função da variação da demanda.

Com isso, verificou-se a importância de tais índices para as empresas, e muitas das utilidades e benefícios dos mesmos. Para o DEC, onde foram analisados mais detalhadamente os resultados, pôde-se, inclusive, perceber o aumento no nível de risco de um determinado valor de DEC ser ultrapassado, quando da imposição de restrição orçamentária. Com os resultados por famílias e por regional, acredita-se ter uma ferramenta bastante completa para auxílio ao planejador de sistemas de distribuição. 
O caso teste de aplicação poderia ainda ser aprimorado, utilizando-se alternativas que solucionem também outras questões. Assim seria interessante, por exemplo, analisar-se um caso onde são relaxados todos os critérios, inclusive o carregamento, verificando-se a evolução do valor do DEC, por exemplo, sem a geração de nenhuma obra. Ou ainda, a liberação de obras de melhoria no sistema, avaliando seu impacto nos investimentos e na melhoria da qualidade do sistema.

Acredita-se que as ferramentas desenvolvidas tenham um potencial enorme para uma série de estudos específicos que não foram abordados neste documento. 


\section{CAPÍTULO 6}

\section{CONCLUSÕES}

Apresenta-se aqui os comentários finais e sugestões de atividades para posterior desenvolvimento.

Os sistemas apresentados fornecem novas ferramentas ao engenheiro planejador, possibilitando a análise do sistema elétrico por famílias ou por regionais do sistema. Permite, assim, uma visão específica das regionais mais problemáticas, no sentido técnico, ou mais dispendiosas, sob a ótica econômica. A análise dos valores globais dos índices possibilita a análise gerencial da evolução da rede elétrica. Conforme discutido em [20], o planejamento agregado é um método eficiente para divisão de recursos entre as diferentes regiões, de forma que as ferramentas apresentadas, sobretudo a referente às regionais, vem de encontro a essa necessidade, uma vez que geralmente as concessionárias não possuem nenhuma metodologia apropriada para realizar esta operação, sendo inclusive usual a utilização de valores históricos e fórmulas empíricas para divisão dos recursos. De acordo com Simões [3], o planejamento agregado não pode ser utilizado como definidor do programa de obras executável, por não estar associado à base geográfica e sim à natureza das obras, devendose, para tanto, utilizar-se o planejamento local. Desta forma, consideramse as duas ferramentas como complementares.

Uma importante contribuição deste trabalho, além dos índices técnicos globais, refere-se à análise probabilística dos índices, por família, regional ou global para o sistema. Tais análises permitem a implementação de novos procedimentos de apoio à tomada de decisão, que consideram os riscos envolvidos frente às incertezas inerentes a um planejamento de longo prazo. 
Finalmente, discute-se a implementação do módulo de cálculo dos Custos Marginais de Expansão do sistema. Essa nova ferramenta fornece um importante auxílio às empresas do setor elétrico, haja visto as mudanças institucionais do setor. A utilização de ferramentas que avaliam os custos marginais das redes de distribuição considerando dados passados para tarifação do fornecimento, usualmente a Lei de Quantidade de Obras (LQO), têm sido questionada no setor elétrico. O planejamento agregado, junto às novas ferramentas desenvolvidas no escopo deste trabalho, vem preencher essa lacuna, tornando-se assim aliados das empresas de distribuição nacionais, permitindo, inclusive, a avaliação do impacto de melhores níveis de qualidade nos custos marginais, o que pode representar importante auxílio para definição de metodologia de tarifas com parâmetros de qualidade de fornecimento.

Como sugestão para prosseguimento deste tema, o desenvolvimento de um módulo para análise de incertezas e cenários para o custo marginal, demonstrando o impacto na qualidade quando de imposição de restrições orçamentárias, seria uma evolução natural das ferramentas aqui desenvolvidas.

Os módulos desenvolvidos possuem um conjunto completo de ferramentas, porém outros índices podem ser explorados. Variações no cálculo de alguns desses índices também podem ser consideradas. Por exemplo, o cálculo do DEC das famílias de subestações e valores globais poderia ser efetuado ponderando-se 0 índice obtido para os alimentadores pela demanda. Outras implementações considerando, por exemplo, ganhos anuais devido a redução de perdas, END e DEC, também seriam índices de interesse para o planejador. 


\title{
ANEXO A RELATÓRIO DO CLUSTER DE SUBESTAÇÕES PARA O CASO TESTE DE APLICAÇÃO
}

\author{
CLUSUB - Grupos de Subestacoes (para VB) - Versao 1.22
}

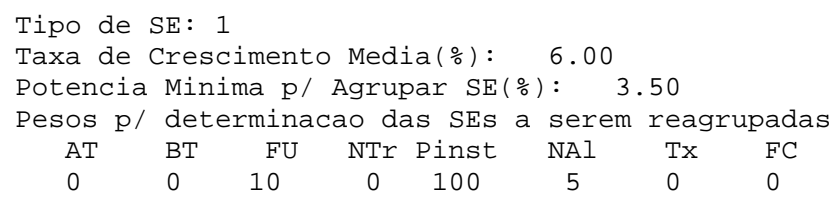

Potencia Total das SE' Desprezadas (MVA): $\quad \odot . \odot \odot$

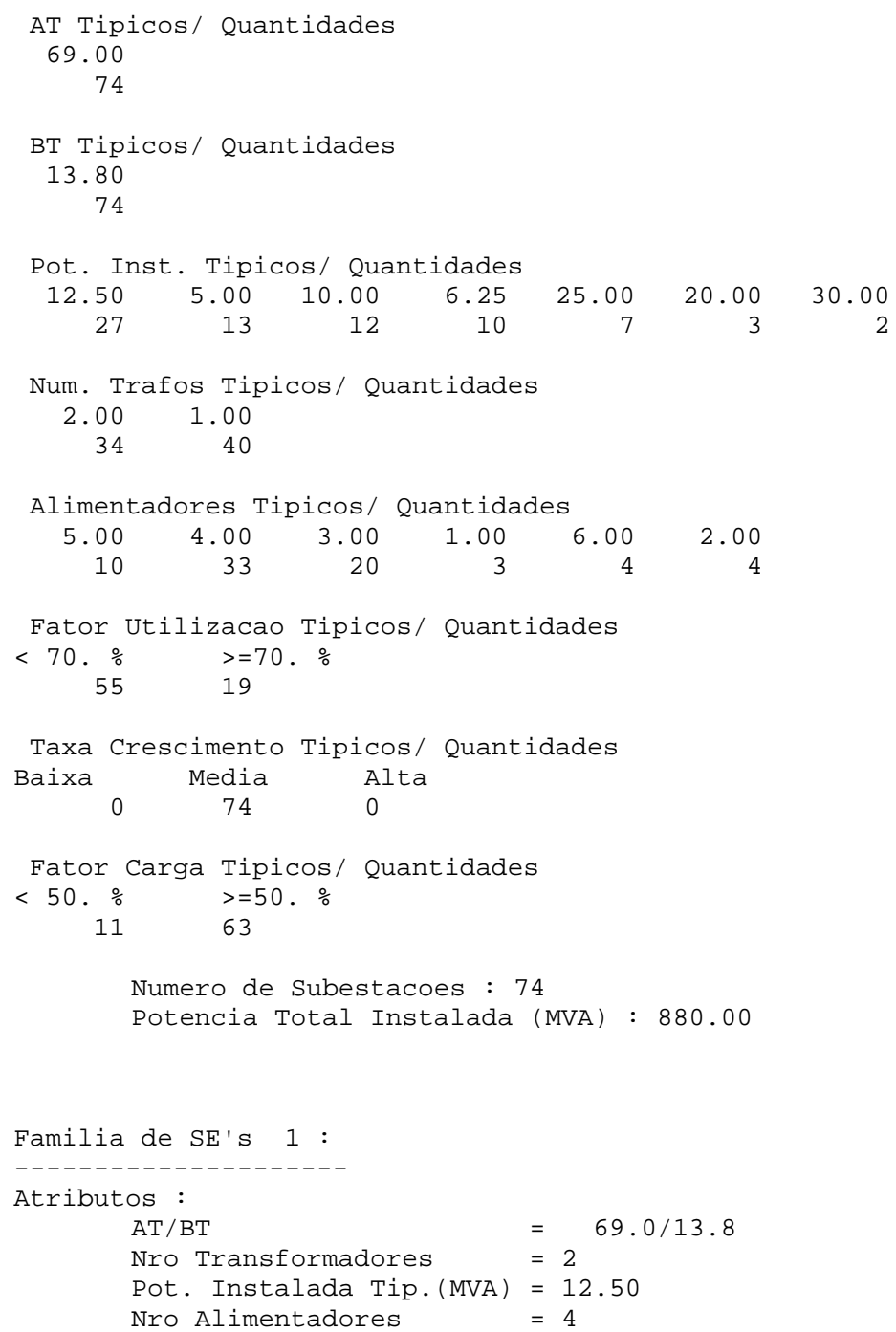




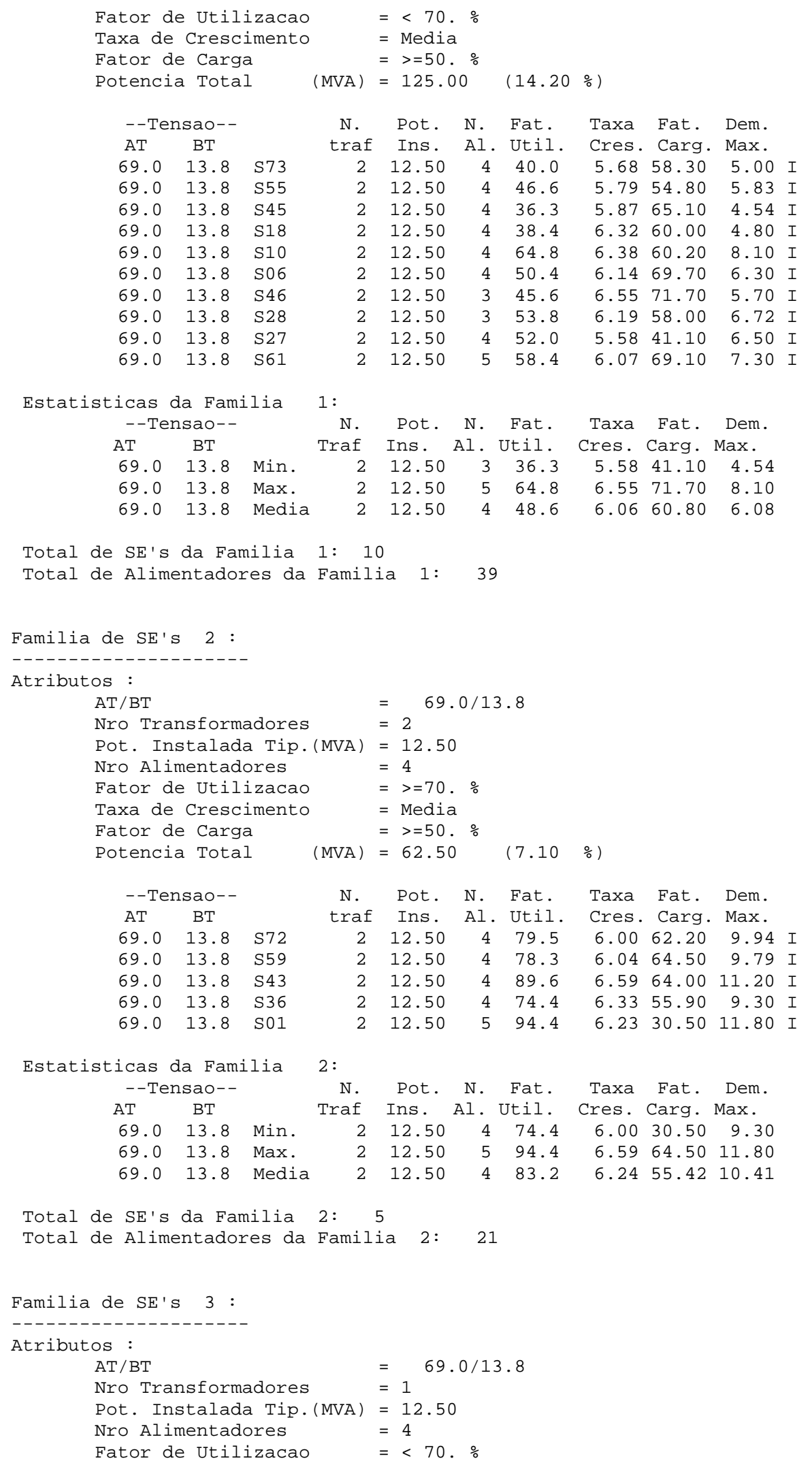




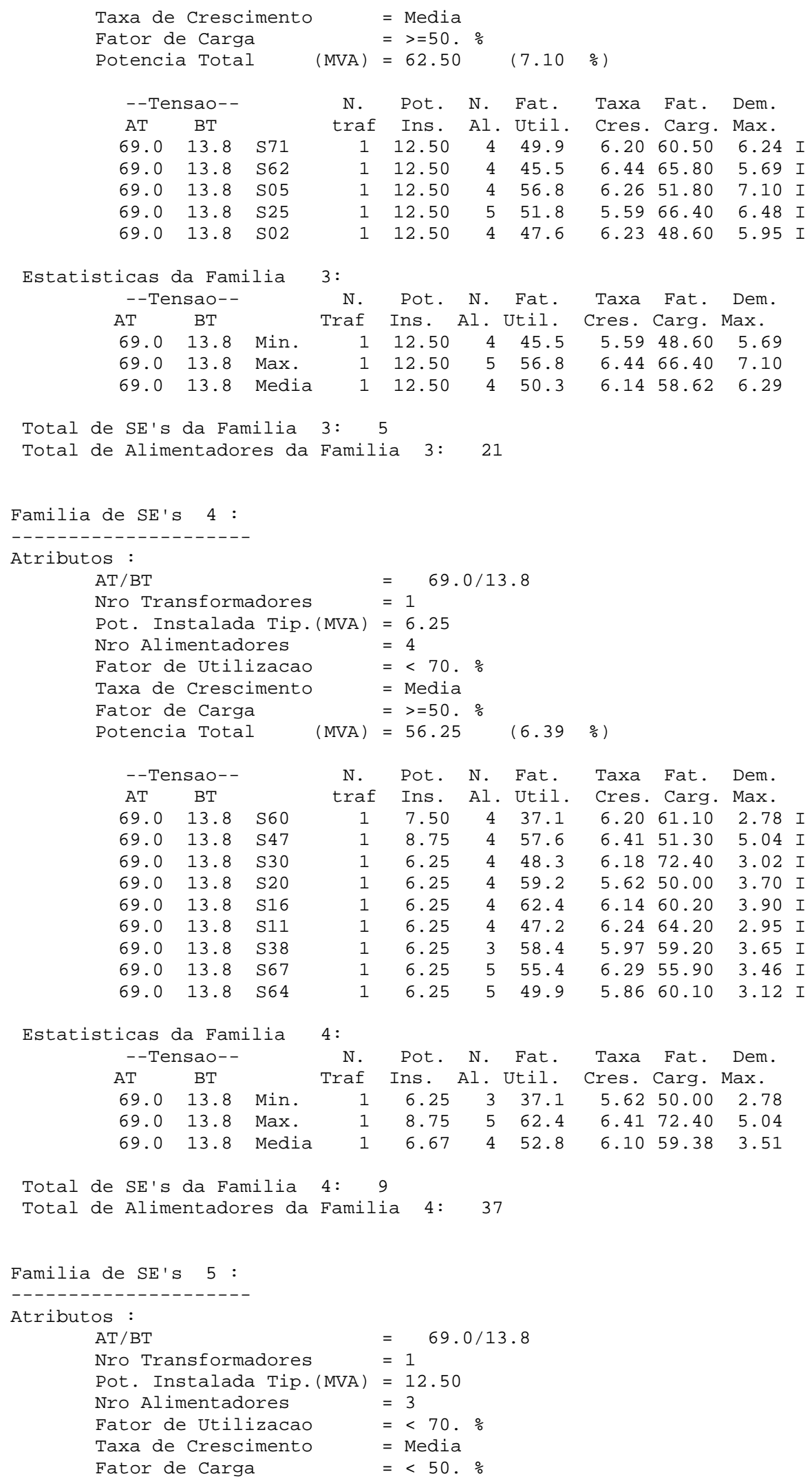




\begin{tabular}{|c|c|c|c|c|c|c|c|c|c|}
\hline Potenci & a Tota & & (MVA) & $=37.56$ & & $(4.26$ & $\%)$ & & \\
\hline - - Ter & 1sao- - & & $\mathrm{N}$. & Pot. & $\mathrm{N}$. & Fat. & Taxa & Fat. & Dem. \\
\hline AT & BT & & traf & Ins. & Al. & Util. & Cres. & Carg. & Max. \\
\hline 69.0 & 13.8 & S58 & 1 & 12.50 & 3 & 25.6 & 6.09 & 48.90 & 3.20 \\
\hline 69.0 & 13.8 & S53 & 1 & 12.50 & 3 & 51.8 & 5.92 & 44.10 & 6.48 \\
\hline 69.0 & 13.8 & S13 & 1 & 12.50 & 3 & 29.6 & 6.17 & 41.10 & 3.70 \\
\hline $\begin{array}{c}\text { statisticas } \\
--T e r\end{array}$ & $\begin{array}{l}\text { da Fam } \\
\text { hsao-- }\end{array}$ & lia & $5:$ N. & Pot. & N. & Fat. & Taxa & Fat. & Dem. \\
\hline AT & BT & & Traf & Ins. & Al. & Util. & Cres. & Carg. & Max. \\
\hline 69.0 & 13.8 & Min. & 1 & 12.50 & 3 & 25.6 & 5.92 & 41.10 & 3.20 \\
\hline 69.0 & 13.8 & $\operatorname{Max.}$ & 1 & 12.50 & 3 & 51.8 & 6.17 & 48.90 & 6.48 \\
\hline 69.0 & 13.8 & Medic & 1 & 12.50 & 3 & 35.7 & 6.06 & 44.70 & 4.46 \\
\hline
\end{tabular}

Total de SE's da Familia 5: 3

Total de Alimentadores da Familia 5: 9

Familia de SE's 6 :

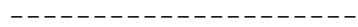

Atributos :

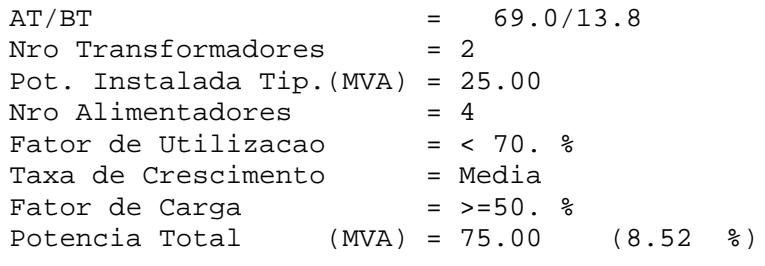

--Tensao-- N. Pot. N. Fat. Taxa Fat. Dem.

AT BT traf Ins. Al. Util. Cres. Carg. Max.

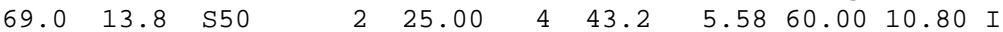

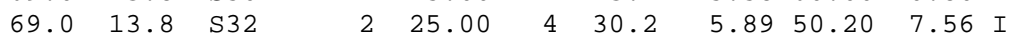

$\begin{array}{lllllllllll}69.0 & 13.8 & \mathrm{~S} 42 & 2 & 25.00 & 5 & 43.2 & 5.58 & 48.90 & 10.80 & \mathrm{I}\end{array}$

Estatisticas da Familia 6:

--Tensao-- N. Pot. N. Fat. Taxa Fat. Dem.

AT BT Traf Ins. Al. Util. Cres. Carg. Max.

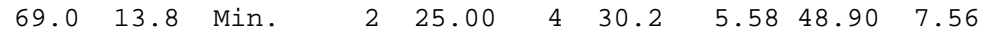

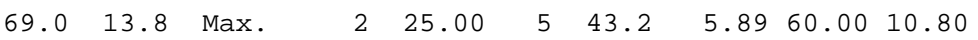

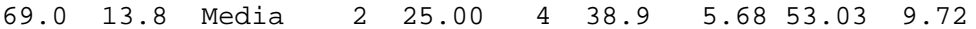

Total de SE's da Familia 6: 3

Total de Alimentadores da Familia 6: 13

Familia de SE's 7 :

- - - - . - . - . - . - . -

Atributos :

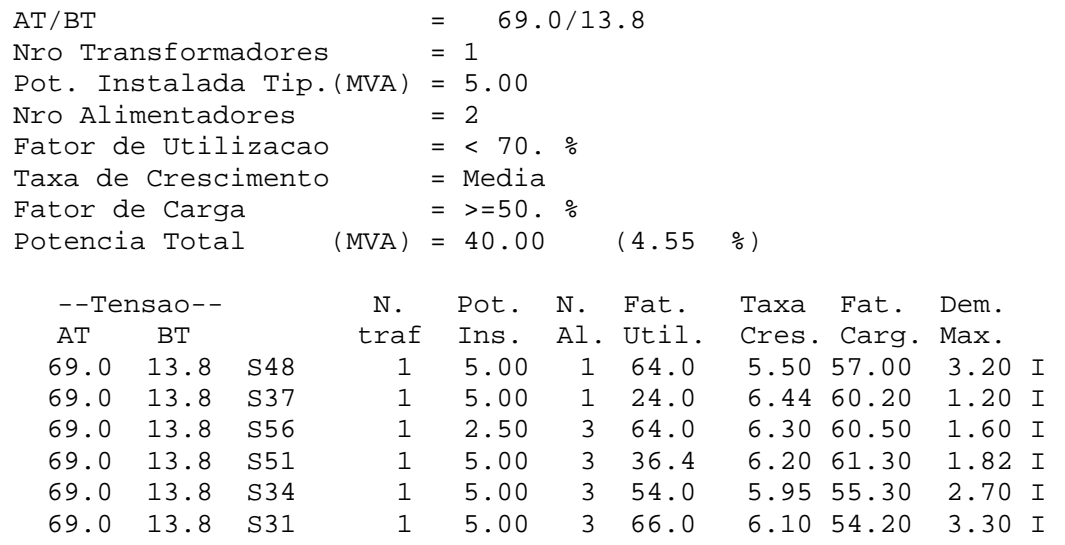




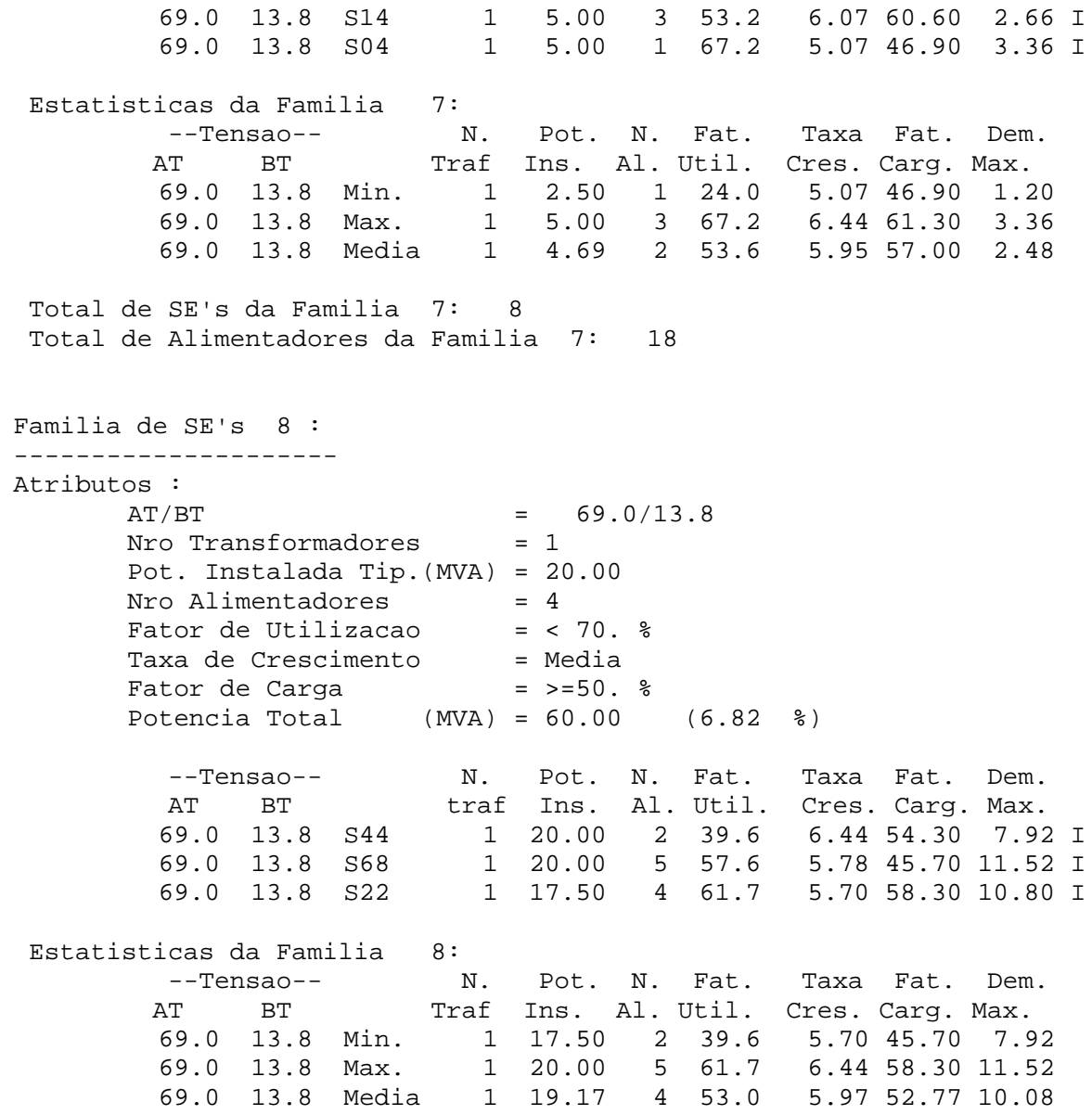




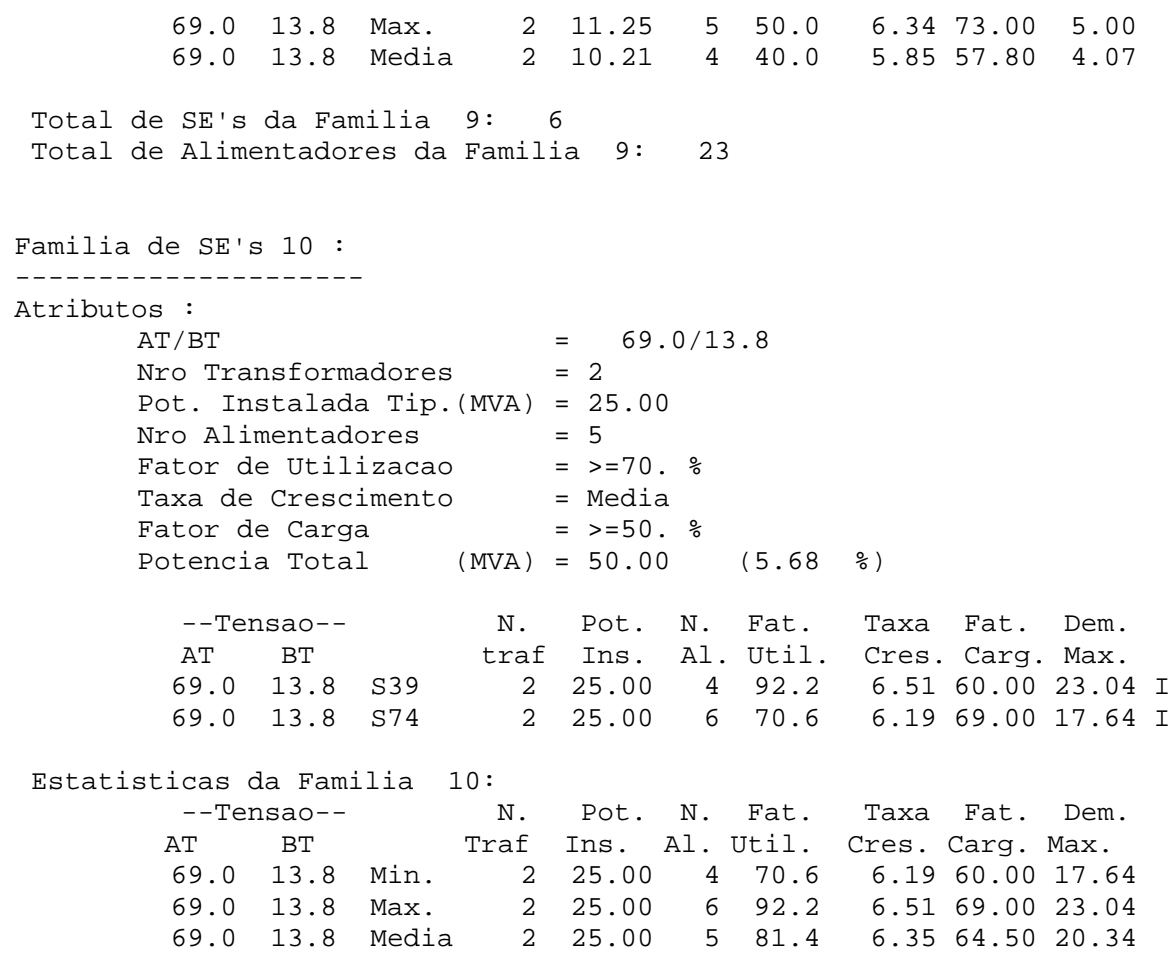




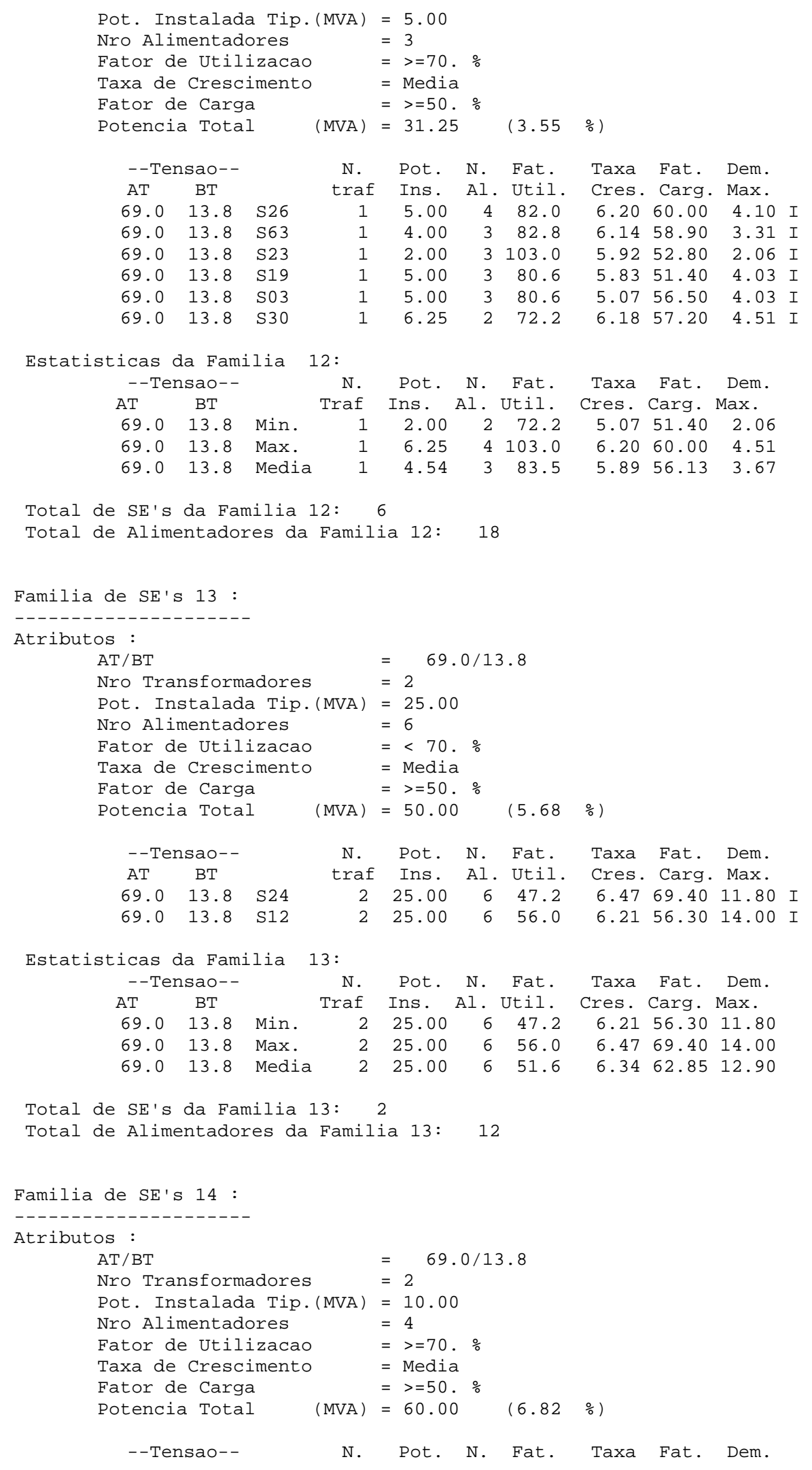




\begin{tabular}{|c|c|c|c|c|c|c|c|c|c|}
\hline AT & BT & & traf & Ins. & $\mathrm{Al}$. & Util. & Cres. & - Carg. & Max. \\
\hline 69.0 & 13.8 & S21 & 2 & $9 . \odot \odot$ & 6 & 72.8 & 6.16 & 62.50 & 6.55 \\
\hline 69.0 & 13.8 & S66 & 2 & 10.00 & 4 & $70 . \odot$ & 6.36 & 59.70 & $7 . \odot \odot$ \\
\hline 69.0 & 13.8 & S52 & 2 & 10.00 & 4 & 83.5 & 6.17 & 68.20 & 8.35 \\
\hline 69.0 & 13.8 & S17 & 2 & 10.00 & 4 & 72.0 & 7.42 & 54.70 & 7.20 \\
\hline 69.0 & 13.8 & S49 & 2 & 11.25 & 3 & 72.9 & 6.50 & 71.00 & 8.20 \\
\hline 69.0 & 13.8 & S65 & 2 & 11.25 & 5 & 88.4 & 6.08 & 57.90 & 9.94 \\
\hline $\begin{array}{r}\text { statisticas } \\
--\mathrm{Te}\end{array}$ & $\begin{array}{l}\text { da Fam } \\
\text { Isao-- }\end{array}$ & Lia & 14: $\mathrm{N}$. & Pot. & $\mathrm{N}$. & Fat. & Taxa & Fat. & Dem. \\
\hline AT & BT & & Traf & Ins. & $\mathrm{Al}$. & Util. & Cres. & Carg. & Max. \\
\hline 69.0 & 13.8 & Min. & 2 & $9.0 \odot$ & 3 & 70.0 & 6.08 & 54.70 & 6.55 \\
\hline 69.0 & 13.8 & Max. & 2 & 11.25 & 6 & 88.4 & 7.42 & 71.00 & 9.94 \\
\hline 69.0 & 13.8 & Media & 2 & 10.25 & 4 & 76.6 & 6.45 & 62.33 & 7.87 \\
\hline
\end{tabular}

Total de SE's da Familia 14: 6

Total de Alimentadores da Familia 14: 26

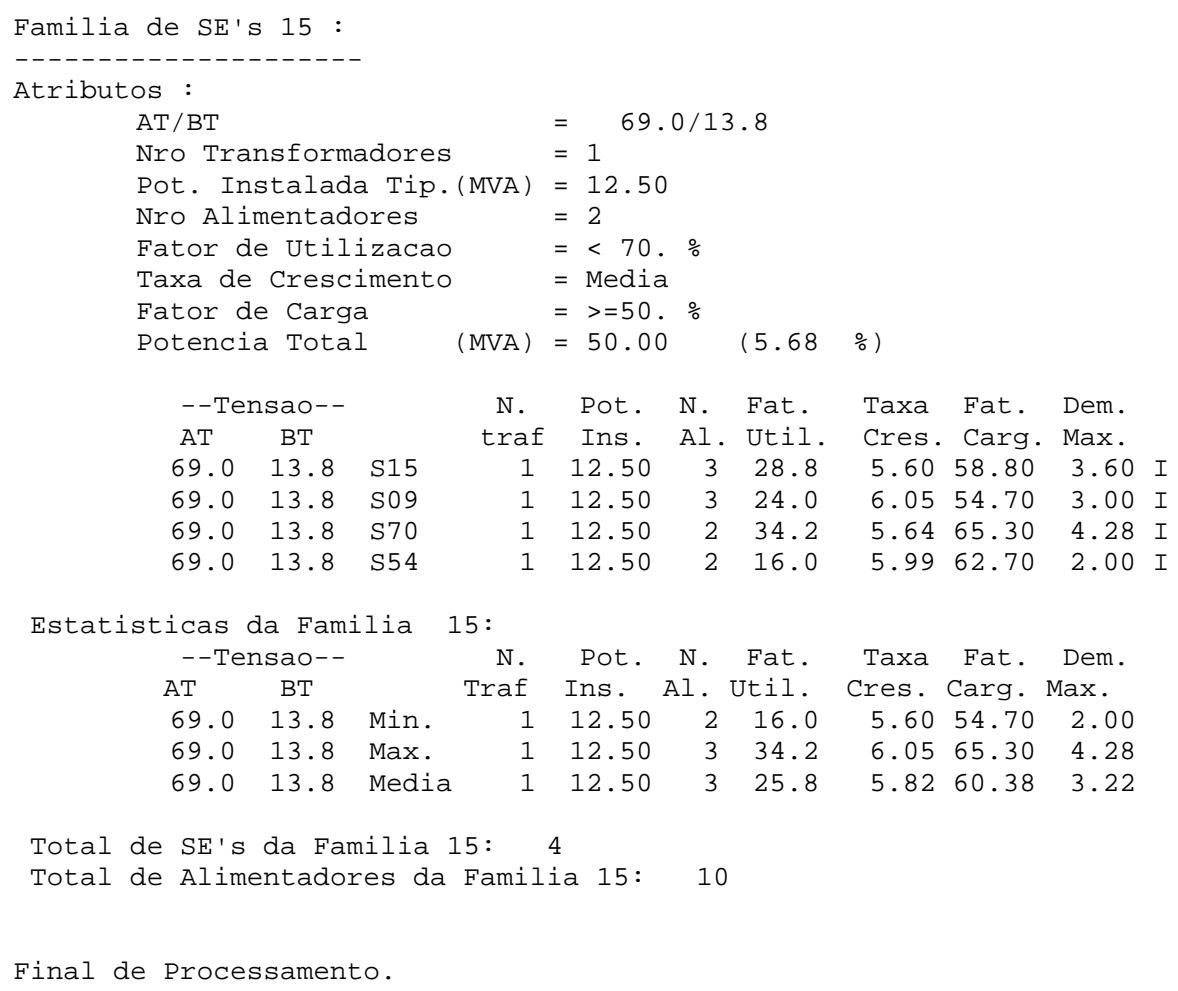




\section{ANEXO B RELATÓRIO DO CLUSTER DE ALIMENTADORES PARA O CASO TESTE DE APLICAÇÃO}

\begin{tabular}{|c|c|c|c|c|c|c|c|c|c|c|c|c|c|c|c|}
\hline SE|N & NAL & $\left|\begin{array}{c}\mathrm{Lt} \\
\mid(\mathrm{km})\end{array}\right|$ & $\mathrm{NP} \mid$ & ANG & $\begin{array}{c}\text { DEM|fC } \\
(\mathrm{MW})|(\%)|\end{array}$ & $\begin{array}{l}\mid \text { CRES } \mid \\
\mid\left(\begin{array}{c}\% \\
(\%)\end{array} \mid\right.\end{array}$ & COSFI & | CABOTRONCO & $0 \mid$ CABO & RAMAL & $\begin{array}{l}\text { DEM. } \mid \\
(M W) \mid\end{array}$ & $\begin{array}{l}\mathrm{km} \\
\text { TOTAL }\end{array}$ & $\begin{array}{l}\text { ANG. } \\
\text { TOTAL }\end{array}$ & $\begin{array}{l}\text { TRAF. } \\
\text { TOTAL }\end{array}$ & $\begin{array}{l}\text { |PTRAF. } \\
\text { I (kVA) }\end{array}$ \\
\hline $\begin{array}{l}1 \mid \\
1 \mid \\
1 \mid\end{array}$ & \begin{tabular}{l|l}
2 & \\
1 & \\
1 &
\end{tabular} & $\begin{array}{l}17 \mid \\
10 \mid \\
75 \mid\end{array}$ & $\begin{array}{r}44 \\
|47| \\
|163|\end{array} \mid$ & $\begin{array}{l}31 \mid \\
28 \mid \\
67 \mid\end{array}$ & $\mid$\begin{tabular}{l|}
$1.2|65|$. \\
$3.2|66|$. \\
$2.6|70|$.
\end{tabular} & $\left|\begin{array}{l}5.4 \\
4.8 \mid \\
6.1\end{array}\right|$ & $\begin{array}{l}.92 \\
.91 \\
.91\end{array}$ & $\begin{array}{l}\mid 10 \mathrm{~L} \\
10 \mathrm{R} \\
\mid 10 \mathrm{~L}\end{array}$ & $\begin{array}{l}\mid \odot 4 L \\
\mid \odot 4 R \\
\mid \Theta 4 L\end{array}$ & & $6.1 \mid$ & 119 & 157 & 298 & 20.4 \\
\hline $\begin{array}{l}2 \mid \\
2 \mid \\
2 \mid\end{array}$ & \begin{tabular}{l|l}
1 & \\
2 & \\
1 &
\end{tabular} & $\begin{array}{r}70 \mid \\
9 \mid \\
38 \mid\end{array}$ & \begin{tabular}{|}
$\left|\begin{array}{r}149 \\
70 \mid \\
\mid 78\end{array}\right|$ \\
$58 \mid$
\end{tabular} & $\begin{array}{l}40 \mid \\
48 \mid \\
43 \mid\end{array}$ & $\begin{array}{r}3.4|61 .| \\
2.7|51 .| \\
.9|58 .|\end{array}$ & $\mid \begin{array}{l}6.3 \mid \\
6.2 \mid \\
6.2 \mid\end{array}$ & $\begin{array}{l}.92 \\
.91 \\
.88\end{array}$ & $\begin{array}{l}\mid 10 \mathrm{~L} \\
\mid 10 \mathrm{R} \\
\mid 10 \mathrm{~L}\end{array}$ & $\begin{array}{l}\mid \odot 4 L \\
\mid \Theta 4 R \\
\mid \odot 4 L\end{array}$ & & 10.4 & 126 & 179 & 347 & 30.0 \\
\hline $\begin{array}{l}31 \\
31\end{array}$ & \begin{tabular}{l|l}
1 & \\
3 &
\end{tabular} & $\begin{array}{l}97 \mid \\
17 \mid\end{array}$ & $\mid \begin{array}{r}139 \mid \\
58 \mid\end{array}$ & $\begin{array}{l}95 \\
19\end{array}$ & $\mid \begin{array}{l}1.4|60 .| \\
1.3|62 .|\end{array}$ & $\mid \begin{array}{l}6.3 \mid \\
5.3 \mid\end{array}$ & $\begin{array}{l}.92 \\
.92\end{array}$ & $\begin{array}{l}10 \mathrm{~L} \\
10 \mathrm{~L}\end{array}$ & $\begin{array}{l}\mid \Theta 4 L \\
\mid \Theta 4 L\end{array}$ & & 5.81 & 148 & 152 & 313 & 18.4 \\
\hline $\begin{array}{l}4 \mid \\
4 \mid \\
4 \mid\end{array}$ & \begin{tabular}{l|l}
2 & \\
1 & \\
1 & $\mid$
\end{tabular} & $\begin{array}{r}8 \mid \\
70 \mid \\
31 \mid\end{array}$ & $\left|\begin{array}{r}34 \\
118 \mid \\
|\quad 49|\end{array}\right|$ & $\begin{array}{l}34 \mid \\
35 \mid \\
42 \mid\end{array}$ & $\mid \begin{array}{r}1.1|64 .| \\
1.3|66 .| \\
.4|64 .|\end{array}$ & $\mid \begin{array}{l}5.4 \mid \\
6.2 \mid \\
5.5 \mid\end{array}$ & $\begin{array}{l}.91 \\
.92 \\
.90\end{array}$ & $\begin{array}{l}\mid 10 \mathrm{R} \\
\mid 10 \mathrm{~L} \\
\mid 04 \mathrm{~L}\end{array}$ & $\begin{array}{l}\mid \odot 4 R \\
\mid \Theta 4 L \\
\mid \Theta 4 L\end{array}$ & & 3.31 & 117 & 145 & 235 & 14.1 \\
\hline $\begin{array}{l}5 \mid \\
5\end{array}$ & \begin{tabular}{l|l}
1 & \\
2 &
\end{tabular} & $\begin{array}{l}40 \mid \\
13\end{array}$ & $\left|\begin{array}{l}95 \\
50 \mid\end{array}\right|$ & $\begin{array}{l}83 \mid \\
32 \mid\end{array}$ & $\mid \begin{array}{l}.6|48 .| \\
2.0|48 .|\end{array}$ & $\left|\begin{array}{l}6.1 \\
6.0 \mid\end{array}\right|$ & $\begin{array}{l}.88 \\
.87\end{array}$ & $\begin{array}{l}\mid 10 \mathrm{~L} \\
\mid 40 \mathrm{R}\end{array}$ & $\begin{array}{l}\mid 04 \mathrm{~L} \\
\mid 04 \mathrm{R}\end{array}$ & & 4.51 & 66 & 147 & 195 & 22.9 \\
\hline $\begin{array}{l}6 \mid \\
6 \mid \\
6 \mid \\
6 \mid\end{array}$ & \begin{tabular}{l|l}
1 & \\
1 & \\
1 & \\
1 &
\end{tabular} & $\begin{array}{r}7 \mid \\
15 \mid \\
53 \mid \\
30 \mid\end{array}$ & $\begin{array}{r}43 \\
63 \mid \\
63 \mid \\
146 \mid \\
|44|\end{array} \mid$ & $\begin{array}{l}16 \mid \\
30 \mid \\
36 \mid \\
48 \mid\end{array}$ & $\begin{array}{l}2.4|63 .| \\
3.8|74 .| \\
2.7|49 .| \\
1.8|68 .|\end{array}$ & $\mid \begin{array}{l}5.8 \mid \\
5.7 \mid \\
5.6 \mid \\
5.7 \mid\end{array}$ & $\begin{array}{l}.92 \\
.92 \\
.92 \\
.92\end{array}$ & $\begin{array}{l}\mid 40 \mathrm{R} \\
\mid 40 \mathrm{R} \\
\mid 10 \mathrm{~L} \\
\mid 40 \mathrm{~L}\end{array}$ & $\begin{array}{l}\mid \Theta 4 R \\
\mid \Theta 4 R \\
\mid \Theta 4 L \\
\mid \Theta 4 L\end{array}$ & i & 9.71 & 105 & 130 & 296 & 32.8 \\
\hline $\begin{array}{l}7 \mid \\
7 \mid\end{array}$ & \begin{tabular}{l|l}
1 & \\
1 & $\mid$
\end{tabular} & $\begin{array}{l}97 \mid \\
26 \mid\end{array}$ & \begin{tabular}{|}
$|143|$ \\
$|41|$
\end{tabular} & $\begin{array}{l}71 \mid \\
26 \mid\end{array}$ & $\begin{array}{r}2.0|59 .| \\
.7|62 .|\end{array}$ & $\mid \begin{array}{l}6.0 \mid \\
6.1 \mid\end{array}$ & $\begin{array}{l}.90 \\
.90\end{array}$ & $\begin{array}{l}\mid 10 \mathrm{~L} \\
110 \mathrm{~L}\end{array}$ & $\begin{array}{l}\mid \Theta 4 L \\
\mid \Theta 4 L\end{array}$ & & $2.7 \mid$ & 123 & 97 & & 14.6 \\
\hline $\begin{array}{l}81 \\
81\end{array}$ & \begin{tabular}{l|l}
1 & \\
3 &
\end{tabular} & $\begin{array}{l}43 \mid \\
18\end{array}$ & \begin{tabular}{|}
$\left|\begin{array}{r}171 \\
\mid \\
55\end{array}\right|$
\end{tabular} & $\begin{array}{l}51 \mid \\
26 \mid\end{array}$ & $\mid \begin{array}{l}2.5|68 .| \\
2.6|63 .|\end{array}$ & $\left|\begin{array}{l}5.8 \mid \\
5.9\end{array}\right|$ & $\begin{array}{l}.92 \\
.90\end{array}$ & $\begin{array}{l}10 \mathrm{~L} \\
\mid 40 \mathrm{~L}\end{array}$ & $\begin{array}{l}\mid 04 \mathrm{~L} \\
\mid \odot 4 \mathrm{~L}\end{array}$ & & $10.6 \mid$ & 97 & 129 & 336 & 31.5 \\
\hline $\begin{array}{l}9 \mid \\
9 \mid \\
9 \mid\end{array}$ & \begin{tabular}{l|l}
2 & \\
1 & \\
1 &
\end{tabular} & $\begin{array}{l}16 \mid \\
23 \mid \\
53 \mid\end{array}$ & $\left|\begin{array}{l}30 \\
92 \\
96 \\
56\end{array}\right|$ & $\begin{array}{l}42 \mid \\
49 \mid \\
44 \mid\end{array}$ & $\begin{array}{l}1.3|62 .| \\
3.1|56 .| \\
1.1|55 .|\end{array}$ & $\mid \begin{array}{l}5.8 \mid \\
5.2 \mid \\
6.1 \mid\end{array}$ & $\begin{array}{l}.92 \\
.92 \\
.92\end{array}$ & $\begin{array}{l}\mid 10 \mathrm{~L} \\
\mid 10 \mathrm{~L} \\
10 \mathrm{~L}\end{array}$ & $\begin{array}{l}\mid \odot 4 \mathrm{~L} \\
\mid \Theta 4 \mathrm{~L} \\
\mid \odot 4 \mathrm{~L}\end{array}$ & & 4.01 & 108 & 177 & 208 & 19.2 \\
\hline $\begin{array}{l}10 \mid \\
10 \mid \\
10 \mid \\
10 \mid \\
10 \mid\end{array}$ & \begin{tabular}{l|l}
1 & \\
1 & \\
1 & \\
1 & \\
1 &
\end{tabular} & $\begin{array}{l}15 \mid \\
11 \mid \\
59 \mid \\
14 \mid \\
38\end{array}$ & $\begin{array}{r}83 \mid \\
|43| \\
160 \mid \\
114 \mid \\
|110|\end{array} \mid$ & $\begin{array}{l}65 \mid \\
18 \mid \\
85 \mid \\
50 \mid \\
65 \mid\end{array}$ & $\begin{array}{l}5.6|65 .| \\
1.6|65 .| \\
2.2|69 .| \\
7.4|60 .| \\
4.0|69 .|\end{array}$ & $\mid \begin{array}{l}6.4 \mid \\
6.3 \mid \\
6.2 \mid \\
6.5 \mid \\
6.2 \mid\end{array}$ & $\begin{array}{l}.92 \\
.92 \\
.92 \\
.92 \\
.92\end{array}$ & $\begin{array}{l}\mid 40 \mathrm{~L} \\
\mid 40 \mathrm{R} \\
\mid 20 \mathrm{~L} \\
\mid 40 \mathrm{~L} \\
\mid 40 \mathrm{~L}\end{array}$ & $\begin{array}{l}\mid \Theta 4 L \\
\mid \Theta 4 R \\
\mid \Theta 4 L \\
\mid \Theta 4 L \\
\mid \odot 4 L\end{array}$ & & $20.3 \mid$ & 137 & 283 & 430 & 47.3 \\
\hline $\begin{array}{l}11 \mid \\
11 \mid\end{array}$ & \begin{tabular}{l|l}
3 & \\
1 &
\end{tabular} & $\begin{array}{l}22 \mid \\
17 \mid\end{array}$ & $\left|\begin{array}{l}76 \\
\mid 73\end{array}\right|$ & $\begin{array}{l}381 \\
35 \mid\end{array}$ & $\mid \begin{array}{l}2.1|60 .| \\
6.0|60 .|\end{array}$ & $\mid \begin{array}{l}5.6 \mid \\
5.6 \mid\end{array}$ & $\begin{array}{l}.91 \\
.90\end{array}$ & $\begin{array}{l}10 \mathrm{~L} \\
\mid 40 \mathrm{~L}\end{array}$ & $\begin{array}{l}\mid \Theta 4 L \\
\mid 04 R\end{array}$ & & 9.4 & 83 & 149 & 301 & 31.1 \\
\hline $\begin{array}{l}12 \mid \\
12 \mid\end{array}$ & \begin{tabular}{l|l}
1 & \\
2 &
\end{tabular} & $\left|\begin{array}{r}108 \\
19\end{array}\right|$ & \begin{tabular}{|}
$|178|$ \\
$|70|$
\end{tabular} & $\begin{array}{l}70 \mid \\
38 \mid\end{array}$ & $\begin{array}{r}1.8|59 .| \\
.9|58 .|\end{array}$ & $\mid \begin{array}{l}5.7 \mid \\
6.0 \mid\end{array}$ & $\begin{array}{l}.90 \\
.89\end{array}$ & $\begin{array}{l}\mid 10 L \\
10 R\end{array}$ & $\begin{array}{l}\mid \Theta 4 L \\
\mid 04 R\end{array}$ & & $4.1 \mid$ & 146 & 146 & 318 & 12.7 \\
\hline $\begin{array}{l}13 \mid \\
13 \mid \\
13 \mid \\
13 \mid \\
13 \mid \\
13 \mid\end{array}$ & \begin{tabular}{l|l}
1 & \\
1 & \\
1 & \\
1 & \\
1 & \\
1 &
\end{tabular} & \begin{tabular}{r|}
$4 \mid$ \\
$44 \mid$ \\
$3 \mid$ \\
$23 \mid$ \\
$2 \mid$ \\
$10 \mid$
\end{tabular} & $\left|\begin{array}{r}10 \\
143 \mid \\
|80| \\
41 \mid \\
4 \mid \\
40 \mid \\
50 \mid\end{array}\right|$ & $\begin{array}{l}10 \mid \\
65 \mid \\
30 \mid \\
33 \mid \\
15 \mid \\
30 \mid\end{array}$ & $\begin{array}{l}2.5|77 .| \\
2.4|63 .| \\
3.7|77 .| \\
1.2|70 .| \\
2.4|56 .| \\
1.8|63 .|\end{array}$ & $\begin{array}{r}.0 \mid \\
6.3 \mid \\
6.5 \mid \\
6.4 \mid \\
.0 \mid \\
6.3 \mid\end{array}$ & $\begin{array}{l}.92 \\
.84 \\
.92 \\
.88 \\
.80 \\
.84\end{array}$ & $\begin{array}{l}\mid 10 R \\
\mid 10 L \\
10 R \\
10 L \\
10 R \\
10 R \\
10 L\end{array}$ & $\begin{array}{l}\mid \Theta 4 R \\
\mid \Theta 4 L \\
\mid \Theta 4 R \\
\mid \Theta 4 L \\
\mid \Theta 4 R \\
\mid \Theta 4 L\end{array}$ & & 12.9 & 86 & 183 & 328 & 39.3 \\
\hline $\begin{array}{l}14 \mid \\
14 \mid \\
14 \mid\end{array}$ & \begin{tabular}{l|l}
2 & \\
1 & \\
1 &
\end{tabular} & $\begin{array}{r}29 \mid \\
8 \mid \\
86 \mid\end{array}$ & 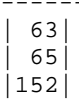 & $\begin{array}{l}47 \mid \\
38 \mid \\
82 \mid\end{array}$ & $\mid$\begin{tabular}{l|}
$1.3|62|$. \\
$2.6|71|$. \\
$1.7|68|$.
\end{tabular} & $\begin{array}{l}6.6 \mid \\
6.3 \mid \\
6.1 \mid\end{array}$ & $\begin{array}{l}.92 \\
.92 \\
.92\end{array}$ & $\begin{array}{l}\mid 10 \mathrm{~L} \\
\mid 10 \mathrm{R} \\
\mid 10 \mathrm{~L}\end{array}$ & $\begin{array}{l}\mid \odot 4 L \\
\mid \odot 4 R \\
\mid \odot 4 L\end{array}$ & & 7.51 & 152 & 214 & 343 & 21.9 \\
\hline $\begin{array}{l}15 \\
15\end{array}$ & \begin{tabular}{l|l}
1 & \\
1 &
\end{tabular} & $\begin{array}{r}20 \mid \\
4 \mid\end{array}$ & $\left|\begin{array}{l}42 \\
\mid \\
46\end{array}\right|$ & $\begin{array}{l}38 \mid \\
38 \mid\end{array}$ & $\begin{array}{r}.5|68 .| \\
2.7|66 .|\end{array}$ & $\begin{array}{l}4.7 \mid \\
5.8 \mid\end{array}$ & $\begin{array}{l}.84 \\
.88\end{array}$ & $\begin{array}{l}10 L \\
\mid 40 R\end{array}$ & $\begin{array}{l}\mid \Theta 4 L \\
\mid 04 R\end{array}$ & & 3.21 & 24 & 76 & 88 & 36.6 \\
\hline
\end{tabular}




\title{
ANEXO C RELATÓRIO DE LEIS ESTATÍSTICAS PARA O CASO TESTE DE APLICAÇÃO
}

\author{
$A L F A=0$ \\ LEI NUMERO 1 - Ltotal \\ $\mathrm{LT}=0.8880 * \mathrm{ND} \wedge \odot .0260 * \mathrm{NP} \wedge \odot .4744 * \mathrm{ZD} \wedge \odot .50 \odot \quad \mathrm{km}$ \\ Correlacao $=99.94$

|
LEI NUMERO 2 Lt \\ LTRONCO $=0.4988 * \mathrm{ND}^{\wedge} 0.5165 * \mathrm{NP} \wedge \odot .0078 * \mathrm{ZD}^{\wedge} 0.500 \mathrm{~km}$ \\ Correlacao $=98.24$ \\ LEI NUMERO 3 - Momento de queda de tensao \\ Para cabos: tronco - 40R ramal - $04 \mathrm{R}$ \\ $\mathrm{MV}=4.1912 * \mathrm{ND}^{\wedge}-0.2747 * \mathrm{NP} \wedge 0.4755 \mathrm{MW}^{*} \mathrm{~km} /($ porc. $)$ \\ Correlacao $=99.79$ \\ Para cabos: tronco - 10R ramal - $04 \mathrm{R}$ \\ $\mathrm{MV}=3.4571 * \mathrm{ND}^{\wedge}-0.3832 * \mathrm{NP} \wedge 0.4808 \quad \mathrm{MW}^{*} \mathrm{~km} /($ porc $)$ \\ Correlacao $=99.60$

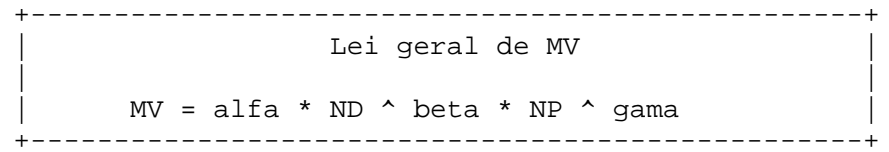 \\ onde \\ alfa $=12.7799 *(Z r+Z r)^{\wedge}-1.4267$ \\ beta $=-0.6187 *(Z t / Z r)^{\wedge} 0.7109$ \\ gama $=0.4781$ \\ $Z t=R t * \cos F I+X t * \operatorname{senFI}$ \\ $\mathrm{Zr}=\mathrm{Rr} * \cos F \mathrm{I}+\mathrm{Xr} * \operatorname{senFI}$ \\ I LEI NUMERO 4 - Momento de perdas \\ Para cabos: tronco - 40R ramal - $\odot 4 R$ \\ $\mathrm{MP}=0.7030 * \mathrm{ND} \wedge-0.2838 * \mathrm{NP} \wedge 0.4815 \quad \mathrm{MW} \wedge 2 * \mathrm{~km} / \mathrm{kW}$ \\ Correlacao $=99.76$ \\ Para cabos: tronco - $10 \mathrm{R}$ ramal - $04 \mathrm{R}$ \\ $\mathrm{MP}=0.5274 * \mathrm{ND}^{\wedge}-0.4180 * \mathrm{NP}^{\wedge} \odot .4845 \quad \mathrm{MW}^{\wedge} 2 * \mathrm{~km} / \mathrm{kW}$ \\ Correlacao $=99.67$
}




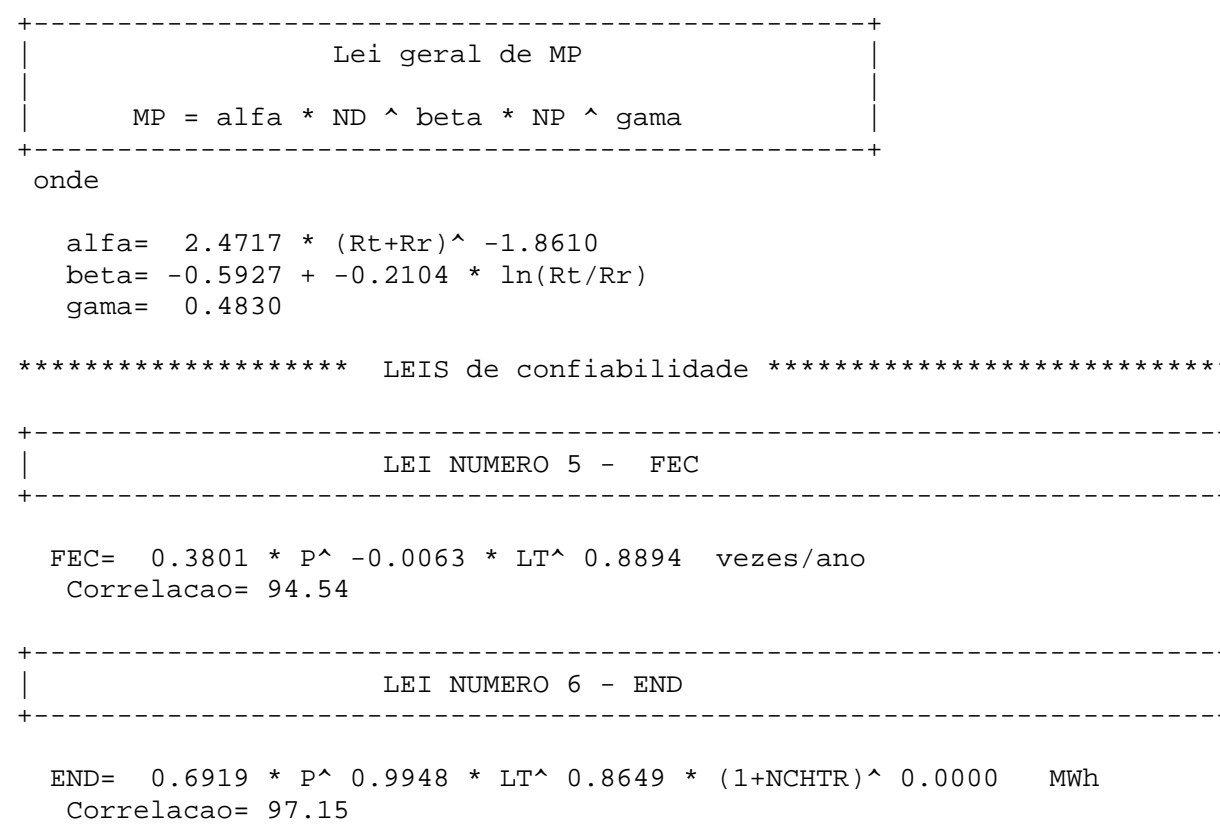

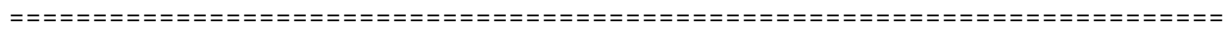
ニニニニニニニニニニニニニニニニニニニニニニニニニニニニニニニニニニニニニニニニニニニニニニニニニニニニニニニニニニニニニニニニニニニニニニニニニ

\section{$A L F A=2$}

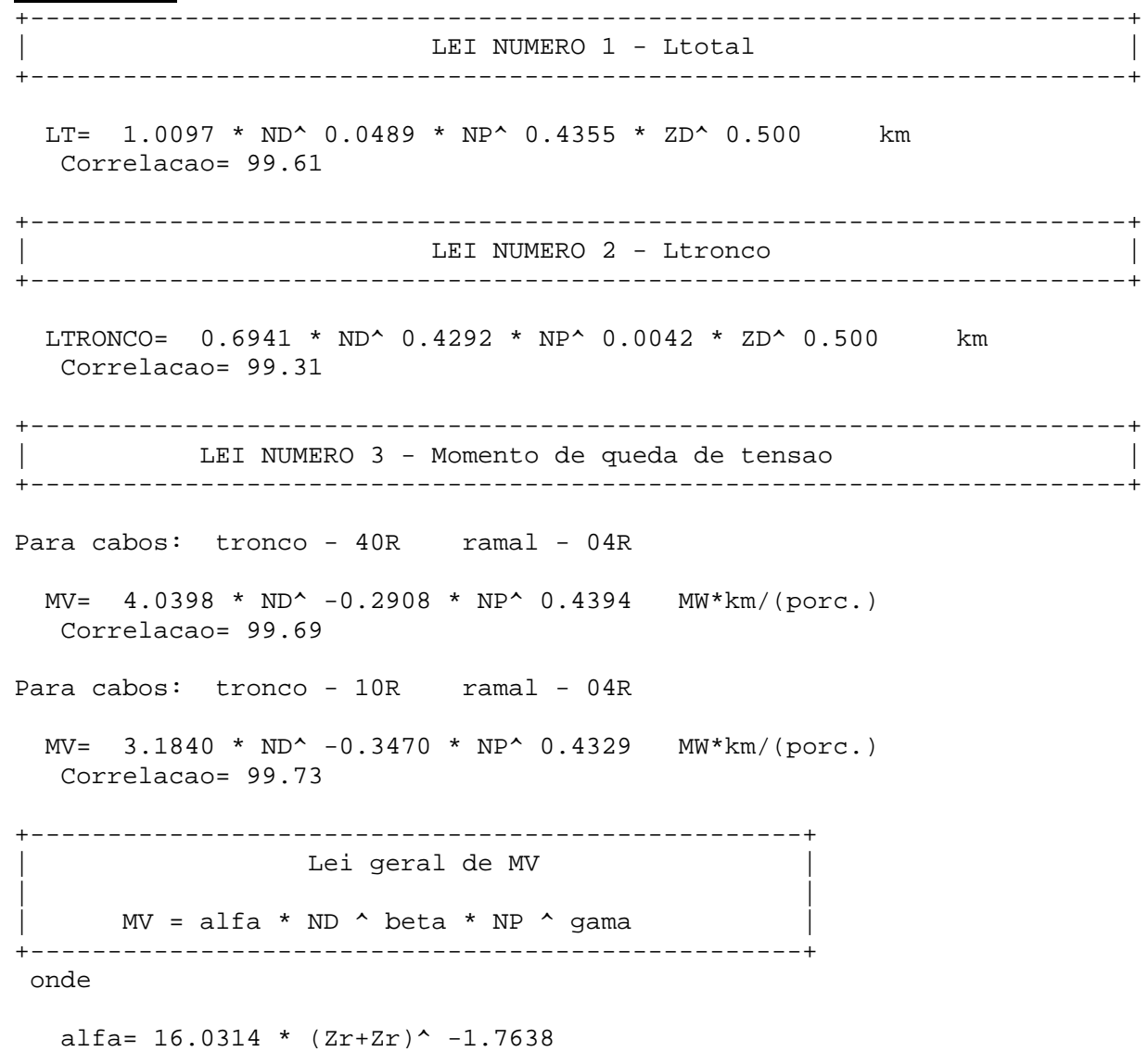




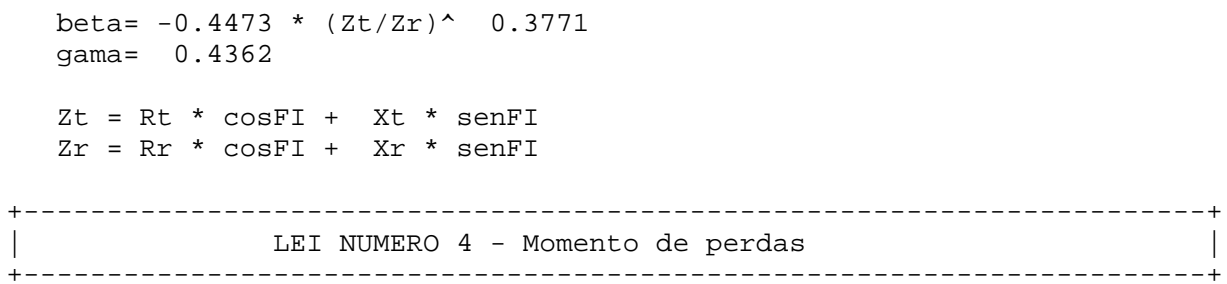

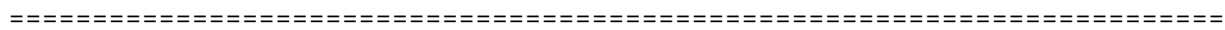

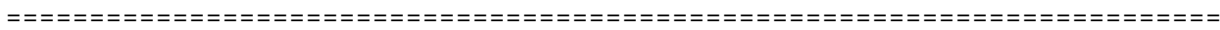
$A L F A=4$

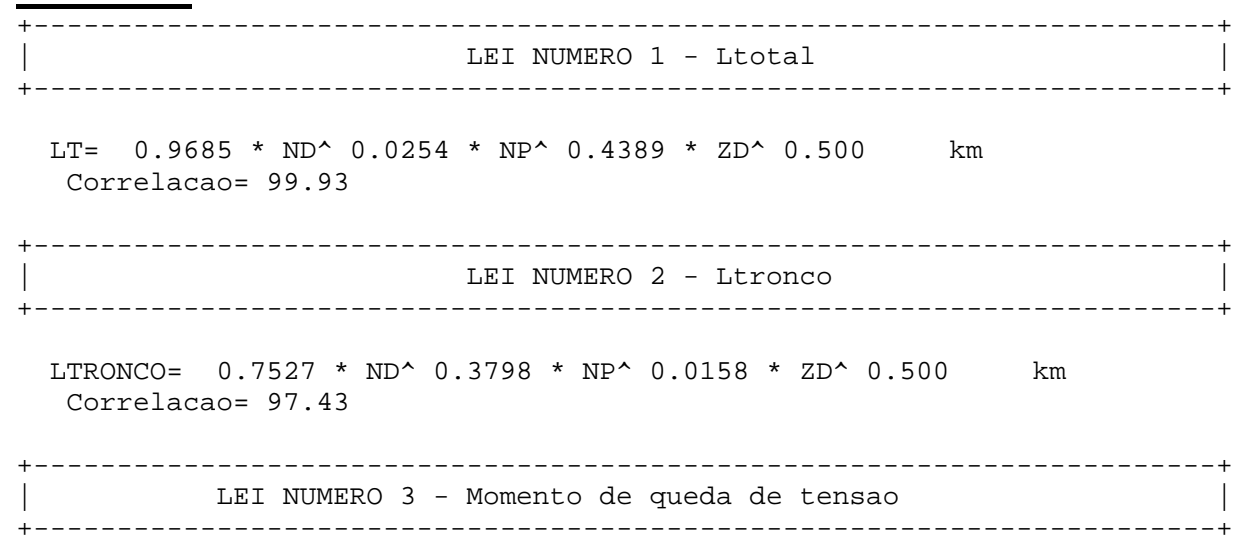




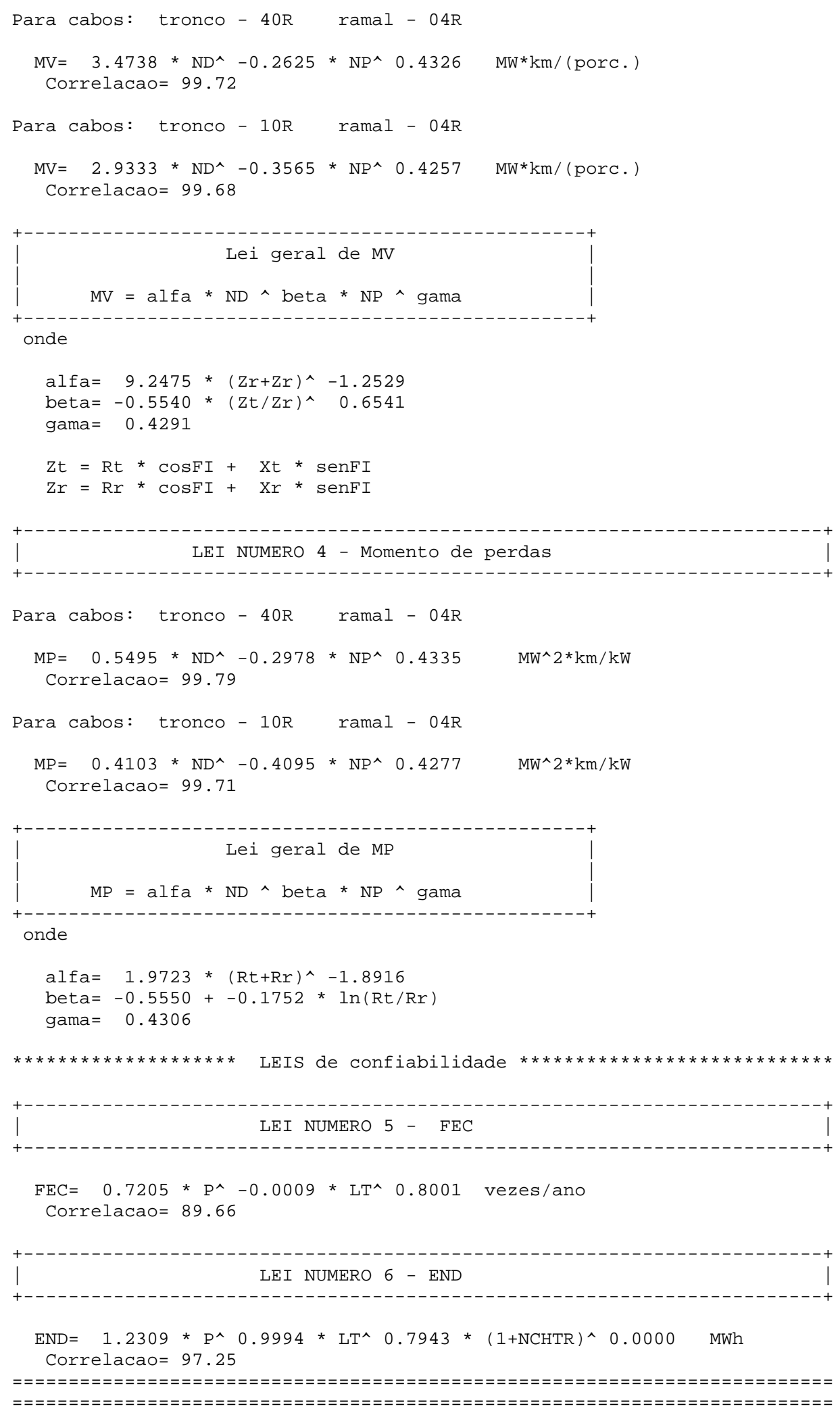




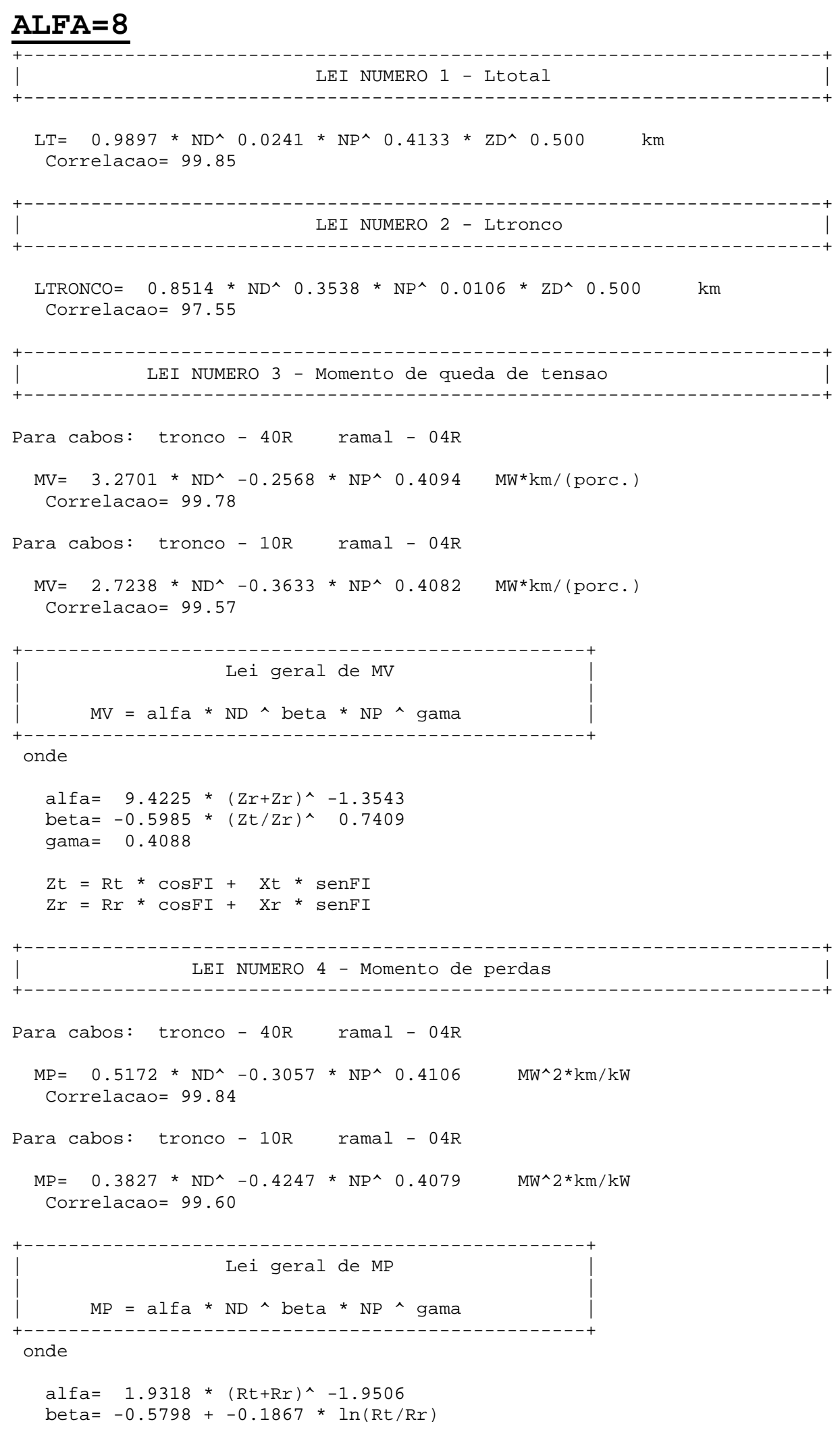




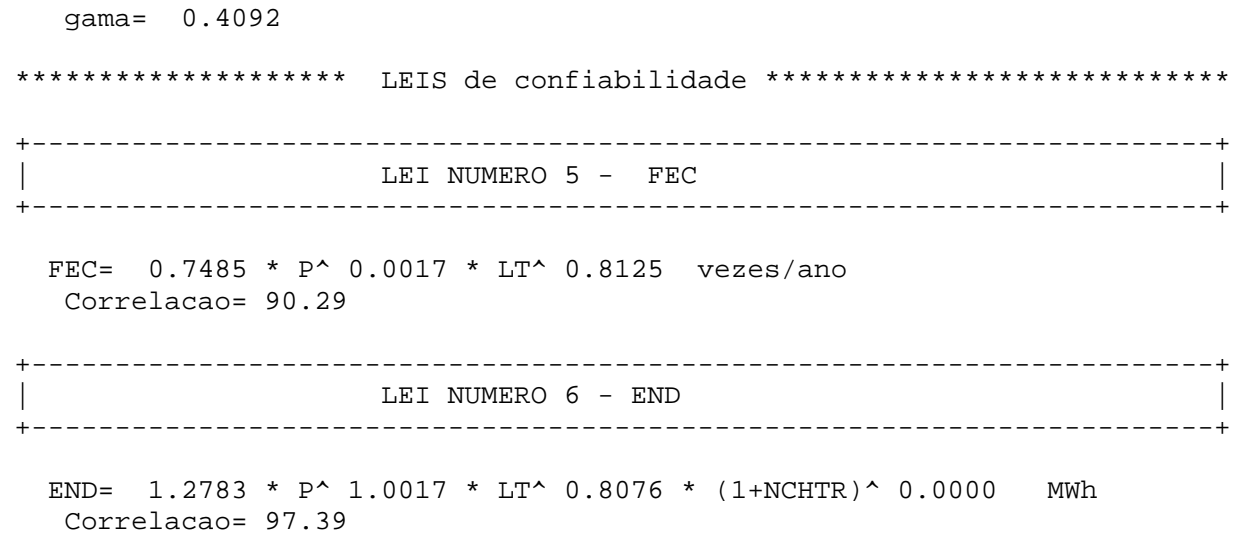




\section{ANEXO D \\ RELATÓRIO GERAL PARA O CASO TESTE DE APLICAÇÃO}

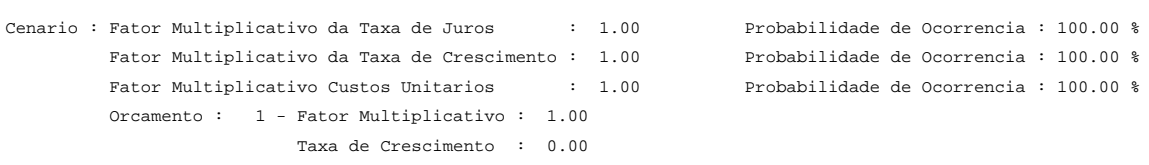

Custo Inv.

Custo Amor

(mil US\$)

Custo Amor. Benef.Total (Perdas END

DV) TRI Tipo N.Redes (mil US\$/ano) (mil US\$/ano) ( mil US\$/ano

da Fam.

$\begin{array}{rr}50.00 & 6.37 \\ 76.24 & 9.72 \\ 104.62 & 13.34\end{array}$

605.64

190.89

87.07
41.50

$\begin{array}{ll}( & 0 \\ ( & 34 \\ ( & 22 \\ 1 & 21\end{array}$

0
9
6
12

$\begin{array}{rr}605 \text { ) } & 95.00 \\ 146) & 19.64 \\ 57) & 6.53 \\ 7 & 1.71\end{array}$

NEC.

24.28

.71 NEC 


\begin{tabular}{|c|c|c|c|c|c|c|c|c|c|c|c|c|c|}
\hline \multirow[t]{2}{*}{ Ano } & \multirow[t]{2}{*}{ Familia } & \multirow[t]{2}{*}{ N.obr } & \multirow[t]{2}{*}{ Tipo } & \multirow{2}{*}{$\begin{array}{l}\text { Custo Inv. } \\
\text { (mil US\$) }\end{array}$} & \multirow{2}{*}{$\begin{array}{l}\text { Custo Amor. } \\
\text { (mil US\$/ano) }\end{array}$} & \multirow{2}{*}{$\begin{array}{c}\text { Benef.Total } \\
\text { (mil US\$/ano) }\end{array}$} & \multicolumn{2}{|c|}{ (Perdas } & \multirow{2}{*}{$\begin{array}{l}\text { END } \\
\text { US\$/ano }\end{array}$} & \multirow{2}{*}{ DV) } & \multirow[t]{2}{*}{ TRI } & \multirow[t]{2}{*}{ Tipo } & \multirow{2}{*}{$\begin{array}{l}\text { N. Rede } \\
\text { da Fan }\end{array}$} \\
\hline & & & & & & & ( & mil & & & & & \\
\hline 4 & 10 & 5 & regul & 50.00 & 6.37 & 128.07 & ( & 0 & 0 & $128)$ & 20.09 & NEC. & 2 \\
\hline 4 & 11 & 1 & regul & 50.00 & 6.37 & 119.99 & ( & 0 & 0 & $119)$ & 18.82 & NEC. & 2 \\
\hline 4 & 11 & 2 & regul & 50.00 & 6.37 & 119.99 & ( & 0 & 0 & $119)$ & 18.82 & NEC. & 2 \\
\hline 4 & 11 & 3 & regul & 50.00 & 6.37 & 119.99 & ( & 0 & 0 & $119)$ & 18.82 & NEC. & 2 \\
\hline 4 & 13 & 1 & novSE & 1615.83 & 201.66 & 70.01 & ( & 56 & 13 & $0)$ & 0.35 & NEC. & 2 \\
\hline 4 & 12 & 1 & novSE & 1647.44 & 206.15 & 33.92 & ( & 20 & 13 & 0 ) & 0.16 & MELH. & \\
\hline
\end{tabular}

\begin{tabular}{|c|c|c|c|}
\hline prcamento & : & 100000.00 & mil US $\$$ \\
\hline Custo Total & & 13516.27 & $7 \mathrm{mil}$ US $\$$ \\
\hline Beneficio anual & & 1319.61 & $1 \mathrm{mil}$ US $\$$ \\
\hline em Perda & & 232 & mil US $\$$ \\
\hline em END & & 104 & $\mathrm{mil}$ US $\$$ \\
\hline em DV & & 970 & mil US\$ \\
\hline
\end{tabular}

\begin{tabular}{|c|c|c|c|c|}
\hline no & Familia & N.obr & Tipo & $\begin{array}{l}\text { Custo } \\
\text { (mil }\end{array}$ \\
\hline 5 & 14 & 4 & novse & 158 \\
\hline \multicolumn{2}{|c|}{ Orcamento } & : & 100000.00 & mil US\$ \\
\hline \multicolumn{2}{|c|}{ Custo Total } & : & 9481.63 & mil US\$ \\
\hline \multicolumn{2}{|c|}{ Beneficio anual: } & & 566.14 & mil US\$ \\
\hline & em Perda & : & 330 & mil US\$ \\
\hline & em END & : & 156 & mil US\$ \\
\hline & em DV & : & 72 & mil US\$ \\
\hline
\end{tabular}

\begin{tabular}{|c|c|c|c|c|c|c|c|c|c|c|c|c|c|}
\hline \multirow[t]{2}{*}{ Ano } & \multirow[t]{2}{*}{ Familia } & \multirow[t]{2}{*}{ N.obr } & \multirow[t]{2}{*}{ Tipo } & \multirow{2}{*}{$\begin{array}{l}\text { Custo Inv. } \\
\text { (mil US\$) }\end{array}$} & \multirow{2}{*}{$\begin{array}{l}\text { Custo Amor. } \\
\text { (mil US\$/ano) }\end{array}$} & \multirow{2}{*}{$\begin{array}{l}\text { Benef.Total } \\
\text { (mil US\$/ano) }\end{array}$} & \multicolumn{2}{|c|}{ (Perdas } & \multirow{2}{*}{$\begin{array}{l}\text { END } \\
\text { US\$/ano }\end{array}$} & \multirow{2}{*}{$\begin{array}{l}\text { DV) } \\
\text { ) }\end{array}$} & \multirow[t]{2}{*}{ TRI } & \multirow[t]{2}{*}{ Tipo } & \multirow{2}{*}{$\begin{array}{l}\text { N. Redes } \\
\text { da Fam. }\end{array}$} \\
\hline & & & & & & & ( & mil & & & & & \\
\hline 6 & 1 & 4 & regul & 50.00 & 6.37 & 187.58 & ( & 0 & $\theta$ & $187)$ & 29.42 & NEC. & 10 \\
\hline 6 & 7 & 1 & regul & 50.00 & 6.37 & 165.22 & ( & 0 & 0 & $165)$ & 25.92 & NEC. & 8 \\
\hline \multicolumn{2}{|c|}{ Orcamento } & $:$ & 100000.00 & mil US\$ & & & & & & & & & \\
\hline \multirow{2}{*}{\multicolumn{2}{|c|}{$\begin{array}{l}\text { Custo Total : } \\
\text { Beneficio anual: }\end{array}$}} & $:$ & 900.00 & mil US\$ & & & & & & & & & \\
\hline & & & 3197.52 & mil US\$ & & & & & & & & & \\
\hline & em Perda & $:$ & 0 & mil US\$ & & & & & & & & & \\
\hline & em END & : & 0 & mil US\$ & & & & & & & & & \\
\hline & em DV & : & 3190 & mil US\$ & & & & & & & & & \\
\hline
\end{tabular}




\begin{tabular}{|c|c|c|c|c|c|c|c|c|c|c|c|c|c|}
\hline \multirow[t]{2}{*}{ Ano } & \multirow[t]{2}{*}{ Familia } & \multirow[t]{2}{*}{ N.obr } & \multirow[t]{2}{*}{ Tipo } & \multirow{2}{*}{$\begin{array}{l}\text { Custo Inv. } \\
\text { (mil US\$) }\end{array}$} & \multirow{2}{*}{$\begin{array}{l}\text { Custo Amor. } \\
\text { (mil US\$/ano) }\end{array}$} & \multirow{2}{*}{$\begin{array}{l}\text { Benef. Total } \\
\text { (mil US\$/ano) }\end{array}$} & \multicolumn{2}{|c|}{ (Perdas } & \multirow{2}{*}{$\begin{array}{l}\text { END } \\
\text { US\$/ano }\end{array}$} & \multirow{2}{*}{$\begin{array}{l}\text { DV) } \\
\text { ) }\end{array}$} & \multirow[t]{2}{*}{ TRI } & \multirow[t]{2}{*}{ Tipo } & \multirow{2}{*}{$\begin{array}{l}\text { N. Redes } \\
\text { da Fam. }\end{array}$} \\
\hline & & & & & & & ( & mil & & & & & \\
\hline 7 & 6 & 3 & regul & 50.00 & 6.37 & 202.09 & ( & 0 & 0 & $202)$ & 31.70 & NEC. & 3 \\
\hline \multicolumn{2}{|c|}{ Orcamento } & : & 100000.00 & $\operatorname{mil}$ US $\$$ & & & & & & & & & \\
\hline \multicolumn{2}{|c|}{ Custo Total } & $:$ & 150.00 & mil US\$ & & & & & & & & & \\
\hline \multicolumn{2}{|c|}{ Beneficio anual } & & 606.28 & $\operatorname{mil}$ US $\$$ & & & & & & & & & \\
\hline & em Perda & : & 0 & mil US\$ & & & & & & & & & \\
\hline & em END & $:$ & 0 & mil US\$ & & & & & & & & & \\
\hline & em DV & $:$ & 606 & mil US\$ & & & & & & & & & \\
\hline \multirow[t]{2}{*}{ Ano } & Familia & N.obr & Tipo & Custo Inv. & Custo Amor. & Benef.Total & \multicolumn{2}{|c|}{ (Perdas } & END & DV) & TRI & Tipo & N. Redes \\
\hline & & & & (mil US\$) & (mil US\$/ano) & (mil US\$/ano) & ( & mil & US\$/ano & ) & & & da Fam. \\
\hline 8 & 1 & 1 & novSE & 1389.13 & 172.99 & 149.60 & ( & 119 & 29 & (0) & 0.86 & NEC. & 10 \\
\hline 8 & 9 & 4 & novSE & 1543.45 & 192.44 & 88.19 & ( & 66 & 21 & (0) & 0.46 & NEC. & 6 \\
\hline \multicolumn{2}{|c|}{ Orcamento } & $:$ & 100000.00 & $\operatorname{mil}$ US $\$$ & & & & & & & & & \\
\hline \multicolumn{2}{|c|}{ Custo Total } & $:$ & 23152.00 & $\operatorname{mil}$ US $\$$ & & & & & & & & & \\
\hline \multicolumn{2}{|c|}{ Beneficio anual } & & 2025.16 & $\operatorname{mil}$ US $\$$ & & & & & & & & & \\
\hline & em Perda & $:$ & 1586 & $\operatorname{mil}$ US $\$$ & & & & & & & & & \\
\hline & em END & $:$ & 416 & mil US $\$$ & & & & & & & & & \\
\hline & em DV & $:$ & 0 & mil US $\$$ & & & & & & & & & \\
\hline \multirow[t]{2}{*}{ Ano } & Familia & N.obr & Tipo & Custo Inv. & Custo Amor. & Benef.Total & \multicolumn{2}{|c|}{ (Perdas } & END & DV) & TRI & Tipo & N. Redes \\
\hline & & & & (mil US\$) & (mil US\$/ano) & (mil US\$/ano) & ( & mil & US\$/ano & ) & & & da Fam. \\
\hline 9 & 6 & 3 & desdb & 127.66 & 16.28 & 61.75 & ( & 47 & 14 & (๑) & 3.79 & NEC. & 3 \\
\hline 9 & 3 & 1 & novSE & 1626.28 & 203.00 & 72.95 & ( & 48 & 24 & 0 ) & 0.36 & NEC. & 5 \\
\hline \multicolumn{2}{|c|}{ Orcamento } & $:$ & 100000.00 & mil US $\$$ & & & & & & & & & \\
\hline \multirow{2}{*}{\multicolumn{2}{|c|}{$\begin{array}{l}\text { Custo Total } \\
\text { Beneficio anual }\end{array}$}} & $:$ & 8514.39 & $\operatorname{mil}$ US $\$$ & & & & & & & & & \\
\hline & & & 549.99 & $\operatorname{mil}$ US $\$$ & & & & & & & & & \\
\hline & em Perda & $:$ & 381 & $\operatorname{mil}$ US\$ & & & & & & & & & \\
\hline & em END & $:$ & 162 & mil US\$ & & & & & & & & & \\
\hline & em DV & : & 0 & mil US\$ & & & & & & & & & \\
\hline
\end{tabular}




\begin{tabular}{|c|c|c|c|c|c|c|c|c|c|c|c|c|c|}
\hline \multirow[t]{2}{*}{ Ano } & \multirow[t]{2}{*}{ Familia } & \multirow[t]{2}{*}{ N.obr } & \multirow[t]{2}{*}{ Tipo } & \multirow{2}{*}{$\begin{array}{l}\text { Custo Inv. } \\
\text { (mil US } \$ \text { ) }\end{array}$} & \multirow{2}{*}{$\begin{array}{l}\text { Custo Amor. } \\
\text { (mil US\$/ano) }\end{array}$} & \multirow{2}{*}{$\begin{array}{l}\text { Benef.Total } \\
\text { (mil US\$/ano) }\end{array}$} & \multicolumn{2}{|c|}{ (Perdas } & \multirow{2}{*}{$\begin{array}{l}\text { END } \\
\text { US\$/ano }\end{array}$} & \multirow{2}{*}{$\begin{array}{l}\text { DV) } \\
\text { ) }\end{array}$} & \multirow[t]{2}{*}{ TRI } & \multirow[t]{2}{*}{ Tipo } & \multirow{2}{*}{$\begin{array}{l}\text { N. Redes } \\
\text { da Fam. }\end{array}$} \\
\hline & & & & & & & ( & mil & & & & & \\
\hline 10 & 2 & 1 & regul & 50.00 & 6.37 & 183.09 & ( & 0 & $\theta$ & $183)$ & 28.72 & NEC. & 5 \\
\hline 10 & 8 & 1 & recond & 83.45 & 10.64 & 111.32 & ( & 51 & 0 & $59)$ & 10.46 & NEC. & 3 \\
\hline 10 & 7 & 1 & desdb & 169.31 & 21.59 & 77.04 & ( & 54 & 22 & $0)$ & 3.57 & NEC. & 8 \\
\hline 10 & 10 & 1 & novSE & 1528.14 & 190.48 & 106.57 & ( & 80 & 25 & ๑) & 0.56 & NEC. & 2 \\
\hline \multicolumn{2}{|c|}{ Orcamento } & $:$ & $90000.00 \mathrm{n}$ & mil US\$ & & & & & & & & & \\
\hline \multicolumn{2}{|c|}{ Custo Total } & $:$ & $4911.07 n$ & mil US\$ & & & & & & & & & \\
\hline \multicolumn{2}{|c|}{ Beneficio anual: } & & $2078.86 n$ & mil US\$ & & & & & & & & & \\
\hline & em Perda & $:$ & $745 \quad n$ & mil US\$ & & & & & & & & & \\
\hline & em END & $:$ & 226 & mil US\$ & & & & & & & & & \\
\hline & em DV & $:$ & 1092 & mil US\$ & & & & & & & & & \\
\hline
\end{tabular}




\section{ANEXO E \\ TABELA DE REGIONAIS DEFINIDAS PARA O CASO TESTE DE APLICAÇÃO}

\begin{tabular}{|c|c|c|}
\hline $\begin{array}{l}\text { Código da } \\
\text { Regional }\end{array}$ & Código da SE & $\begin{array}{l}\text { Número da } \\
\text { Família }\end{array}$ \\
\hline REG2 & S01 & 2 \\
\hline REG6 & S02 & 3 \\
\hline REG2 & S03 & 12 \\
\hline REG2 & S04 & 7 \\
\hline REG1 & S05 & 3 \\
\hline REG3 & S06 & 1 \\
\hline REG5 & S07 & 9 \\
\hline REG3 & S08 & 9 \\
\hline REG2 & S09 & 15 \\
\hline REG7 & S10 & 1 \\
\hline REG6 & S11 & 4 \\
\hline REG1 & S12 & 13 \\
\hline REG1 & S13 & 5 \\
\hline REG6 & S14 & 7 \\
\hline REG1 & S15 & 15 \\
\hline REG3 & S16 & 4 \\
\hline REG2 & S17 & 14 \\
\hline REG4 & S18 & 1 \\
\hline REG2 & S19 & 12 \\
\hline REG1 & S20 & 4 \\
\hline REG6 & S21 & 14 \\
\hline REG4 & S22 & 8 \\
\hline REG2 & S23 & 12 \\
\hline REG7 & S24 & 13 \\
\hline REG1 & $\mathrm{S} 25$ & 3 \\
\hline REG6 & S26 & 12 \\
\hline REG1 & S27 & 1 \\
\hline REG8 & $\mathrm{S} 28$ & 1 \\
\hline REG6 & S29 & 12 \\
\hline REG6 & S30 & 4 \\
\hline REG7 & S31 & 7 \\
\hline REG4 & S32 & 6 \\
\hline REG1 & S33 & 11 \\
\hline REG2 & S34 & 7 \\
\hline REG5 & S35 & 9 \\
\hline REG4 & S36 & 2 \\
\hline
\end{tabular}




\begin{tabular}{|c|c|c|}
\hline $\begin{array}{l}\text { Código da } \\
\text { Regional }\end{array}$ & Código da SE & $\begin{array}{l}\text { Número da } \\
\text { Família }\end{array}$ \\
\hline REG6 & S37 & 7 \\
\hline REG4 & S38 & 4 \\
\hline REG5 & S39 & 10 \\
\hline REG8 & $\mathrm{S} 40$ & 11 \\
\hline REG8 & S41 & 9 \\
\hline REG1 & S42 & 6 \\
\hline REG7 & S43 & 2 \\
\hline REG5 & S44 & 8 \\
\hline REG6 & S45 & 1 \\
\hline REG7 & S46 & 1 \\
\hline REG3 & S47 & 4 \\
\hline REG4 & S48 & 7 \\
\hline REG7 & S49 & 14 \\
\hline REG8 & S50 & 6 \\
\hline REG3 & S51 & 7 \\
\hline REG1 & S52 & 14 \\
\hline REG5 & S53 & 5 \\
\hline REG5 & S54 & 15 \\
\hline REG2 & S55 & 1 \\
\hline REG3 & S56 & 7 \\
\hline REG5 & S57 & 9 \\
\hline REG2 & S58 & 5 \\
\hline REG2 & S59 & 2 \\
\hline REG3 & S60 & 4 \\
\hline REG6 & S61 & 1 \\
\hline REG6 & S62 & 3 \\
\hline REG3 & S63 & 12 \\
\hline REG3 & S64 & 4 \\
\hline REG6 & S65 & 14 \\
\hline REG7 & S66 & 14 \\
\hline REG6 & S67 & 4 \\
\hline REG7 & S68 & 8 \\
\hline REG4 & S69 & 9 \\
\hline REG5 & $\mathrm{S} 70$ & 15 \\
\hline REG3 & S71 & 3 \\
\hline REG3 & S72 & 2 \\
\hline REG7 & S73 & 1 \\
\hline REG8 & S74 & 10 \\
\hline
\end{tabular}




\section{REFERÊNCIAS BIBLIOGRÁFICAS}

\section{Dissertações e Teses}

[1] Gouvêa, M. R. - "Bases Conceituais para o Planejamento de Investimentos em Sistemas de Distribuição de Energia Elétrica". Tese de Doutoramento, Escola Politécnica da Universidade de São Paulo, 1993.

[2] Valente, A. L. C. - "Análise dos Custos Marginais dos Sistemas de Distribuição BT e MT". Dissertação de Mestrado, Escola Politécnica da Universidade de São Paulo", 1989.

[3] Simões, J. S. - "Inter-Relação do Planejamento Agregado de Investimentos com o Planejamento Localizado de Sistemas de Distribuição de Energia Elétrica". Dissertação de Mestrado, Escola Politécnica da Universidade de São Paulo", 1998.

[4] Antunes, A. U. - "Metodologia para Planejamento Agregado de Investimentos em Redes de Distribuição Secundárias". Dissertação de Mestrado, Escola Politécnica da Universidade de São Paulo", 1999.

[5] Njaim, P. R. - "Metodologias para Planejamento de Sistemas de Distribuição: Estado da Arte e Aplicações". Dissertação de Mestrado, Escola Politécnica da Universidade de São Paulo", 1995.

[6] Valente, A. L. C. - "Modelo Probabilístico para Avaliação do Desempenho de Redes de Distribuição Primária". Tese de Doutoramento, Escola Politécnica da Universidade de São Paulo", 1997.

[7] Santos, P. E. S. - "Metodologia para Determinação dos Encargos de Uso dos Sistemas Primários de Distribuição de Energia Elétrica". Tese de Mestrado, Escola Federal de Engenharia Elétrica de Itajubá", 1999.

\section{$\underline{\text { Relatórios e Notas Técnicas }}$}

[8] Gouvêa, M. R.; et al. - "Módulo 1: especificação da representação das redes em família". São Paulo, CED/IEE/USP, Março de 1993 (NT 030/PLAN002/NT001/O1).

[9] Gouvêa, M. R.; et al. - "Módulo 2: especificação de modelo para cálculo de parâmetros de redes por funções estatísticas". São Paulo, CED/IEE/USP, 1993 (NT 041/PLAN002/NT002/OR). 
[10] Gouvêa, M. R.; et al. - "Módulo 3: especificação do modelo de expansão de redes para regiões não completamente urbanizadas". São Paulo, CED/IEE/USP, 1993 (NT 040/PLAN002/NT003/O1).

[11] Gouvêa, M. R.; et al. - "Módulo 4: especificação do modelo de expansão de redes para regiões urbanizadas". São Paulo, CED/IEE/USP, 1993 (NT 085/PLAN002/NT010/OR).

[12] Gouvêa, M. R.; et al. - "Módulo 5: incertezas, cenários e decisão". São Paulo, CED/IEE/USP, 1993 (NT 030/PLAN002/NT001/O1).

[13] Gouvêa, M. R.; et al. - "Especificação do Modelo de Planejamento Agregado de Investimentos em Sistemas de Distribuição." - CED 103 / PLAN 002 / RL 001 / OR - Fevereiro de 1994.

[14] EPUSPIABRADEE - "Planejamento Agregado de Investimentos Aplicação no Sistema Elétrico da ESCELSA - Espírito Santo Centrais Elétricas SIA." - Fevereiro de 1999.

[15] CED - "Planejamento Agregado de Investimentos - Aplicação no Sistema da CPFL - Companhia Paulista de Força e Luz." - Projeto PLAN 004 - 1998.

[16] CED - "Planejamento Agregado de Investimentos - Aplicação no Sistema Elétrico da ELETROPAULO." - Março de 1998.

[17] CODI - "Estudo do Comportamento da Tensão nos Componentes do Sistema de Distribuição". Relatório CODI, 3.2.19.03.0, 1995.

[18] ELETROBRÁS - "Projeto M. 4 - Custo Marginal de Redes Subtransmissão / Distribuição" - Relatório 2 - 1983.

[19] EDF - Relatórios sobre planejamento da distribuição no Brasil Volume 2, 3, 4, 5 - 1987.

\section{Artigos Técnicos}

[20] Gouvêa, M. R.; Kagan, N. \& Arango, H. - A methodology for planning electricity supply systems on aggregated basis. in Proceedings $13^{\text {th }}$ International Conference on Electricity Distribution, vol.1, Session 6, pp. 6.32.1-6.32.5, 1995.

[21] Kagan, N.; Gouvêa, M. R.; Tahan, C.M.V.; Oliveira, C.C.B.; Penin, C.A.S. \& Antunes, A. U. - Long Term Investment Planning in Distribution Companies Considering Quality Indices and Uncertainty. Submetido ao $6^{\text {th }}$ PMAPS - Funchal - Ilha da Madeira, 2000. 
[22] Forte, V. J. Jr.; Putnam, R. Jr.; Pupp, R. L. \& Woo, C. K. - Using Customer Outage Costs in Electricity Reliability Planning. In Energy - Nr.: 0092773/1998 - 0018.3, 1995

[23] Farmer, E. D.; Cory, B. J. \& Perera, B. L. P. P. - Optimal Pricing of Transmission and Distribution Services in Electricity Supply. IEE Proc. - Gener. Trans. Distrib., Vol. 142, No. 1, January 1995.

[24] Ortmeyer, T. H.; Hiyama, T. \& Salehfar, H. - Power Quality Effects of Distribution System Faults. In Electrical Power and Energy Systems Vol. 18, No. 5: 323-329, 1996.

\section{Livros}

[25] DNAEE - ELETROBRÁS - Nova Tarifa de Energia Elétrica Metodologia e Aplicação. 1985.

[26] CODI - ELETROBRÁS - Planejamento de Sistemas de Distribuição de Energia Elétrica - Editora Campus - 1982. 